University of Louisville

ThinkIR: The University of Louisville's Institutional Repository

Electronic Theses and Dissertations

$5-2021$

\title{
In pursuit of innocence: A study of race and ethnicity differences in time to exoneration.
}

Virginia E. Braden

University of Louisville

Follow this and additional works at: https://ir.library.louisville.edu/etd

Part of the Social Justice Commons

\section{Recommended Citation}

Braden, Virginia E., "In pursuit of innocence: A study of race and ethnicity differences in time to exoneration." (2021). Electronic Theses and Dissertations. Paper 3599.

https://doi.org/10.18297/etd/3599

This Doctoral Dissertation is brought to you for free and open access by ThinkIR: The University of Louisville's Institutional Repository. It has been accepted for inclusion in Electronic Theses and Dissertations by an authorized administrator of ThinkIR: The University of Louisville's Institutional Repository. This title appears here courtesy of the author, who has retained all other copyrights. For more information, please contact thinkir@louisville.edu. 


\title{
IN PURSUIT OF INNOCENCE: A STUDY OF RACE AND ETHNICITY
} DIFFERENCES IN TIME-TO-EXONERATION

\author{
By \\ Virginia E. Braden \\ B.S., University of Louisville, 2010 \\ M.S., University of Louisville, 2014

\begin{abstract}
A Dissertation
Submitted to the Faculty of the

College of Arts and Sciences at the University of Louisville in Partial Fulfillment of the Requirements

for the Degree of
\end{abstract} \\ Doctor of Philosophy \\ in Criminal Justice \\ Department of Criminal Justice \\ University of Louisville \\ Louisville, Kentucky
}

May 2021 

IN PURSUIT OF INNOCENCE: A STUDY OF RACE AND ETHNICITY DIFFERENCES IN TIME-TO-EXONERATION

By

Virginia E. Braden

B.S., University of Louisville, 2010

M.S., University of Louisville, 2014

A Dissertation Approved on

March 31, 2021

by the following Dissertation Committee:

Dissertation Committee Chair

Dr. George E. Higgins

Second Committee Member Name

Dr. Deborah Keeling

Third Committee Member Name

Dr. Viviana Andreescu

Fourth Committee Member Name

Dr. Gennaro F. Vito

Fifth Committee Member Name

Dr. Catherine D. Marcum 


\section{DEDICATION}

This dissertation is dedicated to my five children: Jessica, Joshua, Andrew, Sara, and Noah. You are the beat of my heart, the air that I breathe. Your presence has challenged me to leave no effort unspent, to face forward, and to press on in the face of overwhelming obstacles. It is my deepest hope that this will serve as proof of what is possible when you refuse to give up and provide you with courage and inspiration when you need it most, as you have done for me time and time again. 


\section{ACKNOWLEDGMENTS}

I am indebted beyond measure and deeply grateful to each of the following persons who have been a part of this journey. First, I would like to express my deepest heartfelt thanks to Dr. George E. Higgins for his invaluable guidance and constant encouragement throughout the years. His willingness to invest in me has made me not only a better scholar, but a better human being. He is a living example of passion, brilliance, and determination. It is impossible to be in his presence and not feel inspired. I would like to express profound gratitude to Dr. Gennaro Vito as well for his tireless patience and willingness to provide insights and wisdom from his own experiences. These have been of great benefit to me throughout the years and I will carry them with me always. I would also like to thank Dr. Viviana Andreescu who has given generously of her time and knowledge and who has provided words of sound wisdom when they were needed most. What she has provided to me has made a difference and I am grateful

for it. I would like to express wholehearted gratitude to Ginger Brown as well whose kind words and diligent care have allowed me to feel seen in seasons where I felt otherwise lost. I am thankful for the gift of her presence in my life. Last, but certainly not least, I would like to express my deepest thanks and appreciation to Dr. Deborah Keeling. She has been a steadfast source of hope and encouragement through many changing seasons. Her belief in me gave me hope and the willingness to persevere through many storms and trials. I have no doubt without her expression of confidence in me, I would not have arrived at this destination, and for that I will remain eternally grateful. 


\title{
ABSTRACT \\ IN PURSUIT OF INNOCENCE: A STUDY OF RACE AND ETHNICITY DIFFERENCES IN TIME-TO-EXONERATION
}

\author{
Virginia E. Braden
}

March 31, 2021

Wrongful convictions take years from an individual's life, rob them of the comfort and presence of their family, rip them from their place in the community, and subject them to the harsh pains of imprisonment. Exonerees can spend years and even decades in the pursuit of proving innocence and obtaining an exoneration. The purpose of this study is to examine the impact of race and ethnicity upon time-to-exoneration through the lens of focal concerns theory. Focal concerns theory has been used to demonstrate that criminal justice actors are influenced by legal and extralegal factors in decision making and rely on stereotypes to assess blameworthiness, protection of the community, and in navigating practical constraints and consequences. Utilizing data obtained from the National Registry of Exonerations $(\mathrm{N}=507)$ survival analysis was performed. The findings indicate that black exonerees experienced a longer time-toexoneration than did white exonerees and that Hispanic exonerees experienced the shortest time-to-exoneration of all. The legal components of a case were found to affect time-to-exoneration. The impact of these factors affected the racial and ethnic groups differently, resulting in detrimental impact to minorities. The findings offer support for focal concerns theory in the demonstration that racial and ethnic differences are present in time to exoneration resulting in disparities which disadvantage minorities. Further 
support for focal concerns theory is found in that the legal components of a case are shown to be associated with racial and ethnic differences in time-to-exoneration. 


\section{TABLE OF CONTENTS}

PAGE

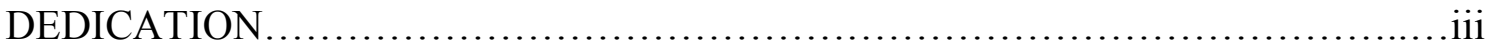

ACKNOWLEDGMENTS.....................................................

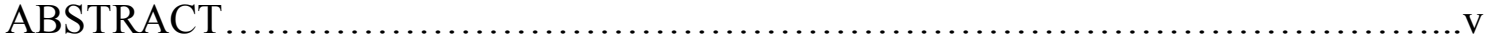

CHAPTER 1 - INTRODUCTION...............................................

CHAPTER 2- LITERATURE REVIEW $\ldots \ldots \ldots \ldots \ldots \ldots \ldots \ldots \ldots \ldots \ldots \ldots \ldots \ldots \ldots \ldots . . . \ldots$

CHAPTER 3- METHODS ...................................................47

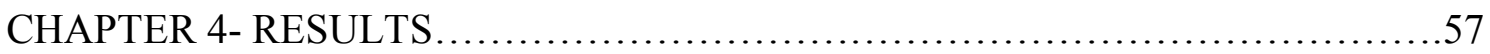

CHAPTER 5- DISCUSSION .............................................. 80

REFERENCES........................................................ 95

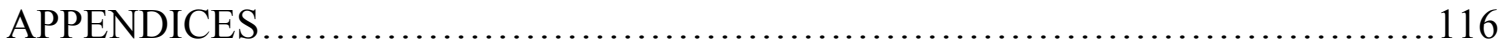

CURRICULUM VITA........................................................ 118 


\section{CHAPTER 1 INTRODUCTION}

An exoneration occurs when an individual who has been convicted of a crime is officially cleared based on new evidence of innocence with no unexplained physical evidence of that individual's guilt remaining (Gross \& Shaffer, 2012; NRE, 2019, para 1). Exoneration is a process spanning from the wrongful conviction of an innocent defendant to an official declaration of the defendant's innocence (Rafail \& Mahoney, 2019). An exoneration may occur while a person is living or be awarded posthumously. No guidelines exist that are provided by law that establish an exact route to an exoneration. Consequently, the journey to exoneration may take years and even decades to complete and present significant obstacles (Gould \& Leo, 2015).

After having been convicted, there are three legal processes that may be undertaken by an individual seeking to be exonerated. Namely, defendants seeking exoneration may file a motion for a new trial based on new evidence, they may file a direct appeal, or they may request a post-conviction review (Mostaghel, 2011). Each of these avenues is fraught with restrictions and formidable obstacles. As a result, an individual seeking an exoneration finds themselves substantially limited in their chances of obtaining an exoneration (Chinn \& Ratliff, 2008; King, 2019).

As an awareness of the plight of the wrongfully convicted has become more and more mainstream, some progress has been made in addressing access to an exoneration. Many of these avenues, however, carry stipulations that effectively bar an innocent inmate from utilizing them (Garrett, 2011). In short, an individual seeking exoneration 
faces an uphill battle with a system that is markedly hesitant to admit and take responsibility for error (Gould \& Leo, 2015; Gutman, 2017). Currently, the most comprehensive research on all known exonerations in the U.S. is conducted by the National Registry of Exonerations (Garrett, 2017, Rafail \& Mahoney, 2019). The data they have compiled shows the number of exonerations has increased dramatically in recent decades (NRE, 2020). Much of this increase corresponds with advancements in DNA technology and forensic capabilities (Gross et al., 2018). As of the time of this writing, the total number of exonerations granted between 1989 and July 2020 is 2,631 with over 23,000 years of wrongful incarceration served before being exonerated (NRE, 2020).

Data collected on exonerations reveals great variance in terms of the number of exonerations arising from various types of crimes (Gross et al., 2017). Some of this disparity arises from the likelihood of the presence of physical evidence making those cases more conducive to review as forensic testing capabilities have increased. For example, data indicates that over half of all exonerations are for the crimes of murder and sexual assault (Garret, 2017; Gross \& Shaffer, 2012). By comparison, felony assault convictions, which occur much more frequently than do homicide and sexual assault convictions, result in only about $1 \%$ of all violent crimes exonerations (Gross, 2016; Gross \& Shaffer, 2012). Similarly, robbery convictions, which also occur at a much higher rate than homicide and rape convictions, account for only about $5 \%$ of all violent crimes exonerations (Gross \& Shaffer, 2012).

The empirical literature on exonerations provides information regarding factors arising as contributing causes to the plight of innocent but convicted defendants (Beadau 
\& Radelet, 1987; Drizin \& Leo, 2003; Gould \& Leo, 2010; Gould et al., 2012). Scholarly research indicates the factors accompanying cases ending in exoneration are: eyewitness misidentification, false confessions, misconduct by police or prosecutors, perjury, inadequate defense, the use of informants, and false or misleading forensic evidence (Acker et al., 2015; Borchard, 1961; Gould \& Leo, 2010; LaPorte, 2017). The vast majority of exonerations have more than one factor present (Gross \& O’Brien, 2007).

Data shows that perjury, false accusations, and eyewitness misidentification are the three most prevalent factors across all types of cases resulting in exoneration (Gould \& Leo, 2010; Norris et al., 2020). Perjury and false accusation have been shown to be present in $70 \%$ of homicide exonerations and in about $85 \%$ of all child sexual abuse cases (Norris et al., 2020). Eyewitness misidentification of the perpetrator occurs in over $75 \%$ of all exoneration cases (Gould \& Leo, 2010). Research shows that approximately 25\% of these eyewitness misidentifications were not mistaken identifications but deliberate (Gross \& Shaffer, 2012).

When considering race and ethnicity, in two ways, analysis of the current data regarding exonerations reveals differences are present (Free \& Ruesink, 2018; Gross et al, 2017; NRE, 2018). First, though blacks comprise about $13 \%$ of the US population, they make up $57 \%$ of all exonerations and $61 \%$ of exonerations won as a result of DNA testing (Bronson \& Carson, 2019; Gross et al., 2017; Innocence Project, 2018). Research on exoneration data also reveals evidence of racial disparity in that blacks are even more greatly overrepresented among exonerated defendants than they are in the prison population (Smith \& Hattery, 2011). In some categories of crimes, such as homicides and sexual assaults or rape the disparity is far greater than in others (Gross \& Shaffer, 2012). 
Second, the race and ethnicity of the victim has importance and has been shown to be a factor in wrongful conviction cases concluding in an exoneration (Gross et al., 2017; Harmon, 2004; Johnson et al., 2013; O’Brien et al., 2019). Research reveals a far greater exoneration rate for minority innocent defendants of any race or ethnicity who were convicted of killing a white victim than for white innocent defendants convicted of killing a white victim (Harmon, 2004). In violent crime exonerations as a whole, there is a much higher rate of exonerations for minority defendants wrongfully convicted of crimes against a white victim (Gross et al., 2017; Smith \& Hattery, 2011).

A review of the exoneration data maintained by the National Registry of Exonerations (NRE) indicates racial and ethnic differences in time-to-exoneration exist. The data compiled shows that black innocent defendants spend $45 \%$ more time wrongfully imprisoned before being exonerated than do white innocent defendants (NRE, 2018). Data on wrongfully convicted Hispanics is scant. However, what data is available on the exonerations of Hispanics shows evidence of disparity in time-to-exoneration when compared to white exonerees in some categories of crimes (Gross et al., 2017; NRE, 2018; Olney \& Bonn, 2015).

An examination of the empirical literature regarding time-to-exoneration reveals there is a dearth of scholarly attention to this particular topic. The few studies that do exist regarding time to exoneration do not focus on race or ethnicity as the central issue but include it as a control variable (Gould \& Leo, 2015; Olney \& Bonn, 2015; Rafail \& Mahoney, 2019). Additionally, none of the empirical literature regarding race and ethnicity and time to exoneration provides a theoretical premise for their research. 
A theory is important in providing context for the results of empirical study (Higgins et al., 2012; Norris et al, 2020). Theories provide an explanation for the relationship between two or more factors or events (Akers, 1999). The lack of theoretical premise in this area demonstrates a critical gap in the literature because the results only demonstrate correlates or factors that may be related to time-to-exoneration. This study aims to overcome this limitation present in the literature. A theoretical premise provides a richer understanding that leads to policy and programming development.

In the present study, Focal Concerns Theory (FCT) serves as a theoretical framework. FCT has been utilized in the scholarly examination of the impact of race and ethnicity in a broad range of arenas within our justice system (Albonetti \& Hepburn, 1996; Steffensmeier \& Demuth, 2001; Steffensmeier et al. 2017; Vito et al., 2018). Focal concerns theory posits that judges and other actors within the justice system utilize heuristics and stereotypes to assist them in making decisions (Steffensmeier, 1980). This template, as it were, becomes a default mechanism by which determinations are made regarding individuals based on both legal and non-legal factors. In this manner, stereotypical beliefs, such as young black males are more prone to criminality, impact the decisions and outcomes for this population within our justice system (Hartley et al., 2007; Steffensmeier et al., 1998).

Focal concerns theory has been used in the study of the impact of race and ethnicity on the decision making of police, prosecutors, and judges, among others (Franklin, 2010; Higgins et al., 2012; Logan et al., 2017). Additionally, it has been utilized to provide context in the analysis of outcomes across a diverse range of legal processes and in a wide range of court settings (Hartley, et al., 2007). However, focal 
concerns theory has not been utilized in examining the impact of race and ethnicity on time-to-exoneration. Since theory provides an avenue for the rational organization of empirical data and aids in understanding how two or more factors are related, the application of focal concerns theory to this topic is logical and can be expected to further our understanding of this important issue. Applying FCT to the study of race and ethnicity on time-to-exoneration will fill a gap in the current literature.

The purpose of this dissertation is to examine racial and ethnic differences in time-to-exoneration applying Focal Concerns Theory using data obtained from the National Registry of Exonerations $(\mathrm{N}=507)$. Survival analysis was performed to address the possibility of racial and ethnic disparities in time-to-exoneration within the context of focal concerns theory. Specifically, the analysis was used to examine the likelihood that black and Hispanic individuals experience greater time-to-exoneration when compared to white individuals. Using survival analysis, Focal Concerns Theory is utilized as the theoretical premise to contextualize the likelihood of racial and ethnic differences in time-to-exoneration. The ability to understand time-to-exoneration using FCT and survival analysis provides insight into how blameworthiness, protection of the community, and practical constraints affect racial and ethnic differences in time-toexoneration that have not been previously tested.

The following chapters expand upon arguments presented in this chapter. In Chapter 2, relevant literature is discussed in three general areas: defining exonerations, the making of an exoneration, general percentages of exonerations, correlates of exonerations, racial and ethnic differences in exonerations, time-to-exoneration, and Focal Concerns Theory. Chapter 2 helped in the development of the conceptual design 
and hypotheses for this dissertation. Data used for this study is discussed in Chapter 3.

Chapter 4, presents the results as well as the interpretation of the study findings. The final chapter includes a discussion of the results as well as some potential policy and programming based on these results. Additionally, Chapter 5 also includes the potential limitations, prospects for future research, and the conclusion. 


\section{CHAPTER 2}

\section{LITERATURE REVIEW}

The literature review begins with an understanding of exonerations, the impact of race and ethnicity on exonerations, and covers the limited literature regarding time-toexonerations. Next, the literature review presents the actions necessary for a convicted innocent defendant to be exonerated. Then, the literature review presents the basic statistics on exonerations. This is followed by a presentation of the correlates to exonerations from the empirical literature. The literature review then moves to present the racial and ethnic differences in exonerations. Next, the literature review moves to the time-to-exoneration literature. Lastly, the literature review presents Steffensmeier's (1998) version of focal concerns theory. Here, the literature review shows that this theoretical premise has been used to contextualize racial and ethnic differences in multiple parts of criminal justice, but not to contextualize the racial and ethnic differences in time-to-exonerations.

\section{Defining Exonerations}

The literature review for exonerations begins by creating some common understanding through a discussion of varied definitions of exonerations and finally, adopting a definition of exoneration for this study. Some scholars reserve the term exoneration for only those cases of wrongful conviction in which a defendant has 
provided proof of innocence by virtue of DNA (Hessick, 2017). However, recent research has primarily defined an exoneration as a legal determination occurring when an individual is relieved of all legal consequences of a criminal act he or she was previously convicted of as result of the presentation of evidence of his or her actual innocence in any form (Garrett, 2017; Leo \& Gould, 2009).

An exoneration also been defined as the decision to vacate a conviction by a court or executive pardon arising from proof of innocence of the crime for which the individual was convicted that was not presented at time of conviction and for which the defendant was not re-tried (Garrett, 2007). Similarly, Gross and Ellsworth (2012, p.164) defined an exoneration as "an official act-a pardon, a dismissal or an acquittal declaring a defendant not guilty of a crime for which he or she had been convicted, because new evidence of innocence that was not presented at trial required reconsideration of the case." In the context adopted by the research of recent years, the decision to exonerate does not arise from procedural or legal error but is predicated on the court's move to eradicate the conviction based upon factual innocence of the convicted person and evidence he or she was not involved or that a crime did not occur (Gould \& Leo, 2015; Leo, 2016; Risinger, 2006; Zalman, 2010). This dissertation will use the National Registry of Exonerations (NRE) definition of exoneration. The National Registry of Exonerations provides a broad definition of exoneration as well as a very precise and detailed definition. This paper will utilize the broad definition of exoneration as put forth by the National Registry of Exonerations and held as criteria for inclusion in their database (NRE, 2019). The National Registry of Exonerations (2019, para 1) broadly defines an exoneration as occurring "when a person who has been convicted of a crime is officially cleared based 
on new evidence of innocence." Furthermore, the NRE's definition stipulates that no unexplained physical evidence of that person's guilt may remain (Gross \& Shaffer, 2012; NRE, 2019).

\section{The Making of an Exoneration}

An exoneration occurs when an individual who has been convicted of a crime is later found to be innocent of that crime and relieved of all legal consequences of that conviction by an authority with the power to do so, based on new evidence of his or her innocence (Gross \& Shaffer, 2012). This may happen while the individual is alive or deceased. Though there is a known and established process of law by which an individual can be convicted and found guilty of a crime, there is no process set by law that lays forth how a convicted individual may be proven innocent. An individual seeking an exoneration faces significant obstacles which arise from procedural restrictions, as well as the reluctance of the justice system to admit error (Gould \& Leo, 2015; Gutman, 2017).

Generally, states allow for three types of legal action an individual may take in hopes of establishing innocence and obtaining an exoneration (Mostaghel, 2011). A convicted individual may file a motion for a new trial based on new evidence not presented at the original trial. Additionally, he or she may file a direct appeal. Lastly, the convicted individual may file a request for a postconviction review using grounds that could not have been raised on direct appeal.

Major and substantial restrictions and requirements exist regarding these postconviction legal measures, often resulting in the failure of the courts to accurately recognize innocence. For example, in filing motions for a new trial based on new 
evidence, many states limit the time period in which a motion for a new trial may be filed. This time limit may vary from a few months to a few years (King, 2019). In the state of Ohio, for instance, except in the instance of a Brady violation ${ }^{1}$, an inmate must file a motion for a new trial within 120 days of the jury verdict (M. Thomas, personal communication, October 7, 2019). Minnesota allows just 15 days from the date of the verdict while other states such as Alabama have time limits of up to 60 days (White, 2000). In contrast, the state of Kansas provides a period of two years from the date of the final judgment to file a motion for a new trial based on newly discovered evidence (KS Stat $\S 22-3501,2019)$. Approximately one-third of states allot a time period of between one and three years to file a motion for a new trail based upon the discovery of new evidence (White, 2000). Since most new evidence does not come to light until long after the original trial, and quite often only after an investigation has been undertaken, few who have been wrongfully convicted and imprisoned have the ability to provide evidence of their innocence within this time frame. Other formidable barriers may be present as well such as the requirement to prove the new evidence could not have been discovered earlier, and the burden of showing that the evidence would rise to a standard that would reasonably assure an acquittal at trial (Chinn \& Ratliff, 2008; Mostaghel, 2011). Winning

\footnotetext{
${ }^{1}$ In 2006 the Supreme Court defined a Brady violation as: "A Brady violation occurs when the government fails to disclose evidence materially favorable to the accused. This Court has held that the Brady duty to disclose extends to impeachment evidence as well as exculpatory evidence, and Brady suppression occurs when the government fails to turn over even evidence that is 'known only to police investigator and not to the prosecutor.' 'Such evidence is material if "there is a reasonable possibility that had the evidence been disclosed to the defense, the result of the proceeding would have been different",' although a 'showing of materiality does not require demonstration by a preponderance of the evidence that disclosure of the suppressed evidence would have resulted ultimately in the defendant's acquittal.' The reversal of a conviction is required upon a 'showing that the favorable evidence could reasonably be taken to put the whole case in such a different light as to undermine confidence in the verdict."
} 
a new trial does not guarantee the individual will be found innocent but it affords the defendant a second chance at presenting his or her case.

An examination of the direct appeal process and the post-conviction review reveals problems with the utility of these means in obtaining an exoneration. Demanding standards of review, limited access for various reasons, and a demonstrated lack of willingness to address "trial errors" such as eyewitness identification unless there is other evidence supporting innocence, are generally held as common barriers to proving innocence postconviction (King, 2019). Demonstrating this, research that examined outcomes of 250 cases in which DNA ultimately proved the defendant innocent showed that $90 \%$ of those defendants failed in challenging their convictions utilizing one or more of judicial processes outlined above (Garrett, 2011). This points to a judicial system that is virtually unable to detect innocence in the aftermath of a wrongful conviction.

In recent years, as states have been willing to examine the legal hurdles that have blocked the establishment of innocence postconviction, several new options have been added that may be utilized by individuals claiming innocence and seeking an exoneration. First, all states now have statutes that allow a convicted individual to request access to DNA testing. It is important to note that while all states have DNA testing access statutes, some present significant hurdles that prevent the convicted individual from being able to access DNA testing (McGlynn, 2019). For example, in an in-depth analysis of DNA exonerations Garrett (2011) found that prosecutors opposed DNA testing in 1 out of 5 cases. Further, in some cases, prosecutors have made waivers of the right to seek DNA a condition of the plea deal (Wiseman, 2012). Therefore, an individual may not in fact be able to access critical DNA testing which could definitively prove innocence and 
exonerate him or her. Further, even defendants who are eventually able to secure DNA testing, often face lengthy delays due to opposition from prosecutors which significantly impacts the length of time it takes to be exonerated (Sheck, et al., 2000).

Second, some states have established Conviction Integrity Units, which are typically housed within the prosecutor's office, and are charged with preventing, identifying, and correcting wrongful convictions. Though this fundamental change in addressing wrongful convictions would seem to indicate a shift in attitudes of government actors, many remain skeptical that the process of conviction review is in large part held in name only (Holloway, 2016). The latest data available shows the rate of exonerations procured by Conviction Integrity Units is increasing yearly (Norris et al,. 2020). However, research on specialized units shows wide and varied impact and range of activity and it is generally acknowledged that, for many of the units, it is too soon to assess their effectiveness (Scheck, 2017).

Only after having accessed one or more of the aforementioned legal options and having been successful in proving innocence, may a wrongfully convicted person may be exonerated of the crime for which he or she was convicted. Procedurally an exoneration may happen by means of a pardon, a dismissal of charges by the courts in light of the newly presented evidence that was not previously presented at the original trial, as an acquittal after being granted a new trial, by issue of a certificate of innocence, or by posthumous exoneration (Gross \& Shaffer, 2012). The exoneration may include more than one of these elements in the process of the exoneration. For example, a convicted individual who has been acquitted after being granted a new trial may also have a pardon issued by the governor or other state entity. 


\section{General Exoneration Statistics}

In the past two decades, concerted efforts aimed at the comprehensive collection of data on exonerations have been initiated. Data regarding exonerations is largely compiled by organizations such as Innocence Project organizations and the National Registry of Exonerations (Hampikian et al., 2011). Some bodies of research focus solely on post-conviction DNA exonerations. Specifically, these are exonerations in which DNA evidence was the basis of proof of innocence that resulted in the conviction being vacated or the indictment dismissed (West \& Meterko, 2015). In contrast, other bodies of research study all known exonerations in which innocence was proven regardless of the presence of DNA evidence. The most well-known research that examines and reports on all known exonerations in the U.S. is that conducted by the National Registry of Exonerations (Garrett, 2017, Rafail \& Mahoney, 2019)².

The data on exonerations points to substantial growth in the number of exonerations over the past decades. For example, research aimed at identifying historical exonerations shows that between 1980 and 1988, 73 individuals were exonerated (Gross et al., 2018). From 1989 to 2003 the number of exonerations increased from approximately 8 per year to 33 per year, which is a $312 \%$ increase per year (Gross et al., 2005; Gross \& Shaffer, 2012). The increase for this time period corresponded with advancements in DNA technology and the rise of organizations, such as the Innocence

\footnotetext{
${ }^{2}$ It is widely acknowledged that capturing the true number of exonerations is an unattainable goal as there simply exists no mechanism to capture them (Gross \& Ellsworth; 2012; Gross, 2013). Without the publicity of an innocence organization's involvement or the visibility of high profile case exonerations can and do go unnoticed (Gross \& Shaffer, 2012). The efforts to collect data on exonerations is ongoing with new and historical cases routinely added as they come to light (Gross, 2016). Despite the limitations, the data which has been collected on known exonerations provides us with critical insights.
} 
Project, which is dedicated to reviewing cases of possible wrongful conviction and seeking exonerations on behalf of their clients (Gross, et al., 2018).

The ability of DNA testing to prove innocence and win exonerations also had the result of birthing an "innocence consciousness" in the public, attuning them to the need for continued efforts to exonerate innocent defendants and resulting in a willingness to address the errors that led to the wrongful conviction (Zalman, 2010). Each decade since has yielded dramatic increases in the numbers of exonerations. By the year 2012 there were 1,301 known exonerations. By 2015, exonerations occurred at a rate of nearly three per week (Gross, 2016).

The number of exonerations and the statistics compiled regarding the aspects of all exonerations are fluid and fluctuate as the number of exonerations continues to increase. Though advances in DNA testing were responsible for the initial dramatic increase in exonerations, the data shows that the majority of exonerations have been won through proof of innocence that did not include DNA evidence. This is not surprising as $80 \%$ to $90 \%$ of cases do not contain biological evidence conducive to DNA testing (Sheck, 2007). Additionally, the available data shows many of the known exonerations have been achieved through the efforts of organizations and agencies that work solely on procuring exonerations (Norris et al., 2020). To summarize, according to the National Registry of Exonerations (2020) as of June 2020, there have been 2,631 total exonerations since 1989 , totaling more than 23,000 years lost. DNA exonerations have accounted for 716 ( $27.2 \%$ ) of the 2,631 exonerations.

Second, the data suggests the type of offense for which someone was wrongfully convicted has importance for exoneration. The overwhelming majority of exonerations 
occur in wrongful convictions of violent crimes, specifically murder and rape/sexual assault or a combination of the two (Gross \& Shaffer, 2012; Garret, 2017). Data shows that over half of all exonerations are in homicide and sexual assault cases though these two crimes comprise only about $2 \%$ of all convictions (Gross, 2013; Gross \& Shaffer, 2012). About $5 \%$ of violent crime exonerations come from robbery crimes (Gross, 2016). Non-violent crimes cases such as drug crimes account for about $7 \%$ of exonerations (Gross \& Shaffer, 2012). A study of DNA exonerations specifically found that $91 \%$ of all exonerations included a sexual assault component (West \& Meterko, 2015). Additionally, it was found that roughly three quarters of exonerations were in cases where the victim and offender were strangers (West \& Meterko, 2015).

Research indicates that capital cases where the death sentence has been imparted yielded an exoneration rate that is nine times greater than for all homicide convictions and 140 times greater than that of other felony convictions (Gross \& O’Brien, 2007; Gross \& Shaffer, 2012). One study that examined exonerations from 1989 to 2012 found that death sentence exonerations accounted for $12 \%$ of all exonerations, though death sentences accounted for less than a tenth of $1 \%$ of all sentences meted out (Gross et al., 2014). According to the findings of other research between $2.3 \%$ to $3.3 \%$ of death sentences since 1973 have resulted in an exoneration (Gross, 2013). The Death Penalty Information Center (2020), which maintains a database on death sentence exonerations, reports that since $01 / 01 / 1973,185$ death-row inmates have been exonerated.

Exonerations on murder and rape cases happen at higher rates for several reasons. First, murder and rape cases are more likely to yield biological evidence than other types of crimes (Gross \& Shaffer, 2012; Gross, 2013). Second, serious crimes such as 
homicide, and especially those that result in a death sentence, are more likely to gather attention post-conviction and have significant resources committed to them (Gross, 2013). Third, the substantial difficulties posed for an innocent defendant in proving his or her innocence mean that significant amounts of time are expended in unsuccessful efforts. It is likely that a defendant who is serving time for a crime that yielded a lesser sentence will serve out the full sentence before making any headway in the exoneration process, if he or she even attempts an innocence claim (Gross \& Shaffer, 2012; West \& Meterko, 2015).

Data shows felonious assault cases account for about half of all violent felony convictions in the U.S. but only $1 \%$ of exonerations (Gross \& Shaffer, 2012). The low number of exonerations in relation to the high incidence of convictions is likely due to the fact that these cases are less likely to have DNA, and, therefore, it is more difficult to prove the innocence of the convicted defendant. Additionally, felonious assault cases routinely yield shorter sentences than homicide and rape cases, providing less time and motivation for the innocent defendant to acquire assistance with an innocence claim. Lastly, several organizations working to exonerate innocent defendants have stipulations that must be met in order to take the case such as that all appeals must have been exhausted (Gross \& Shaffer, 2012). Tragically, the data shows that exoneration efforts came far too late for at least 22 innocent defendants who have been exonerated posthumously (NRE, 2020).

A special type of exoneration has been termed group exoneration (Gross, et al., 2017; West \& Meterko, 2015). These are aggregations of exonerations that occur as a result of a large scale corruption of justice officials such as police and/or prosecutors. In 
Los Angeles, California for example, 156 individuals, nearly all Hispanic, had their convictions vacated and dismissed between 1999 and 2000 when it was discovered that a group of officers from the Rampart division had routinely and systematically lied in reports and planted evidence. Most of the innocent defendants had pled guilty.

In East Cleveland, Ohio the exposure of the actions of three police officers who routinely framed innocent defendants resulted in the convictions of 43 defendants being vacated from 2016-2017. All of the innocent defendants target by the East Cleveland police officers were black. In Baltimore, Maryland over 130 defendants had their convictions dismissed when it was discovered that fifteen members of a task force had engaged in systematic corruption which included making false arrests, and stealing property and narcotics. The investigation is still ongoing with thousands of cases still to be reviewed.

Since 1989 2,500 innocent defendants have been exonerated in 17 group exonerations (Gross, 2018). In every single instance, the groups of innocent defendants had been wrongfully convicted due to large scale police perjury and corruption. The groups were exonerated as the result of the corruption coming to light.

Group exonerations differ fundamentally from individual exonerations and because of this, researchers have routinely elected to study them separately (Gross, 2018). The primary difference between individual exonerations and group exonerations is the unit of observation. In individual exonerations, the unit of observation is the defendant and the facts of that specific case. There is an investigation of the facts of the case and an establishment of the actual innocence of the defendant. In group exonerations however, the unit of observation is a pattern of corruption or conspiracy by a justice 
official, such as framing innocent defendants and perjury (Gross et al., 2017). Once the pattern of corruption is exposed, there may be little investigation of the facts of the individual cases and the dismissal of convictions happens rapidly. In many cases the wrongful convictions are for relatively minor charges resulting in sentences of a few months to a few years and the expense of an investigation of each individual case is not warranted nor feasible.

The manner in which group exonerations are handled prevents an understanding of the individual elements present in each case and makes it impossible to glean information regarding the specific aspects of each individual wrongful conviction and exoneration. Though both types of exonerations are important to study, due to the fundamental difference in the way they are enacted, these two types of exonerations are best studied separately (Gross, 2018). For this reason, group exonerations are not included in this study.

\section{Correlates of Exonerations}

Studies of exonerations are present in empirical literature and these researchers provide some evidence of correlates of exoneration. Research demonstrates there are certain distinctive factors present in cases that end in the exoneration of a wrongfully convicted innocent defendant (Gould \& Leo, 2010; Gould et al., 2012). These contributing factors or correlates are widely held to be eyewitness misidentification, false confessions, misconduct by police or prosecutors, perjury, inadequate defense, the use of 
informants, and false or misleading forensic evidence ${ }^{3}$ (Acker et al., 2015; Beadau \& Radelet, 1987; Borchard, 1961; Gould \& Leo, 2010; LaPorte, 2017).

Additional factors that have been shown to be present in cases that resulted in exoneration include a younger defendant, defendants residing in states with a punitive culture, defendants with a criminal history, tunnel vision by investigators and prosecutors, and the defendant using a family member as a witness, (Gould \& Leo, 2010; Gould \& Leo, 2015; Gould et al., 2012). Research shows that most cases have multiple contributing factors present (Gross \& O’Brien, 2007). Some of these factors are more difficult to study than others and further, the presence of multiple factors can make it difficult to isolate them in the study of exoneration cases (Yaroshefsky \& Shaefer, 2014).

According to data gathered by the National Registry of Exonerations (NRE), perjury and false accusations are the leading factors in cases in which innocent defendants were convicted and then later exonerated (Norris et al., 2020). Perjury and false accusations occurred in $85 \%$ of all child sexual abuse cases contained within the NRE database and in $70 \%$ of all homicide cases. Perjury and false accusations encompass any lies by a victim, witness, or informant (West \& Meterko, 2015). This includes deliberate lies about the identity of the perpetrator as well as fabrication of crimes (Gross \& Shaffer, 2012; West \& Meterko, 2015). Research shows that nearly $25 \%$ of exonerations included deliberate misidentification of the perpetrator and approximately $11 \%$ of all exonerations were for crimes that never occurred (Gross \& Shaffer, 2012).

Misidentification of the perpetrator is present in over $75 \%$ of all exoneration cases and is considered the most prevalent factor in DNA exonerations (Gould \& Leo, 2010;

\footnotetext{
${ }^{3}$ See Appendix
} 
Norris et al., 2020). Eyewitness errors occur as a natural product of the psychological processes of human memory and recall (Loftus, 1975). Research indicates eyewitness error is present in over $88 \%$ of rape exonerations and $50 \%$ of murder exonerations (Gross \& O'Brien, 2007). One study of death sentence exonerations found that eyewitness misidentification played a role in over half of the cases (Warden, 2001). Misidentifications in exonerations cases often involve cross racial identifications (Gross \& Shaffer, 2012). Cross racial identifications have been shown to be particularly unreliable (Meissner \& Brigham, 2001).

Over several decades of both DNA and non-DNA exonerations, false confessions has also emerged as a leading factor (Gross \& Shaffer, 2012). Research shows it is a factor in $15 \%-25 \%$ of all exonerations and present in $30 \%$ of DNA exonerations (Drizin \& Leo, 2003; Hampikian et al., 2011). These false confessions are primarily police induced and have been found to be a result of misclassification, coercion, or contamination (Leo, 2009).

Garrett (2015) examined exonerations that were won on the basis of DNA evidence from the years 1989-2014 and found that 66 of the exonerated defendants had falsely confessed. When a study of both DNA and non-DNA exonerations for a similar time frame of 1989-2012 was undertaken, the analysis showed that a false confession was a factor in $135(15.4 \%)$ of the 874 cases. In $87 \%$ of those cases the false confession was made by the defendant and in $13 \%$ of the cases it was an accomplice who offered it (Gross \& Shaffer, 2012). Additionally, research shows that cases in which an innocent defendant pled guilty often included a false confession by the innocent defendant (West \& Meterko, 2015). 
Misconduct by criminal justice officials such as police and prosecutors has been found to be present in nearly half of all exonerations (Norris et al., 2020). Exonerations of homicides show the greatest percentages of official misconduct occurrences (Gross \& Shaffer, 2012). Further, research that has studied group exonerations indicates that misconduct by police and prosecutors is the primary factor in these cases (Gross et al., 2017).

The use of informants, especially those who are incentivized by promise of sentence reductions or monetary gains, has also been linked to criminal convictions that later resulted in exoneration (Garrett, 2008; Garrett, 2011; Joy, 2006; Raeder, 2007). Research collected by the Innocence Project (2018) reveals that the use of informants was a factor in $20 \%$ of DNA-based exonerations. Research on capital case exonerations shows that more than $45 \%$ of those cases utilized a police informant (Natapoff, 2006).

Recent decades have seen the evolution of forensic capabilities that have been utilized in the course of investigations both to identify the perpetrator and eliminate suspects. However, research indicates that false and misleading forensic testimony and what is often termed "junk science" is often present in cases that resulted in an exoneration after a wrongful conviction (Garrett \& Neufeld, 2009; Gross \& Shaffer, 2012; West \& Meterko, 2015). Illustrating this, a review of 156 DNA exonerations in which forensic testimony had been given at the initial trial found that in $60 \%$ of the cases forensic analysts had provided testimony that was erroneous and/or not supported by empirical data (Garrett \& Neufeld, 2009).

Research shows that misuse of forensic evidence is most likely to be found in cases of sexual assault, homicide, and child sex abuse, occurring in $37 \%, 23 \%$, and $21 \%$ 
of the cases respectively (Gross \& Shaffer, 2012). The types of forensics most often associated with cases that result in an exoneration are serology, microscopic hair analysis, and bite marks (LaPorte, 2017). Additionally, the language utilized by forensic experts in relaying the reliability and accuracy of testing has been found to play a role in exoneration cases (Hampikian et al., 2011).

As a case in point, in the trial of Gary Dotson, the first individual exonerated by DNA evidence, a forensic expert for the state had testified that both Dotson and the semen donor had blood type B. He further communicated that blood type B is found in only about $11 \%$ of the Caucasian population. This implied that Dotson was included in the $11 \%$ of the population who could have been the offender and that $89 \%$ of the population was excluded. However, the expert failed to inform that jury that victim also had type B blood and that her fluids were mixed in the sample, which meant all of the B markers could have come from the victim and could have masked those from the semen of the offender. This meant it was possible for any male of any blood type to have been the donor (Garrett \& Neufeld, 2009).

Inadequate defense or "bad lawyering" has also been linked to cases that have resulted in post-conviction exoneration (Gould et al., 2012; Leo \& Gould, 2009).

According to research about a quarter of all DNA exonerees had ineffective or inadequate defense counsel (Berry, 2003). Other research indicates that $80 \%$ of innocent defendants who are later exonerated are unsuccessful in raising the issue of ineffective counsel in their attempts at appeal (West, 2010). Circumstances commonly held as illustrating ineffective counsel are: failure to communicate with the client, or communicating in a hurried, callous, or dismissive manner, little to no attempts given towards discovery, little 
to no investigation, failing to secure needed forensic experts, failure to test physical evidence, negligible preparation, perfunctory cross-examination and feeble trial advocacy (Berry, 2003).

\section{Racial and ethnic differences in exonerations}

Available information on exonerations demonstrates racial and ethnic differences are present in all major categories of crimes for which data is collected (Free \& Ruesink, 2012, 2018; Gross et al, 2017; Parker et al., 2003; Rizer, 2003; Smith \& Hattery, 2011). Though blacks represent $13 \%$ of the US population and roughly $33 \%$ of the prison population, they comprise $47 \%$ of all exonerations and $61 \%$ of DNA exonerations (Bronson \& Carson, 2019; Gross et al., 2017; IP, 2018). When comparing prison population to black and white defendants who have been exonerated, we find that black defendants make up a substantially higher percentage of those who are exonerated than are incarcerated and that the opposite is true for white defendants (Smith \& Hattery, 2011).

In some categories of crime, the difference is even more marked. The data on sexual assault shows that blacks comprise $25 \%$ of all prisoners convicted of sexual assault but make up $63 \%$ of exonerees (Gross \& Shaffer, 2012). A black defendant serving time for rape is three and a half times more likely to be found innocent than a white defendant serving time for sexual assault (Gross et al., 2017).

Similarly, black defendants make up $40 \%$ of those incarcerated for homicide but comprise $50 \%$ of homicide exonerations and $53 \%$ of those defendants who had been given a death sentence (Gross et al. 2017). Innocent black defendants charged with murder are seven times more likely to be wrongfully convicted of murder than are 
innocent whites and blacks convicted of murder are $50 \%$ more likely to be innocent than other convicted murderers (Gross et al. 2017).

In the category of drug crimes exonerations we find racial disparities as well. Data shows that whites use drugs at higher rates than blacks, but black and Hispanic defendants are much more likely to go to prison for drug possession (Gross et al., 2017; Gross \& Shaffer, 2012; SAMHSA, 2019). Data on exonerations of drug crimes reveals that black convicts serving time for drug crimes are about 12 times more likely to be innocent of the drug crime than a white convict serving time for drug crimes (Gross et al., 2017).

Data shows that exonerations of black defendants are more likely to contain justice official misconduct. Specifically, $70 \%$ of the exonerations of a black defendant for murder crimes included official misconduct that resulted in the wrongful conviction compared to $63 \%$ of white innocent defendants (Gross et al., 2017). Overall, exonerations of black defendants are $22 \%$ more likely to have had the element of police misconduct in their wrongful conviction (Gross et al., 2017). Further, research demonstrates exonerees of group exonerations arising from the misconduct of police and prosecutors are overwhelmingly black and/or Hispanic (Gross et al., 2017).

As previously mentioned, data on Hispanics is nearly non-existent due to the disturbing and persistent flaws in how data on race and ethnicity is collected at many levels of the justice system. This makes it impossible to capture actual arrest, conviction, and imprisonment data that is needed to fully explore the topic of disparities in wrongful convictions and exonerations of Hispanics (Gross et al., 2017; O'Brien et al., 2019; Rizer, 2003). However, the current data indicates that approximately $12 \%$ of all exonerees are 
Hispanic (Gross et al., 2017; Gross \& Shaffer, 2012). Current research indicates that many Hispanics face unique challenges in regards to wrongful conviction and exoneration due to language barriers and the threat of deportation (O'Brien et al., 2019). The majority of exonerations of Hispanics are found in the category of drug crimes, followed by robbery (Gross et al., 2017).

The race of the innocent defendant and the race of the victim have also been found to be a factor in exonerations (Gross et al., 2017; Harmon, 2004; Johnson et al., 2013; Smith \& Hattery, 2011). Research indicates the rate of exoneration for innocent minority defendants of any race or ethnicity convicted of killing a white victim is twice as great as for that of an innocent white defendant convicted of killing a white victim (Harmon, 2004). Research also shows homicide exonerations of black innocent defendants with a white victim constitute $31 \%$ of homicide exonerations though only about $15 \%$ of murders by blacks have white victims (Gross et al., 2017). Stated another way, exonerations for murder with a black defendant and white victim occurs double the number of times for all murders.

Similarly, the majority of blacks who have been exonerated for sexual assault had been wrongfully convicted of raping a victim who was white (Gross et al., 2017). An empirical analysis of DNA exonerations found that $78 \%$ of the exonerations in rape cases were of a black defendant with a white victim, though crime demographics showed black men commit just $16 \%$ of all rapes against white women (Smith \& Hattery, 2011). Another study that examined all known exonerations found that black men convicted of raping a white woman accounted for over half of all rape exonerations, though this specific inter-racial combination occurred in less than 11\% of all rapes (Gross et al., 
2017). Further, the data on exonerations shows that a black defendant convicted of raping a white woman is about eight times more likely to be innocent than a white defendant convicted of raping a white woman (Gross et al, 2017).

Researchers point out that cross-racial identification, a known factor in convictions that result in exonerations, likely plays a role in the race based disparities found in these exonerations (Gross et al., 2017; Johnson et al., 2013). However, black innocent defendants account for $40 \%$ of all rape exonerations in which eye witness misidentification was not present (Grosset.al, 2017). Additionally, murder investigations of black defendants later exonerated of killing white victims have been shown to be less accurate even without erroneous eye witness identification (Gould \& Leo, 2015; Gross et al., 2017; Olney \& Bonn, 2015; Rafail \& Mahoney, 2019). With all of the information on exonerations in general and by racial and ethnic differences, less is known about timeto-exoneration.

\section{Time-to-Exoneration}

Empirical research examining any aspect of time-to-exoneration is virtually nonexistent. A review of the available empirical literature finds that only four studies have reviewed time-to-exoneration on any level. Three of those four studies examined time-toexoneration and its relationship to race and/or ethnicity. However, in those three studies race or ethnicity was included as a part of an examination of the impact of a variety of other legal and non-legal factors and was not the primary focus. In short, there is a marked deficit in scholarly research on time-to-exoneration and race and ethnicity though a review of the data maintained by the National Registry of Exonerations indicates racial 
and ethnic differences are present in time-to-exoneration. Specifically, the data indicates that for all offense types the average time served is 10.7 years for black exonerees, 7.2 years for Hispanic exonerees, and 7.2 years for white exonerees (NRE, 2018). Additionally, this data showed that in the category of drug crimes, child sexual abuse, and sexual assaults, Hispanic innocent defendants serve more time before exoneration than did white innocent defendants but less than black innocent defendants. These statistics point to a similar pattern in that white innocent defendants took less time to be exonerated than did Hispanic and black innocent defendants.

Gross et al. (2017) reviewed over 1,900 exonerations and examined the relationship of race to various aspects of exonerations, including time-to-exoneration. The findings revealed that black innocent defendants spend more time wrongfully imprisoned than white innocent defendants in every single category of crimes for which exoneration data was collected. Additionally, the study assessed the data in greater detail for the categories of murder, sexual assault, and drug crimes as those three categories yield the highest number of exonerations.

In examining murder exonerations Gross et al.'s (2017) study showed that black innocent defendants incarcerated for murder spent three years longer in prison than did white innocent defendants. The analysis also revealed that black innocent defendants serving time for sexual assault spent 4.5 years more before being exonerated than did white innocent defendants serving time for sexual assault. Lastly, the study revealed that black innocent defendants make up a large portion of the innocent defendants who were incarcerated for 25 years or longer for murder or sexual assault. 
Olney and Bonn (2015) examined the impact of race and ethnicity as a non-legal factor and the presence of DNA evidence as a legal factor on the wrongful conviction outcome and exoneration process. They found that the availability of DNA testing increased the chances of exoneration for violent crimes for all races. However, their findings indicated that being black produced a higher chance of being exonerated for murder and sexual assault crimes, even when controlling for the factor of DNA testing. Additionally, they found that black innocent defendants experienced the longest time-toexoneration relative to defendants of all other races.

Rafail and Mahoney (2019) focused specifically on time-to-exoneration in what they termed the "exoneration pipeline" and found significant differences arising from race, evidentiary content, and place. They concluded that the time-to-exoneration was impacted by state level characteristics, DNA testing, advocacy by an innocence organization, and race. Their findings on the impact of race pointed to significant disadvantage for black exonerees as evidenced in longer periods of time spent wrongfully incarcerated before being exonerated than innocent defendants of other races. However, their study failed to provide a theoretical construct in examining the relationship of race to time-to-exoneration.

While these three studies do examine time-to-exoneration with a racial and ethnic focus, they do not do so through the lens of a theoretical premise. Leo (2005, p. 213) argued scholarship on innocence is "theoretically impoverished". The review of the literature shows a deficit in the application of theory in the time-to-exoneration from a racial and ethnic perspective. This represents a gap in the existing literature. 
The application of theory is critical in providing context for the results (Higgins et al., 2012; Norris et al, 2020). Theory provides the framework for the rational organization of empirical data, aids in exposing patterns, and promotes understanding of how factors and events are connected to each other (Akers, 1999; Fuller, 2009; Higgins, 2005). When a study lacks a theoretical framework, relevant predictors may not be included in the analysis and there is no basis for the determination of variables to be included (Vito, 2015). The application of theory makes it possible to understand why certain behaviors and outcomes are occurring (Higgins, 2005). Focal concerns theory provides the context to understand racial and ethnic differences in time-to-exoneration. Further, focal concerns theory may provide some foundation for practice and policy recommendations.

\section{Focal Concerns Theory}

Focal concerns theory originally emerged as a theoretical model within the scholarly exploration of gender differences in sentencing (Steffensmeier, 1980). This early application of the theory posited that judicial decision making assessing blameworthiness was based upon stereotypical beliefs regarding gender. Specifically, Steffensmeier's study found females were seen by judges as less blameworthy, and therefore less deserving of harsh punishments than males, based upon a belief that females commit less serious crimes than males and have less extensive criminal history. According to Steffensmeier (1980) the judge's biased perception of female offenders by judges resulted in sentencing disparities between genders. 
In later years, Steffensmeier et al., (1998) reformulated the theory to include Albonetti's (1991) premise that judges may be influenced by various cultural stereotypes in arriving at their decisions and he expanded the theory to include other social characteristics such as race, ethnicity, and age. Steffensmeier and colleagues found support for the premise that stereotypical perceptions consistent with young black males as a "dangerous class" influenced judicial decision making. Specifically, the analysis examined the influence of race, age, and gender on two sentencing outcomes, namely, decision to incarcerate and length of sentence. The study controlled for the legal variables often associated with stricter and harsher sentencing. Additionally, the analysis implemented controls for additional factors associated with sentencing outcomes such as mode of conviction, court size, and factors specific to the county (Steffensmeier, et al.,1998).

The independent effects of each of the variables of race, gender, and age upon sentencing was examined, then the race-age data was disaggregated by gender for both males and females. The findings indicated that young black males were more severely sentenced than any other group and that race was more influential in the sentencing of younger male defendants than in the sentencing of older male defendants. It was also found that age was more influential in sentencing of male defendants than it was when the female defendants' sentencing outcomes were examined. Finally, the interaction of age, race, gender, was found to be greater than the impact of race and gender alone. Steffensmeier proposed specific mechanisms by which the interaction of social characteristics, such as the defendant's race, ethnicity, age, and gender, influence decision making regarding punishment to the advantage of some and the disadvantage of 
others (Steffensmeier et al., 2017). The theory's "key notion" is that judges and other court actors are guided by three focal concerns in reaching sentencing decisions: blameworthiness, protection of the community, and practical implications of the resulting decision" (Steffensmeier et al., 2017, p. 813). In focal concerns theory, the social characteristics of the defendant are understood to influence the decision making process as these three focal concerns are assessed, resulting in disparities in the outcomes (Steffensmeier et al., 1998).

Blameworthiness and the degree of harm that was inflicted upon the victim can be understood as relevant in that sentencing severity is indicated by law to be commiserate with the degree of severity of the harm to the victim (Steffensmeier et al., 1998). Similarly, the protection of the community is of exigent concern as a judge must weigh the risk an offender might pose to society in the future. This necessitates consideration of such elements as prior criminal history, prior victimization, the nature of the crime, and socioeconomic characteristics of the defendant (Steffensmeier et al., 1998). Lastly, practical constraints and consequences address the necessity of the consideration of items that impact both the organizations and the individuals within the organizations. This encompasses the maintenance of working relationships between the criminal justice actors, concerns with timely processing of cases, consideration of factors such as jail and prison overcrowding, and reaction from the community (Steffensmeier et al., 1998).

Focal concerns theory draws upon and integrates elements of conflict theory, racial/group threat theory, and organizational efficiency theory. Additionally, it is strongly influenced by sociological theory, particularly as it pertains to the origins of bias, and incorporates tenets of both attribution and labeling theories (Steffensmeier, 
2017). These theories inform the processes by which we explain the behavior of others which result in bias and argue that perception of an individual as belonging to a certain group gives rise to labeling and results in the individual being assigned the expectations and scripts associated with the group (Becker, 2008; Harvey \& Weary, 1984).

A guiding principle of focal concerns theory is the understanding that judges and other justice decision makers often face situations where they either do not have enough information to arrive at a rational decision, or, conversely, have an overwhelming amount of information and often a short amount of time in which to consider it. In these circumstances, focal concerns theory argues that these decision makers resort to heuristics to guide their decisions about how dangerous the offender is and how likely he or she is to continue to offend.

These scripts, which are largely unconscious, are heavily dependent on social beliefs that posit certain races and ethnicities are more prone to criminal behavior. (Hartley et al., 2007). The heuristics incorporate stereotypical interpretations of personal characteristics such as gender, race/ethnicity, age, and social class in making determinations (Harris, 2009; Spohn \& Holleran, 2000; Steffensmeier et al., 1998). Once established and reinforced through use, the heuristics function as a default mechanism that guides decision making, is resistant to change, and provides insight into how aspects of the person such as race, gender, and ethnicity impact decision making in the criminal justice arena (Tillyer \& Hartley, 2010).

Ideally, the assessment of the focal concerns would be applied with consistency across all individuals. However, research has consistently shown that factors such as race, gender, and age impact the assessment of these concerns and impact the final decision. 
For example, it has been demonstrated that minority defendants are stereotyped and are more likely to be seen as more blameworthy, more dangerous, more deserving of punishment and less likely to be able to be reformed than other offenders (Bridges \& Steen, 1998; Carnevale \& Stone, 1995; Spohn \& Holleran, 2000; Spohn \& Sample, 2013; Steen et al., 2005; Steffensmeier et al., 1998).

Though originally designed to explore gender disparities in sentencing, in recent years, scholars have applied focal concerns theory to a variety of settings and actors within the criminal justice system such as prosecutorial decision making (Beichner \& Spohn, 2012; Franklin, 2010; Harris, 2009; Ulmer et al., 2007), police decision making (Crow \& Adrion, 2011; Higgins et al., 2012; Ishoy \& Dabney, 2018; Vito et al., 2018) decisions made by corrections officers (Logan et al., 2017) and parole officers, (Huebner \& Bynum, 2006), as well as the decisions made by judges at all stages of the legal process (Crow \& Bales, 2006; Freiburger, 2009; Freiburger et al., 2010; Hartley et al., 2007; Pierce, 2012; Sharp et al., 2000; Spohn \& Holleran, 2000; Steffensmeier \& Demuth, 2001). Focal concerns theory has also been utilized to investigate racial disparities in sentencing across different modes of conviction as well as across a variety of crime types and levels of severity (Demuth \& Steffensmeier, 2004; Erickson \& Eckberg, 2016; Higgins, et al., 2013; Johnson, 2003: Leiber \& Blowers, 2003; Ray \& Dollar, 2013; Schlesinger, 2005; Sharp et al., 2000).

Empirical literature on the effects of race and ethnicity upon sentencing outcomes consistently finds evidence of bias in that blacks and Hispanics are shown to be more likely to be incarcerated then whites and receive longer sentences than comparable whites for similar crimes (Albonetti, 1997; Bishop, et al., 2020; Brennan \& Spohn, 2008; 
Crawford, et al., 1998; Kramer \& Steffensmeier, 1993; Mitchell \& MacKenzie, 2004; Petersilia, 1983; Pratt, 1998; Rehavi \& Starr, 2014; Spohn, 2000). The focal concerns framework sees these disparities as the outcome of a reliance on attributions and stereotypes which judges and other criminal justice decision makers employ to navigate in an environment which holds marked uncertainty and complexity (Steffensmeier, et al., 2017). Due to the perception of certain groups as having extra-legal characteristics associated with criminality, focal concerns posits that certain defendants are more likely to experience harsher outcomes than those not associated with criminality. Scholarly literature which utilizes focal concerns to examine decision making within the criminal justice system supports the argument that the outcomes of these stereotypical heuristics are often detrimental to minority defendants.

Take for example, Bridges \& Steen (1998) whose findings indicated that probation officers differed significantly in their assessments of attributions about the causes of criminality when assessing white and minority juvenile offenders. The analysis revealed that blacks were more often assessed an internal attribution as a cause of criminal activity while white juveniles were more often assessed an external attribution. Further, their findings indicated that even when controlling for the legal variables of seriousness of the offense and the criminal history of the offender, the differences in attributions impacted the risk assessments of the offenders. Namely, black juvenile offenders were held to be more at risk for re-offending than were white juvenile offenders.

Higgins and his colleagues highlighted the use of stereotypically based heuristics by prosecutors when making the decision to incarcerate. 
Propensity score matching was utilized to ascertain the impact of race upon prosecutorial decision making in regards to juvenile offenders. They found that race was a "single, isolated cause" of the decision to incarcerate. Specifically, the findings indicated that black defendants were 1.28 times more likely to be incarcerated than were their white counterparts (Higgins et al., 2013).

Other research supports differential assessments of dangerousness and risk to the community which are impacted by race. As a case in point, one examination of juvenile diversionary outcomes showed that minority defendants were significantly less likely to be given diversion by police than were white juvenile arrestees race (Ericson \& Eckberg 2016). This resulted in minority arrestees entering the juvenile court system earlier than the white arrestees. Additionally, non-white defendants were more likely to be charged rather than diverted by prosecutors, especially in theft cases. Further, it was shown that the extra-legal variables associated with socioeconomic status significantly impacted the decision to charge. Specifically, defendants with an inner city offense location, a single parent household, and a lower household income were more likely to be charged regardless of race.

Results consistent with bias in outcomes for minorities have also been found in the pre-trial processing of adult felony defendants. Take for example, Schlesinger's (2005) findings that being black or Hispanic increased the odds of being denied bail by about $25 \%$. The analysis showed that when bail was granted, bail amounts between blacks and whites were fairly equal, while the amount imposed upon Hispanics was found to be about $12 \%$ higher than for whites. Further it was found that the odds of pretrial incarceration for Hispanics was double that of whites while black defendants faced 
odds that were $87 \%$ greater than whites. Legal variables related to the severity of the crime, status within the justice system at time of arrest, and the number of charges were also found to be significant predictors of outcomes.

Similar results have been found when examining the impact of ethnicity and race on severity of punishment. Research indicates that Hispanic defendants are sentenced more in line with the outcomes of black defendants, that both black and Hispanic defendants are more likely to receive harsher punishments than white defendants, and that in some cases, Hispanic defendants receive the harshest treatment of all (Demuth \& Steffensmeier, 2004; Spohn \& Holleran, 2000; Steffensmeier \& Demuth, 2000; Steffensmeier \& Demuth, 2001). Demuth and Steffensmeier (2004) additionally found that the effects of ethnicity were largest in the cases involving drugs and that race effects were strongest in cases involving property crimes.

Leiber and Blowers (2003) substantiate differential assessments of dangerousness and threat to the community predicated on race. Their analysis showed that in cases with elements indicating a more serious nature, such as assault, black defendants were more likely to be prioritized as serious offenses by prosecutors than were similar cases with white defendants. Additionally, black defendants were less likely to be granted a continuance by judges than were similar serious cases with white defendants. Their research indicated that these two discretionary decisions by judges and prosecutors increased the chances of conviction and incarceration for black defendants in these types of cases.

The literature demonstrates support for focal concerns and consequent disparities based on race even when accounting for different modes of conviction and varying types 
of prosecutorial and judicial discretion. Johnson's (2003) analysis found that extralegal factors of race and ethnicity had a greater impact on sentencing outcomes than did legal factors. Specifically, it was found that across all modes of convictions, minorities were less likely to be sentenced at below the recommended guidelines and more likely to be sentenced above the recommended guidelines than were white defendants (Johnson, 2004).

In short, empirical investigation of the disparities in pre-trial and sentencing outcomes consistently shows that factors consistent with focal concerns theory, including extralegal factors such as race, ethnicity, age, and gender, do impact decision making. Further, the literature shows that the bias arising from reliance on stereotypical attributions does result in harsher sanctions such as incarceration and longer sentences for some defendants. Research shows it is often blacks and Hispanics that are disadvantaged.

In recent years, scholars have also elected examine the intersection of legal factors and the combined impact of multiple non-legal characteristics utilizing a focal concerns theory perspective. Support has been found for combined effects of the interaction of extra-legal factors such as race, ethnicity, gender, age, employment, and education, in decision making (Steffensmeier, et al., 2017). The literature shows that net of legal factors, the impact of these interactions often disadvantages blacks and Hispanics in the outcomes realized (Doerner \& Demuth, 2010; Feldmeyer, et al., 2015; Spohn \& Holleran, 2000; Steffensmeier, et al., 2017; Warren, et al., 2012).

For example, Steffensmeier and Demuth (2000) examined the sentencing outcomes for over 89,000 male defendants and found that the interaction of legal and extralegal factors influenced sentencing severity. The results showed that white male 
defendants were treated most leniently, followed by Hispanic, and then black male defendants. This was found to be especially true in drug cases. Additionally, the impact of legal factors such as offense severity, and prior record as well as the extralegal factors of age and education were found to effect the harshness of the outcome.

In a similar fashion, Munoz and Freng (2008) demonstrated the interaction of race, age, and gender upon misdemeanor sentencing. They found that whites were more likely to be convicted of traffic offenses and that defendants of other races were more likely to be convicted of other types of offenses. Their findings also revealed that while most defendants received a fine, young adult and adult minority males were more likely to have other punitive sanctions levied at them instead of or in addition to fines.

Sharp et al., (2000) probed the outcomes in drug court for black and white female defendants and found support for an "evil black woman" stereotype. Specifically, it was found that prior convictions and employment were predictors of sentence length for white offenders. However, for black offenders, it was self-reported use of crack cocaine that predicted sentence length in spite of the fact that both white and black offenders were nearly equally as likely to report crack cocaine use. Additionally, trial by jury was found to increase the length of the sentence more significantly for black offenders than for white offenders.

In exploring the outcomes of mental health courts, Ray and Dollar (2013) identified significant effects for the interaction of gender and race. Their findings revealed that white females were significantly less likely to be terminated from the program than any other defendants. Based on their observations and analysis they concluded that the mental health court facilitators relied on a "perceptual shorthand" in 
assessing the defendant's culpability and blameworthiness for non-compliant behaviors as well as dangerousness.

Steffensmeier et al., (2017) set out to examine how the age of a defendant might contextualize the impact of gender, race and ethnicity on sentencing outcomes. The results showed that legal factors such as past criminal history and the current crime were the primary predictors of sentencing but that race/ethnicity, age, and gender combinations resulted in varying disparities for different group members. Young black males ages 1834 and Hispanic males of any age were found to receive the harshest sentences. It was also shown that combinations of extra-legal factors yielded substantial differences in sentencing outcomes. For example, young adult minority males were shown to have approximately a $25 \%$ greater chance of being incarcerated than the oldest white females and about a $30 \%$ greater chance than the youngest white, black, and Hispanic females.

In a similar exploration of the combined impact of extralegal variables, Warren and colleagues (Warren, et al., 2012) focused attention on young black and Hispanic males due to their perceived association with drugs, violence, and crime in general which is commonly portrayed through popular media in our society. The study used multinomial logistic regression to ascertain the likelihood of the three outcomes of community supervision, jail sentence, and prison sentence. The researchers controlled for factors known to be associated with sentence severity. Specifically, they controlled for current offence, prior criminal record, whether or not the case went to trial. Additionally, control measures for year of sentencing and jurisdiction were also utilized. The results showed that for more serious types of crime, the seriousness of the crime and prior records, not the demographics of the offender drove the sentencing outcomes. However, 
for lesser crimes and especially for drug crimes, young black males were found to be at a significant disadvantage.

Freiburger, et al., (2010) analyzed the impact of race and gender upon pre-trial decisions within the frame work of focal concerns. Specifically, they explored the impact of race upon a judge's decision to release the defendant on their own recognizance as well as on the amount of bail imposed. The findings indicated that black defendants were approximately $80 \%$ less likely to be released on their own recognizance than were white defendants and more likely to be detained prior to trial. Race was not found to have an impact on the amount of bail that was given, but the extra-legal variable of gender had an impact in that females received significantly less bail amounts. The extra-legal variable of employment was found to have the effect of increasing the likelihood of the defendant being released on their own recognizance. These findings are consistent with the premise of focal concerns theory and the reliance on stereotypes regarding race, gender, community ties, and criminality.

In an attempt to extricate the elements of stereotypes relating to crime and race and ethnicity, Spohn and Sample (2013) explored the impact associations with dangerousness and threat have upon sentencing. They conceptualized the elements of the stereotype of a dangerous drug offender as being an offender with a prior conviction and who had used a weapon in the commission of the current crime. In their analysis of federal sentencing data of white, black, and Hispanic drug offenders, they found that the elements associated with the image of dangerous federal drug offender resulted in lengthier sentences for black offenders but not for white or Hispanic offenders. This was especially true for those black offenders who offense included crack cocaine. Further, the 
lengthiest sentences were given to black offenders who met all of the elements of the stereotypical dangerous drug offender.

Freiburger (2009) examined disparities in sentencing outcomes for drug offenders through the lens of focal concerns. The study results indicated that the interaction of legal and non-legal factors such as seriousness of the crime, prior felony convictions, race and educational attainment, influenced the decisions of judges to incarcerate the offender. Additionally, it was found that white women were less likely to be incarcerated and that employment status more heavily impacted the decision to incarcerate black women than it did white women. The results are consistent with the predictions of outcomes based on focal concerns theory which posits that characteristics of the defendant such as race, gender, and ties to the community, are embedded in the "perceptual shorthand" utilized in judicial decision making (Albonetti, 1991; Steffensmeier, et al., 1998; Ulmer \& Johnson, 2004).

In summary, judges and prosecutors utilize discretion in their capacity as decision makers in regards to many aspects of punishment, including imprisonment and type and length of sentence (Fontaine \& Emily, 1978; Kramer \& Steffensmeier, 1993;

Steffensmeier et al., 1998). Scholarly research further demonstrates in order to facilitate the decision-making process, judges and prosecutors resort to heuristics that incorporate stereotypical beliefs regarding characteristics of the individual such as their race or ethnicity in considering blameworthiness, protection of the community, and practical constraints and consequences (Albonetti, 1991; Ford, 2009; Freiburger, 2009: Johnson, 2003; Leibers \& Blowers, 2003; Steffensmeier et al., 2001; Warren et al., 2012). Further, this has been shown to result in disparities in the outcomes such as the decision to 
incarcerate and lengthier sentences and these disparities often negatively impact minorities (Bridges \& Steen, 1998; Demuth \& Steffensmeier, 2004; Doerner \& Demuth, 2010; Sharp, et al., 2000; Spohn \& Sample, 2013; Steffensmeier, et al., 2017; Steen, et al., 2005).

The application of focal concerns theory to time-to-exoneration is logical. Following Steffensmeier (1980), judges and prosecutors are likely to harbor racial and ethnic stereotypes. These stereotypes provide them a basis for the determination that minorities are more likely to be involved in criminality and therefore less likely to be innocent, are able to serve out their time better than whites, and that the community needs to be protected from blacks and Hispanics. Because of this logic, blacks and Hispanics are not likely to be exonerated in a similar amount of time as whites. Operating with these stereotypes, judges, prosecutors, and other justice decision makers are likely to treat whites, blacks, and Hispanics differently resulting in differences in the time that it takes for an exoneration.

The literature review indicates this version of focal concerns theory is valid when trying to understand criminal justice actor decision-making. It is reasonable to apply focal concerns to the topic of time-to-exoneration based on the large body of literature which finds evidence of bias at every stage of contact with the criminal justice system. Further, there is an ample body of research which applies focal concerns theory to a wide range of decision making and outcomes within the criminal justice arena which supports the legitimacy of the application of this theory to the decision to exonerate.

Scholarly literature which assesses the impact of race and ethnicity on time-toexoneration is scant. The studies which do exist point to significant disparities. Gross et 
al., (2017) found that black exonerees spent more time in prison than white exonerees in every category of crime for which data was collected. Similarly, in their examination of the impact of DNA on exonerations, Olney and Bonn (2015) also found that black exonerees encounter the longest time to exoneration. Lastly, utilizing survival analysis, Rafail and Mahoney (2019) focused on the length of time it takes for exonerees to complete the process of exoneration. Their findings exposed significant differences arising from factors of place, evidence type, and race. Further, the temporal gap in achieving exoneration was found to disadvantage black exonerees. None of these studies, however, apply the theoretical context of focal concerns theory to racial and ethnic differences in time-to-exoneration. This type of logic and a study that examines this issue is lacking from the literature leaving a gap that is a relevant and critical area of empirical exploration.

\section{Purpose of the Study}

The purpose of this study is to examine exoneration data to determine and contextualize racial and ethnic differences among those who have been wrongfully convicted. Specifically, the data was examined for evidence of racial and ethnic differences in time-to-exoneration. Additionally, time to exoneration was examined in the context of focal concerns theory.

The study utilizes focal concerns theory as the context, as demonstrated in the hypotheses below, to guide in greater understanding of disparities found between racial and ethnic groups. This study expands previous literature on focal concerns by applying it to exoneration data, to determine the racial and ethnic differences in time to exoneration. 
The study addresses two hypotheses derived from the focal concerns theoretical perspective.

Hypothesis 1: Racial and ethnic differences are present in length of time-toexoneration.

Specifically, it is expected that the length of time-to-exoneration will be greater for blacks and Hispanics than for whites. This takes place because non-whites are more likely to be considered crime-prone, more aggressive, and more "streetwise" than whites (Devine \& Elliot, 1995; Mann \& Zatz, 2002; Steffensmeier, 1980; Steffensmeier et al., 1998; Steffensmeier \& Demuth, 2001). In other words, judges, prosecutors, and other criminal justice actors who have the authority to make decisions which impact time-toexoneration are likely to be utilizing stereotypes to assist in making their decisions (Albonetti, 1991; Steffensmeier et al., 1998).

Hypothesis 2: The legal components of a case are associated with the racial and ethnic differences in the length-of-time to exoneration.

The legal aspects of a case (e.g., offense severity, type of crime, false accusation, etc.) will result in both positive and negative impacts on time-to-exoneration depending on the specific legal aspect (Albonetti, 1991; Gross \& Shaffer, 2012; Olney \& Bonn, 2015; Steffensmeier et al., 1998). It is expected that beneficial factors (non-violent offenses, older age, etc.) will yield greater benefit in regards to shortening time-toexoneration for whites than for blacks and Hispanics. Similarly, it is expected that negative factors (violent offense, official misconduct, younger age, etc.) will yield greater negative impact in lengthening time-to-exoneration for innocent blacks and Hispanics 
defendants than for innocent whites defendants. Central to this is the judicial concern about the blameworthiness of the individual and the potential protection of the community (Albonetti, 1991; Steffensmeier et al., 1998.) In other words, the legal factors will illuminate why racial differences in the length-of-time to exoneration exist. Specifically, legal factors such as severity of the crime, will have an impact on the assessment of the dangerousness of the convicted defendant, as well as impact concerns with the threat to the community. Additionally, non-white offenders are likely to be seen as more dangerous and as more able to cope with incarceration. Due to this, legal factors will have a differing impact on defendants based upon race and ethnicity and this is consistent with focal concerns theory. 


\section{CHAPTER 3}

\section{METHODS}

The data utilized in this study comes from a comprehensive database maintained by the National Registry of Exonerations (NRE). The NRE is a collaborative effort between the Newkirk Center for Science and Society at University of California Irvine, University of Michigan Law School, and the Michigan State University College of Law in conjunction with the Center for Wrongful Convictions at Northwestern University School of Law. The registry collects, analyzes, and disseminates information on all known wrongful convictions and exonerations of innocent defendants from 1989 forward. The NRE defines an exoneration as occurring when "a person who has been convicted of a crime is officially cleared based on new evidence of innocence." (National Registry of Exonerations, 2020, para 1). The NRE relies entirely on public information. The data for this study used a subsample $(\mathrm{N}=489)$ of the larger data set of exonerations from the NRE. ${ }^{4}$ The data used were of exonerations which occurred from the years 2008 to 2018. This was done to provide a manageable subsample of the population and still provide a decade's worth of exoneration information.

\section{Measures}

To address the hypotheses, a number of measures were used in the present study. These measures include the days to exoneration, whether an exoneration took place within a

\footnotetext{
${ }^{4}$ The original sample $(\mathrm{N}=507)$ contained 18 exonerees whose race or ethnicity was not white, black, or Hispanic. Those 18 exonerees were excluded from the sample, resulting in the sample size $\mathrm{N}=489$.
} 
specified number of days, as well as extralegal and legal factors that are associated with studies of focal concerns theory.

\section{Days-to-exoneration}

A central measure to this study is capturing the number of days that it takes an individual to be exonerated (Kleinbaum \& Klein, 2010). To calculate this measure, two data points are present in the data. The two data points are the date of conviction and the date of exoneration. These two data points allow for the precise measure of days-toexoneration. To arrive at this precise measure the following calculation was performed: exoneration date - conviction date. This provided the exact number of days-toexoneration.

\section{Exoneration Event}

Another key measure is whether an exoneration took place in a specified amount of time (Kartsonaki, 2016). In other words, this provides a specific time of occurrence for the study. Two measures were utilized for the exoneration event (i.e., median daysto-exoneration). For the median of days, the exoneration event was coded as 1 for above the median and 0 for below the median.

\section{Focal Concerns Theory Measures}

The literature is diverse when it comes to measuring the different aspects of this version of Focal Concerns Theory (FCT). For instance, the policing literature provides detailed measures for each of the FCT concepts (Albonetti \& Hepburn, 1996; Kramer \& Ulmer, 2002; Spohn \& Holleran, 2000; Steffensmeier \& Demuth, 2000). In the sentencing literature the measurement of these concepts is generalized around extralegal and legal factors (Albonetti, 1991; Steffensmeier et al.,1998; Steffensmeier \& Demuth, 
2001). This dissertation follows the sentencing literature and groups the measures that are available in the data into the context of extralegal and legal factors.

\section{Extralegal Factors}

The available extralegal factors that exist in the data are: age, race, and biological sex. Age is captured in years at the time of crime commission. Race is captured as a nominal level measure. Specifically, black, Hispanic, Native American (includes Alaska Native), Other (includes native Hawaiians and Pacific Islanders), Caucasian (refers to White Americans), Asian (includes all peoples on the Asian continent including Indian, Filipinos, and Indonesians but not Russians), and Don't Know. In this study, White refers to non-Hispanic Whites and Blacks refer to non-Hispanic blacks. Due to potential data constraints (i.e., small n's within categories), three dummy codes for race were used, and they are as follows: $1=$ White and $0=$ other, $1=$ Black and $0=$ other, $1=$ Hispanic and $0=$ other. For the purposes of survival analysis, race was coded $0=$ White and $1=$ Black and $0=$ White and $1=$ Hispanic. Coding race in this way facilitates two comparative analyses of days-to-exoneration. ${ }^{5}$ The first analysis compares whites to blacks, and the second analysis compares whites to Hispanics. Additionally, multivariate analyses compared subsamples differentiated by race.

Biological sex is captured as the biological sex of the individual at the time of the crime. The measure was recoded so that $0=$ female and $1=$ male.

\section{Legal Factors}

\footnotetext{
${ }^{5}$ The number defendants that were of a race or ethnicity other than black, Hispanic, or white due was so small $(\mathrm{n}=18)$ that they were excluded from this study.
} 
A number of legal factors were used in this analysis. They are as described below.

False or misleading forensic evidence: False or misleading forensic evidence was considered a legal factor in the case as well. This means the individual's conviction was based at least in part on forensic information that was (1) caused by errors in forensic testing, (2) based on unreliable or unproven methods, (3) expressed with exaggerated and misleading confidence, or (4) fraudulent (LaPorte, 2017; NRE, 2019). This measure was coded as $0=$ no and $1=$ yes.

Perjury or False Accusation: Perjury or false accusation was considered a legal factor as well. A person other than the individual committed perjury by making a false statement under oath that incriminated the individual in the crime for which the individual was later exonerated or made a similar unsworn statement that would have been perjury if made under oath (Gould \& Leo, 2010; NRE, 2019). This measure was coded as $0=$ no and $1=$ yes.

Mistaken Eyewitness ID: Whether there was a mistaken eyewitness identification. This refers to at least one eyewitness affirmatively and mistakenly said that he or she saw the individual commit the crime or saw the individual under circumstances that suggest that the individual participated in the crime (e.g. Witness claims he saw Individual flee from the scene) (Gould et al., 2012; NRE, 2019). This measure was coded as $0=$ no and $1=$ yes.

Official Misconduct: Another legal factor is whether official misconduct in the case took place. Police, prosecutors, or other government officials significantly abused 
their authority or the judicial process in a manner that contributed to the individual's conviction (Joy, 2006; NRE, 2019). The measure was coded as $0=$ no and $1=$ yes.

Inadequate Legal Defense: Another legal factor is whether the legal defense was inadequate. This means the individual's lawyer at trial provided obviously and grossly inadequate representation (Sharp et al., 2000; NRE, 2019). This was coded as $0=$ no and $1=$ yes.

Drug Offense: Whether the offense was a drug related offense was considered a legal factor (ADD CITES!). The measure was coded as $0=$ no and $1=$ yes.

Violent Offense: Whether the offense was violent was considered a legal factor (Steffensmeier, et al., 2017; Steffensmeier \& Demuth, 2000). The measure was coded as $0=$ no and $1=$ yes.

\section{Data Analysis Plan}

The data analysis occurred in a series of steps. Step one was a presentation of the overall descriptive statistics namely, the mean, standard deviation, skewness, kurtosis, and range. By utilizing univariate statistics, this step offers a brief description of the distribution of the sample while providing an indication of variation in the measures.

Step two was a presentation of the bivariate correlations. This step is important because it shows how much variation the measures share (Lee \& Nicewander, 1988). Further, it shows the strength and direction of the shared variation (Taylor, 1990). While the shared variation between all of the measures is important, particular attention was paid to the shared variation between the legal factors used in this study. Because of the 
large number of legal factors, the possibility of multicollinearity was present, and the bivariate correlations were helpful in determining the presence of this issue. In the event multicollinearity had been detected, multiple remedies were held in consideration. First, combining the measures was considered. Second, alternative modeling was considered. Third, dropping measures was considered. Through these methods, the possibility of multicollinearity was handled.

Step three was a presentation of the survival analysis. Survival analysis is a family of techniques designed to model the time it takes for an event to occur when there is a possibility that the event will not occur for all in a given sample (Cox, 1972; Cox \& Oakes, 1984). This type of data is often non-normal. This is because of censoring, a common feature of survival analysis (Leung et al., 1997).

Censoring occurs when some of the information regarding survival time is known, but not the exact survival time (Singh \& Mukhopadhyay, 2011). Censored data can be left censored or right censored. The most common type of censoring encountered is right censoring. Right censoring occurs when the period of observation comes to an end or an individual left the study before the event is experienced (Fox \& Weisberg, 2011). This is the type of censoring that occurred in this study. Left censoring occurs when the event being examined happened prior to the commencement of the study period (Singh, \& Mukhopadhyay, 2011). Because of the non-normality distribution of these data, techniques like ANOVA and OLS may not be used because the normality assumption would be violated (Cox, 1972; Hosmer \& Lemeshow, 1999; Prinja et al., 2010).

In the present study, the main event is exoneration. The time of interest is the median length of time it takes for a person to receive an exoneration after being 
wrongfully convicted. The study period spans 2008- 2018. At the end of the study period, all individuals will have been exonerated since the data for this study is for completed exonerations. Therefore, in order to examine whether or not racial and ethnic bias exists in the time it takes to become exonerated, the median time to exoneration was established. This provides the variation needed to allow for an examination of the impact of race and ethnicity on time-to-exoneration. To address time in this manner, two techniques were used to examine the time-to-exoneration.

The Kaplan-Meier technique was used to determine the proportion of individuals who were exonerated by the median time to exoneration established. In this study time is measured in days. This technique provides a method of estimating the length of time that it will take for someone to be exonerated (Kaplan \& Meier, 1958; Klein \& Moeschberger, 1997; Kleinbaum \& Klein, 2010). The Kaplan-Meier technique performs this type of assessment by generating two functions (Cox \& Oakes, 1984; Singh, \& Mukhopadhyay, 2011). The first is the survival function. The survival function is the probability of exoneration occurring at a specified time (Goel et al., 2010; Klein \& Moeschberger, 1997; Kleinbaum \& Klein, 2010). The time period being utilized for this study is the days-to-exoneration for the eleven years spanning 2008-2018. The second function is the hazard function. The hazard function is simply the risk of the exoneration occurring after the median days-to-exoneration (Hosmer \& Lemeshow, 1999; Singh, \& Mukhopadhyay, 2011; Spruance et al., 2004). The survival and hazard functions are presented graphically.

The Kaplan-Meier, also allowed for a direct test of the difference of these functions by groups. In the present study, the groups were differentiated by race (i.e., whites vs. blacks and whites vs. Hispanics). The comparison of the groups took place 
using the log rank test. Applied to this study, the log rank test allowed for the examination of the survival and hazard functions of exoneration by race (Kaplan \& Meier, 1958; Cox \& Oaks, 1984; Singh, \& Mukhopadhyay, 2011). To do this, the log rank test allows the survival and hazard functions to be weighted equally with time. This provided the opportunity for a chi-square test of difference between exoneration by racial group.

Step four consisted of logistic regression. This form of regression is important because of the dichotomous nature of the dependent measure. Specifically, the median time to exoneration was dummy coded " 0 " for exonerated before the median time of 1,000 days and " 1 " for exonerated after the median time to exoneration. The logistic regression model allowed for a dichotomous dependent variable while examining the impact of multiple predictor variables. In the logistic regression model, the model fit is determined by the chi-square statistic. Specifically, the chi-square statistic is to be statistically significant to indicate a good fitting model by comparing and empirically examining the improvement between a null model (i.e., a model without the legal and extralegal factors) and a complete model (i.e., a model with the legal and extralegal factors) (Bewick et al., 2004; Fox, 2002; Parzen \& Lipsitz, 1999). When interpreting the coefficients in this form of regression, it is important to understand the coefficients represent a link between the covariates and the odds of for falling into the group of exonerees who were not exonerated by the median time to exonerations. The interpretation of the dummy variables indicated either an increased or decreased likelihood of being exonerated by the median time for that variable. The interpretation of the continuous variable of age showed when coefficients were positive, higher values 
indicated greater days-to-exoneration, and when the coefficients were negative, higher values indicated fewer days-to-exoneration (Clark et al., 2003; Singh \& Mukhopadhyay, 2011).

The effect size for this form of logistic regression is the $\operatorname{Exp}(\mathrm{b})$. In this form of regression, the $\operatorname{Exp}(\mathrm{b})$ is interpreted as an odds ratio (Cox \& Oakes, 1984; Fox, 2002; Harre et al., 1988; Singh \& Mukhopadhyay 2011). In the present dissertation, this form of binomial logistic regression allowed for the proper modeling of the dichotomous dependent measure, days-to-exoneration, and the legal and extralegal measures representing the focal concerns theory to address the hypotheses of interest. Specifically, five models were estimated. The first model consisted of all the data and the legal and extralegal measures for a subsample that included only black and white exonerees. The second model was comprised of all the data and the legal and extralegal measures for a subsample which included only Hispanic and white exonerees. The third model was for the data for white exonerees. The fourth model was for the data for black exonerees. The fifth model consisted of the data for Hispanic exonerees.

To address the hypothesis that there are racial differences in the focal concern measures, the Paternoster et al. (1998) z-score was applied to the slopes and standard errors of the white, black, and Hispanic models. Applying the z-score allowed for the understanding of whether the focal concern measures are equal across the racial groups. For clarity, Table 1 maps the connection between the steps of the analysis, the statistical test, and the hypotheses that were examined. 
Table 1. Data Analysis Plan.

\begin{tabular}{|c|c|c|c|}
\hline Analysis Step & Hypothesis & Statistical Test & Statistical Package \\
\hline 1 & Normality of Data & $\begin{array}{c}\text { Mean, Standard } \\
\text { Deviation, } \\
\text { Skewness, and } \\
\text { Kurtosis } \\
\end{array}$ & SPSS \\
\hline 2 & Shared Variation & Correlation & SPSS \\
\hline 3 & $\begin{array}{l}\text { Racial and ethnic } \\
\text { differences are } \\
\text { present in the } \\
\text { length-of-time to } \\
\text { exoneration }\end{array}$ & Kaplan-Meier Test & SPSS \\
\hline 4 & $\begin{array}{l}\text { The legal } \\
\text { components of a } \\
\text { case are associated } \\
\text { with the racial and } \\
\text { ethnic differences in } \\
\text { the length-of-time } \\
\text { to exoneration. }\end{array}$ & $\begin{array}{l}\text { Logistic Regression } \\
\text { Models } 1 \text { and } 2 \text { : } \\
\text { comparison groups } \\
\text { Models } 3,4,5 \\
\text { individual race }\end{array}$ & SPSS \\
\hline 5 & $\begin{array}{l}\text { The legal } \\
\text { components of a } \\
\text { case are associated } \\
\text { with the racial and } \\
\text { ethnic differences in } \\
\text { the length-of-time } \\
\text { to exoneration. }\end{array}$ & $\begin{array}{l}\text { Paternoster et al. Z- } \\
\text { score to assess the } \\
\text { equality of the } \\
\text { slopes }\end{array}$ & Excel \\
\hline
\end{tabular}




\section{CHAPTER 4}

\section{RESULTS}

The current study is designed to provide an understanding of time-to-exoneration (i.e., days-to-exoneration). To provide this understanding of time-to-exoneration, the study makes use of focal concerns theory. The results of the study take place in a series of steps.

Step 1

The first step is a presentation of the descriptive statistics. The results from the descriptive statistics measure are shown in Table 2. Black exonerees comprised $46 \%$ of the sample, white exonerees $41 \%$, and Hispanic exonerees made up the remaining $13 \%$. The sample of exonerees was $85 \%$ male. This is in line with overall known statistics regarding gender and incarceration (Carson \& Anderson, 2015). The average age of the exonerees was 32.6 years old at time of crime commission. The youngest exoneree at time of crime commission was 13 years old and the oldest was 83 years old.

The mean time to exoneration was found to be $1,223.12$ days. The median time to exoneration was 1,000 days. The shortest time to exoneration was 3 days and the longest time to exoneration in this study was 8,199 days. As expected, it was found that the exoneration event variable needed to be censored, pointing to the necessity for survival analysis. 
Table 2. Descriptive Statistics of the Measures

\begin{tabular}{|c|c|c|c|c|c|}
\hline Measure & Mean & Median & $\begin{array}{l}\text { Standard } \\
\text { Deviation }\end{array}$ & Min & Max \\
\hline Biological Sex (Male) & .85 & - & & 0 & 1 \\
\hline Age & 32.60 & - & 11.44 & 13 & 83 \\
\hline \multicolumn{6}{|l|}{ Race/Ethnicity } \\
\hline White & .41 & - & - & 0 & 1 \\
\hline Black & .46 & - & - & 0 & 1 \\
\hline Hispanic & .13 & - & - & 0 & 1 \\
\hline Official Misconduct & .35 & - & - & 0 & 1 \\
\hline $\begin{array}{l}\text { Inadequate Legal } \\
\text { Defense }\end{array}$ & .24 & - & - & 0 & 1 \\
\hline Drug Crime & .39 & - & - & 0 & 1 \\
\hline Violent Crime & .29 & - & - & 0 & 1 \\
\hline $\begin{array}{l}\text { False/Misleading } \\
\text { Forensic Evidence }\end{array}$ & .27 & - & - & 0 & 1 \\
\hline $\begin{array}{l}\text { Mistaken Eyewitness } \\
\text { ID }\end{array}$ & .10 & - & - & 0 & 1 \\
\hline $\begin{array}{l}\text { Perjury or False } \\
\text { Accusation }\end{array}$ & .40 & - & - & 0 & 1 \\
\hline Dependent Measure & & & & & \\
\hline $\begin{array}{r}\text { Time (days) to } \\
\text { Exoneration } \\
\end{array}$ & 1223.12 & 1000 & 1013.823 & 3 & 8199 \\
\hline
\end{tabular}

According to the data, $29 \%$ of the crimes for which wrongfully convicted inmates were eventually exonerated of were violent crimes. Drug related crimes comprised 39\% of the exonerations. The data showed $40 \%$ of the cases had perjury or false accusation as 
a factor. Additionally, 35\% of the cases contained an instance of official misconduct in the wrongful conviction that ended in exoneration. Inadequate legal defense played a role in $24 \%$ of exonerations. False or misleading forensic evidence was a factor in $27 \%$ of the cases and mistaken eyewitness identification occurred in $10 \%$ of the cases. Further, these results indicated ample variation of these measures for further analysis. ${ }^{6}$

An examination of the descriptive statistics of the split sample reveals that $81 \%$ of white exonerees were male, while $88 \%$ of black exonerees and $85 \%$ of Hispanic exonerees were male ${ }^{7}$. The average age at time of crime commission for white exonerees was found to be 34.7. For black exonerees the average age at time of crime commission was 31.5 years and for Hispanic exonerees it was 29.9.

A slightly higher percentage of black exonerees (31\%) had been convicted of a Violent Crime when compared to white exonerees (30\%). Hispanic exonerees had the least percentage of Violent Crime convictions (21\%). Additionally, a much higher percentage of blacks (47\%) and Hispanics (49\%) had been convicted of a Drug Crime than had white exonerees (26\%). 18\% of black exonerees had Eyewitness Misidentification as a factor in their wrongful conviction. This is compared to $3 \%$ of all white exonerees and 9\% of Hispanic exonerees.

Across the board, the legal component most often found in the wrongful convictions of white, black, and Hispanic exonerees was Perjury and False Accusation.

\footnotetext{
${ }^{6}$ The variables of fraud, firearms, DNA, false confession, guilty plea, sex crimes, and child victim were dropped from the study due to small numbers of occurrences across all race/ethnicities and extreme kurtosis and skewness that was not able to be remedied.

${ }^{7}$ See Table A2 in Appendix.
} 
Additionally, about one third of each group had experienced Official Misconduct as a factor in their wrongful conviction. The data shows that $56 \%$ of black exonerees, $49.5 \%$ of white exonerees and $34 \%$ of Hispanic exonerees waited longer than the median time of approximately three years to be exonerated.

\section{Step 2}

The correlations showed ample shared variation between the extralegal, legal, the exoneration event, and time to exoneration. First, the results indicated that exonerees with Official Misconduct $(r=.14 ; \mathrm{p}<.01)$, Inadequate Legal Defense $(r=.21 ; \mathrm{p}<.01)$, or Perjury and False Accusation $(r=.10 ; \mathrm{p}<.05)$ as a factor in their case were more likely to be incarcerated longer than 1,000 days before being exonerated. Those innocent defendants who were convicted of a Drug Crime were more likely to experience a time to exoneration that was less than 1,000 days $(r=-.22 ; \mathrm{p}<.01)$. In contrast, those innocent defendants who were convicted of a Violent Crime were more likely to wait longer than 1,000 days to be exonerated $(r=-.26 ; \mathrm{p}<.01)$.

Additionally, the results of the analysis indicated that both legal and non-legal factors were associated with the number days to exoneration. Specifically, the legal variables of Official Misconduct $(r=.17 ; \mathrm{p}<.01)$, Inadequate Legal Defense $(r=.17 ; \mathrm{p}$ $<.01)$, Violent Crime $(r=.17 ; \mathrm{p}<.01)$ and Perjury and False Accusation $(r=.10 ; \mathrm{p}<.05)$ were found to be associated with increased days to exoneration. The data shows that exonerees convicted of a Drug Crime $(r=-13 ; \mathrm{p}<.01)$ spent less time incarcerated awaiting an exoneration. Additionally, the analysis revealed that on average, innocent male defendants had to wait longer to be exonerated than did innocent female defendants $(r=.14 ; \mathrm{p}<.01)$. Similarly, black innocent defendants endured longer periods of 
incarceration before being exonerated $(r=.17 ; \mathrm{p}<.01)$ when compared to innocent white and Hispanic defendants $(r=-.16 ; \mathrm{p}<.01)$.

Among the legal factors the strongest positive associations were found between Official Misconduct and Perjury and False Accusation $(r=.49 ; \mathrm{p}<.01)$, Drug Crime and False and Misleading Forensic Evidence $(r=.49 ; \mathrm{p}<.01)$ and Violent Crime and Mistaken Eyewitness ID $(r=.40 ; \mathrm{p}<.01)$. The strongest negative associations among legal variables was found between Drug Crime and Violent Crime ( $r=-.51 ; \mathrm{p}$ $<.01)$, Perjury and False Accusation $(r=-.38 ; \mathrm{p}<.01)$, and Inadequate Legal Defense $(r=$ $-.38 ; \mathrm{p}<.01)$.

The results indicated that race and ethnicity were associated with several legal and non-legal factors. A positive association was found between race variable of Black and Drug Crime $(r=.15 ; \mathrm{p}<.01)$ as well as the variable of Mistaken Eyewitness ID $(r=.23$; $\mathrm{p}<.01)$ and False and Misleading Forensic Evidence $(r=.13 ; \mathrm{p}<.01)$. A positive association was also found between the race variable of Black and biological sex $(r=.10$; $\mathrm{p}<.05)$

A negative association was found for the variable capturing Hispanic ethnicity and age $(r=.10 ; \mathrm{p}<.05)$ while a positive association was found between the race variable White and age $(r=.15 ; \mathrm{p}<.01)$ Additionally, a positive association was found between White and Inadequate Legal Defense $(r=.10 ; \mathrm{p}<.01)$. The results indicated that there was a negative association between White and Drug Crimes $(r=-.21 ; \mathrm{p}<.01)$ and Mistaken Eyewitness Identification $(r=-.21 ; \mathrm{p}<.01)$.

The results revealed that the highest amount of shared variation was found within the legal factors. There were no issues with multi-collinearity found in the bivariate 
results, but additional tests of for multi-collinearity were performed with the regressions.

The results of the bivariate analysis can be found in Table 3 . 
Table 3. Bivariate Correlations of the Measures $(n=489)$

\begin{tabular}{|c|c|c|c|c|c|c|c|c|c|c|c|c|c|c|}
\hline & 1 & 2 & 3 & 4 & 5 & 6 & 7 & 8 & 9 & 10 & 11 & 12 & 13 & 14 \\
\hline $\begin{array}{l}\text { 1.Biological Sex } \\
\text { (Male) }\end{array}$ & 1 & & & & & & & & & & & & & \\
\hline 2. Age & 0.04 & 1 & & & & & & & & & & & & \\
\hline 3. Black & $.10^{*}$ & -0.8 & 1 & & & & & & & & & & & \\
\hline 4. White & $-.10 *$ & $.15^{* *}$ & $-.76 * *$ & 1 & & & & & & & & & & \\
\hline 5. Hispanic & .00 & $-.10^{*}$ & $-.37 * *$ & $-.33 * *$ & 1 & & & & & & & & & \\
\hline $\begin{array}{l}\text { 6. Days to } \\
\text { Exoneration }\end{array}$ & $.14^{* *}$ & 0.06 & $.17^{* *}$ & -0.6 & $-.16^{* *}$ & 1 & & & & & & & & \\
\hline 7. Median Days & $.11^{*}$ & 0.02 & $.10^{*}$ & -.01 & $-.13 * *$ & $.78^{* *}$ & 1 & & & & & & & \\
\hline $\begin{array}{l}\text { 8. Official } \\
\text { Misconduct }\end{array}$ & 0.08 & 0.02 & -.01 & .00 & 0.02 & $.17^{* *}$ & $.14 * *$ & 1 & & & & & & \\
\hline $\begin{array}{l}\text { 9. Inadequate } \\
\text { Legal Defense }\end{array}$ & 0.08 & 0.06 & -0.5 & $.10^{*}$ & -0.07 & $.17 * *$ & $.21 * *$ & 0.02 & 1 & & & & & \\
\hline 10. Drug Crime & $-.16 * *$ & $-.12 * *$ & $.15^{* *}$ & $-.21 * *$ & 0.08 & $-.13 * *$ & $-.22 * *$ & $-.29 * *$ & $-.38 * *$ & 1 & & & & \\
\hline $\begin{array}{l}\text { 11.Violent } \\
\text { Crime }\end{array}$ & $.09 *$ & $-.18 * *$ & 0.04 & 0.01 & -0.08 & $.17 * *$ & $.26 * *$ & $.26 * *$ & $.29^{* *}$ & $-.51 * *$ & 1 & & & \\
\hline $\begin{array}{l}\text { 12. False/ } \\
\text { Misleading } \\
\text { Forensic Evi }\end{array}$ & $-.12 *$ & -.01 & $.13^{* *}$ & -0.8 & -0.07 & 0.02 & -0.01 & $-.28 * *$ & $-.16^{* *}$ & $.49 * *$ & $-.17 * *$ & 1 & & \\
\hline $\begin{array}{l}\text { 13. Mistaken } \\
\text { Eyewitness ID }\end{array}$ & $.11^{*}$ & $-.10^{*}$ & $.23 * *$ & $-.21 * *$ & -0.02 & 0.07 & 0.09 & $.12 * *$ & $.17 * *$ & $-.27 * *$ & $.40 * *$ & $-.16^{* *}$ & 1 & \\
\hline $\begin{array}{l}\text { 14.Perjury/False } \\
\text { Accusation }\end{array}$ & $.15^{* *}$ & -.02 & -0.7 & 0.09 & -0.02 & $.10 *$ & $.10 *$ & $.49 * *$ & 0.08 & $-.38 * *$ & $.19^{* *}$ & $-.36^{* *}$ & $-.14 * *$ & 1 \\
\hline
\end{tabular}

* Correlation is significant at the 0.05 level (2-tailed)

** Correlation is significant at the 0.01 level (2-tailed) 
Step 3

Next Kaplan Meier analysis was performed. The Kaplan-Meier analysis demonstrated that the survival and hazard functions do vary by race and ethnicity. The results can be seen in Figure 1 and Figure 2 below. Specifically, the chi-square statistic and the graphs from the Kaplan-Meier analysis provide evidence that there are differences in the survival and hazard functions of the comparison groups (i.e., whites vs. blacks and whites vs. Hispanics). The Chi-square statistic for this analysis indicates significant inter-group differences in the time to exoneration, when one's race is considered. The results of the Kaplan-Meier analysis showed that black exonerees experienced a longer time to exoneration than did white exonerees. These results provide supporting evidence for the first hypothesis that racial and ethnic differences exist in time-to-exoneration. Not only does this support the hypothesis, but it is the first supportive evidence for focal concerns theory in the context of time-to-exoneration.

The results of the second Kaplan-Meier analysis indicated that overall, Hispanic exonerees experienced a shorter time to exoneration than did white exonerees, though the Chi-square indicated the differences were not significant (see Figure 2 for specific information). This means there are no statistically significant differences among these groups. 
Figure 1

Survival Analysis Results of Blacks versus Whites Median Days to Exoneration

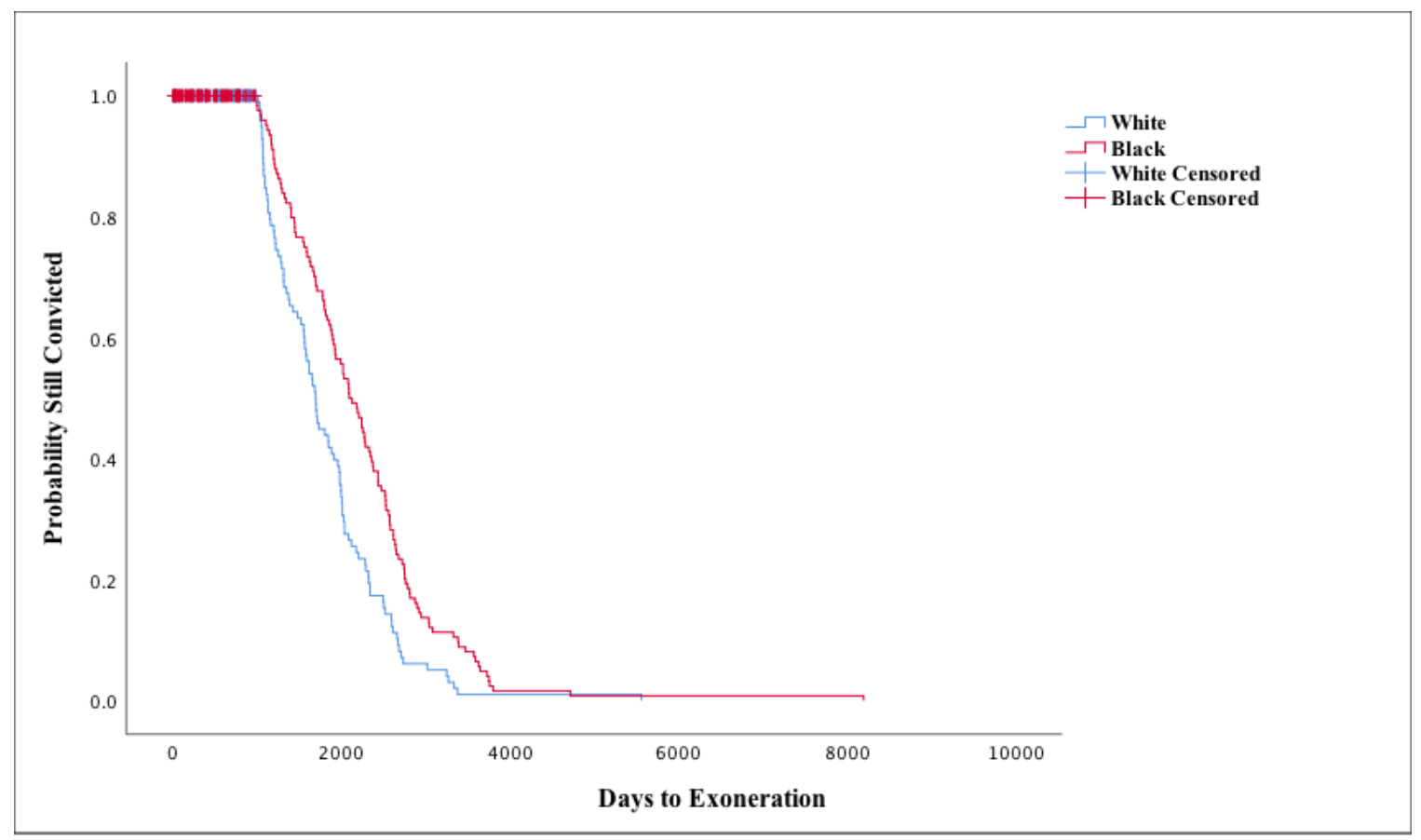

Chi-square $=14.75,1 d f * \mathrm{p}=.000$ 
Figure 2

Survival Analysis Results of Hispanics versus Whites Median Days to Exoneration

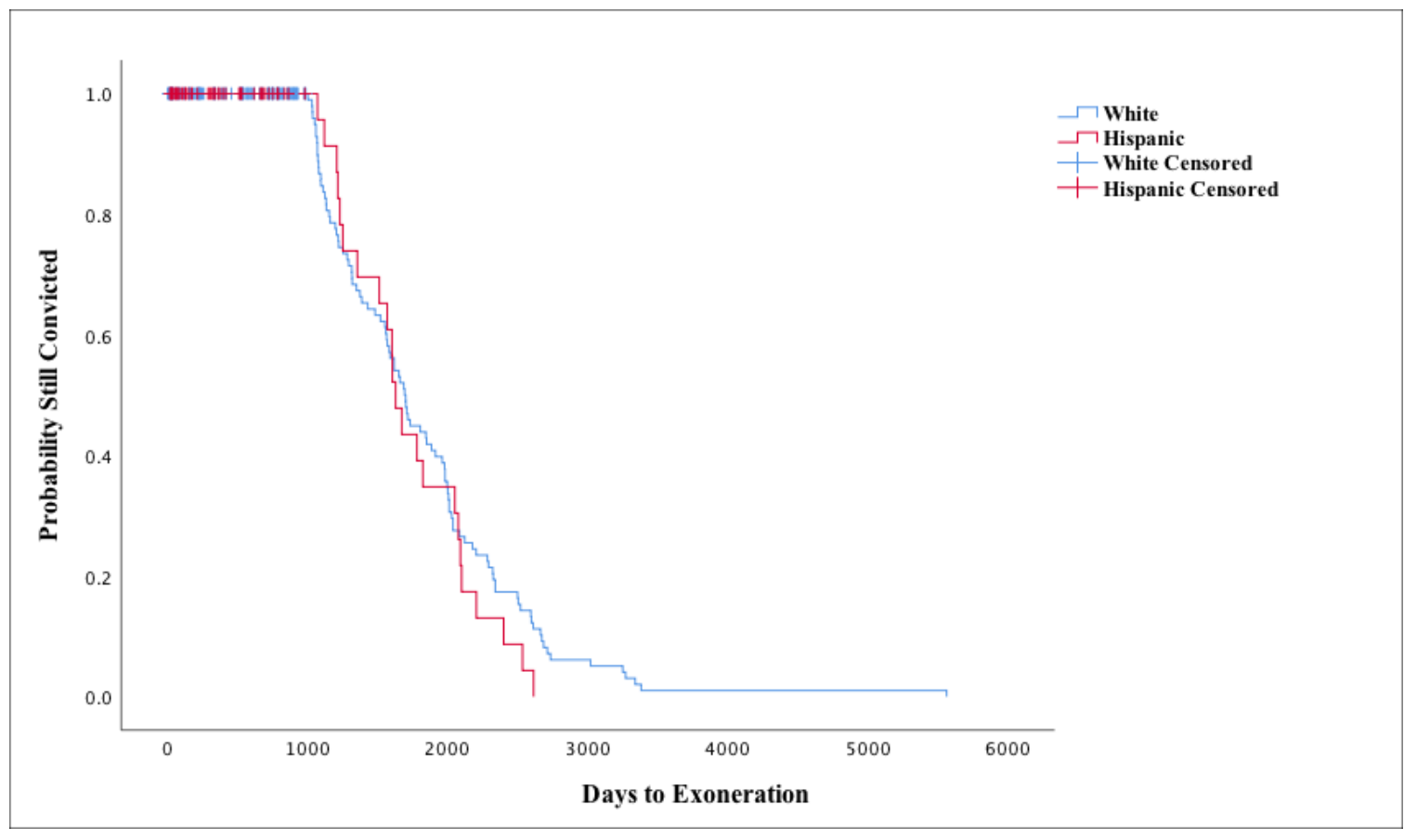

Chi-square $=.610,1 d f \mathrm{p}=.435$ 


\section{Step 4}

Next logistic regression analysis was performed to explore how the extralegal and legal measures are associated with the time-to-exoneration. This is important so as to gain an understanding of how the extralegal and legal factors may affect time-to-exoneration for each racial and ethnic group. ${ }^{8}$ In this study, logistic regression was performed on two comparison groups. Specifically, logistic regression was performed first on one group which included only black exonerees with white exonerees as the comparison. Then logistic regression was performed on the second group, which included only Hispanic exonerees with white exonerees as the comparison.

Black vs. white defendants: Inter-group comparisons in time-to-exoneration

The results of the logistic regression analysis performed for the comparison group of blacks vs whites show that for black exonerees the odds of being exonerated after 1,000 days were about $50 \%$ higher $(b=405, \operatorname{Exp}(b)=1.499, p<.10)$ than for white exonerees when controlling for other variables in the model. The results also indicated that male exonerees were 1.7 times more likely $(b=.533, \operatorname{Exp}(b)=1.704, p<.10)$ to be exonerated after the median exoneration time of 1,000 days than female exonerees. Additionally, when the legal variables of Official Misconduct $(b=.477, \operatorname{Exp}(b)=1.612, p$ $<.10)$ or Inadequate Legal Defense $(b=.580, \operatorname{Exp}(b)=1.787, p<.05)$ were present in a case, those exonerees were significantly more likely to experience longer times of incarceration before being exonerated than exonerees who did not have these elements

\footnotetext{
${ }^{8}$ Cox Proportional Hazard Regression was attempted but due to lack of occurrences or extreme low occurrences within the racial groups for certain crime types the results were non-sensical. A log transformation was performed and this did not resolve the issue. Therefore, logistic regression was utilized.
} 
present. The results also showed that exonerees in this group who had been wrongfully convicted of a violent crime were 2.095 times more likely $(b=.739, \operatorname{Exp}(b)=2.095, p<$ $.01)$ to be exonerated after the median time to exoneration than exonerees convicted of any other type of crime other than a drug offense.

These results showed that the effect of being black rather than white is approaching significance, suggesting a racial effect is possible $(\mathrm{p}<.10)$. This provides tentative support for the first hypothesis that racial differences do exist in time to exoneration. Further, these results also show support for the second hypotheses in that it demonstrates the legal factors of a case had an impact on time to exoneration. Specifically, the legal factors of Official Misconduct and Inadequate Legal Defense were shown to impact time to exoneration. Of these two, Inadequate Legal Defense had the great impact on the length of time-to-exoneration. Additionally, Violent Crime, a legal measure which Focal Concerns theory posits is likely to impact decision making, was shown to have a significant impact on the length of time an exoneree in this group experienced before being exonerated. This supports the premise of Focal Concerns that the severity of the crime is of importance to decision makers and is considered as they perform their assessments and arrive at their judgments (Steffensmeier et al., 1998).

Similarly, support for Focal Concerns was also found in the results which illustrated the non-legal variable of being black had an impact on the length of time to exoneration. This is in line with Focal Concerns theory in its assertion that judges and other justice officials rely on stereotypes, such as a young black predator and inherent criminality, in arriving at their decisions (Albonetti, 1991; Bridges \& Steen, 1998; Fontaine \& Emily 1978; Steffensmeier et al., 1998). 
For this group, the results also indicated that the non-legal variable of biological sex impacted the likelihood of being exonerated after the median time to exoneration. The results showed that males were more likely to be exonerated after the median time than were female exonerees in this group. This again supports Focal Concerns theory in that decision makers rely on stereotypes, in this instance, relating to gender and criminality (Albonetti, 1991; Steffensmeier et al., 1998). The results of the logistic regression analysis performed for the comparison group of blacks vs whites are illustrated in Table 4. 
Table 4. Black and White Group Exonerees Logistic Regression Analysis N=421

\begin{tabular}{|c|c|c|c|c|}
\hline Measure & $\mathrm{B}$ & SE & $\operatorname{Exp}(\mathrm{B})$ & Tolerance \\
\hline Biological Sex (Male) & $.533 *$ & .302 & 1.704 & .933 \\
\hline Age & .008 & .010 & 1.008 & .858 \\
\hline Race/Ethnicity (Black) & $.405^{*}$ & .228 & 1.499 & .828 \\
\hline Official Misconduct & $.477 *$ & .261 & 1.612 & .709 \\
\hline Inadequate Legal Defense & $.580 * *$ & .267 & 1.787 & .830 \\
\hline Drug Crime & -.526 & .330 & .591 & .416 \\
\hline Violent Crime & $.739 * * *$ & .298 & 2.095 & .568 \\
\hline $\begin{array}{l}\text { False/Misleading Forensic } \\
\text { Evidence }\end{array}$ & .422 & .297 & 1.524 & .620 \\
\hline Mistaken Eyewitness ID & -.449 & .421 & .639 & .659 \\
\hline Perjury or False Accusation & -.168 & .276 & .845 & .584 \\
\hline \multicolumn{5}{|l|}{$-2 \log$ liklihood $=539.378$} \\
\hline \multicolumn{5}{|l|}{ Nagelkerke $\mathrm{R}^{2}=.130$} \\
\hline \multicolumn{5}{|l|}{ Cox \& Snell $\mathrm{R}^{2}=.097$} \\
\hline $\begin{array}{l}\text { Chi-square }=42.994 \\
p=.000\end{array}$ & & & & \\
\hline
\end{tabular}


Hispanic vs. white defendants: Inter-group comparisons in time-to-exoneration.

The results of the analysis for the second comparison group, Hispanics vs whites, are illustrated in Table 5. The results of this analysis indicated that exonerees in this group who had Inadequate Legal Defense present in their wrongful conviction were 1.810 times more likely $(b=593, \operatorname{Exp}(b)=1.810, p<.10)$ to be exonerated after the median time of 1,000 days than those exonerees who had access to adequate legal defense. The presence of False or Misleading Forensic Evidence was found to result in an exoneree being 2.823 times more likely $(b=1.038, \operatorname{Exp}(b)=2.823, p<.01)$ to $b e$ exonerated after the median time than those exonerees who did not have this factor. Those exonerees in this comparison group who had been wrongfully convicted of a Violent Crime were 2.491 times more likely $(b=.913, \operatorname{Exp}(b)=2.491, \mathrm{p}<.01)$ to be exonerated after the median time to exoneration than those convicted of any other type of crime, other than a drug crime. Exonerees who had been convicted of a Drug Crime were shown to be $64.1 \%$ less likely $(b=-1.025, \operatorname{Exp}(b)=.359, p<.05)$ to be exonerated after 1,000 days than those who had been convicted of other types of offenses. 
Table 5. Hispanic and White Group Exonerees Logistic Regression Analysis N=266

\begin{tabular}{|c|c|c|c|c|}
\hline Measure & $\mathrm{B}$ & $\mathrm{SE}$ & $\operatorname{Exp}(B)$ & Tolerance \\
\hline Biological Sex (Male) & .157 & .380 & 1.170 & .929 \\
\hline Age & .001 & .012 & 1.001 & .824 \\
\hline Race/Ethnicity (Hispanic) & -.390 & .338 & .677 & .885 \\
\hline Official Misconduct & .105 & .326 & 1.110 & .724 \\
\hline Inadequate Legal Defense & $.593 *$ & .332 & 1.810 & .836 \\
\hline Drug Crime & $-1.025 * *$ & .431 & .359 & .510 \\
\hline Violent Crime & $.913 * * *$ & .345 & 2.491 & .730 \\
\hline False/Misleading Forensic & $1.038 * * *$ & .400 & 2.823 & .798 \\
\hline \multicolumn{5}{|l|}{ Evidence } \\
\hline Mistaken Eyewitness ID & .580 & .711 & 1.786 & .885 \\
\hline Perjury or False Accusation & .276 & .332 & 1.318 & .657 \\
\hline \multicolumn{5}{|l|}{$-2 \log$ liklihood $=316.370$} \\
\hline \multicolumn{5}{|l|}{ Nagelkerke $\mathrm{R}^{2}=.230$} \\
\hline \multicolumn{5}{|l|}{ Cox \& Snell $\mathrm{R}^{2}=.172$} \\
\hline \multicolumn{5}{|l|}{ Chi-square $=50.216$} \\
\hline $\mathrm{p}=.000$ & & & & \\
\hline
\end{tabular}

The results of this group comparison are not supportive of the first hypothesis that there are racial and ethnic differences in time to exoneration in that the results of the analysis for this particular group, Hispanic vs white, did not show race/ethnicity to be a significant 
factor in time to exoneration. However, the results were supportive of the second hypothesis that the legal components of a case are associated with the racial and ethnic differences in the length-of-time to exoneration. Specifically, the legal variables of Inadequate Legal Defense, Drug Crime, Violent Crime, and False or Misleading Forensic Evidence were found to impact time to exoneration. Additionally, these findings demonstrate support for focal concerns theory which proposes legal factors do wield influence on outcomes.

Probing this for racial and ethnic differences among the focal concerns theory concepts, next logistic regression analysis was re-estimated for each race and ethnicity (i.e., whites, blacks, and Hispanics). After the estimation of this regression, the Paternoster et al. (1998) z-score was applied in order to assess any racial differences that occur in the measures of focal concerns as they relate to time-to-exoneration. This is an important step in exploring the data for support of the second hypothesis, that the legal components of a case are associated with the racial and ethnic differences in the lengthof-time to exoneration. Further, this is also a necessary step in determining if there is support for the expectation that the extralegal and legal measures, which represent the focal concerns measures, are more important for blacks and Hispanics than for whites. The results of the regression analysis and z-scores for the whole sample are depicted in Table 6 . 
Table 6. Logistic Regression Analysis of Exonerees by Race/Ethnicity

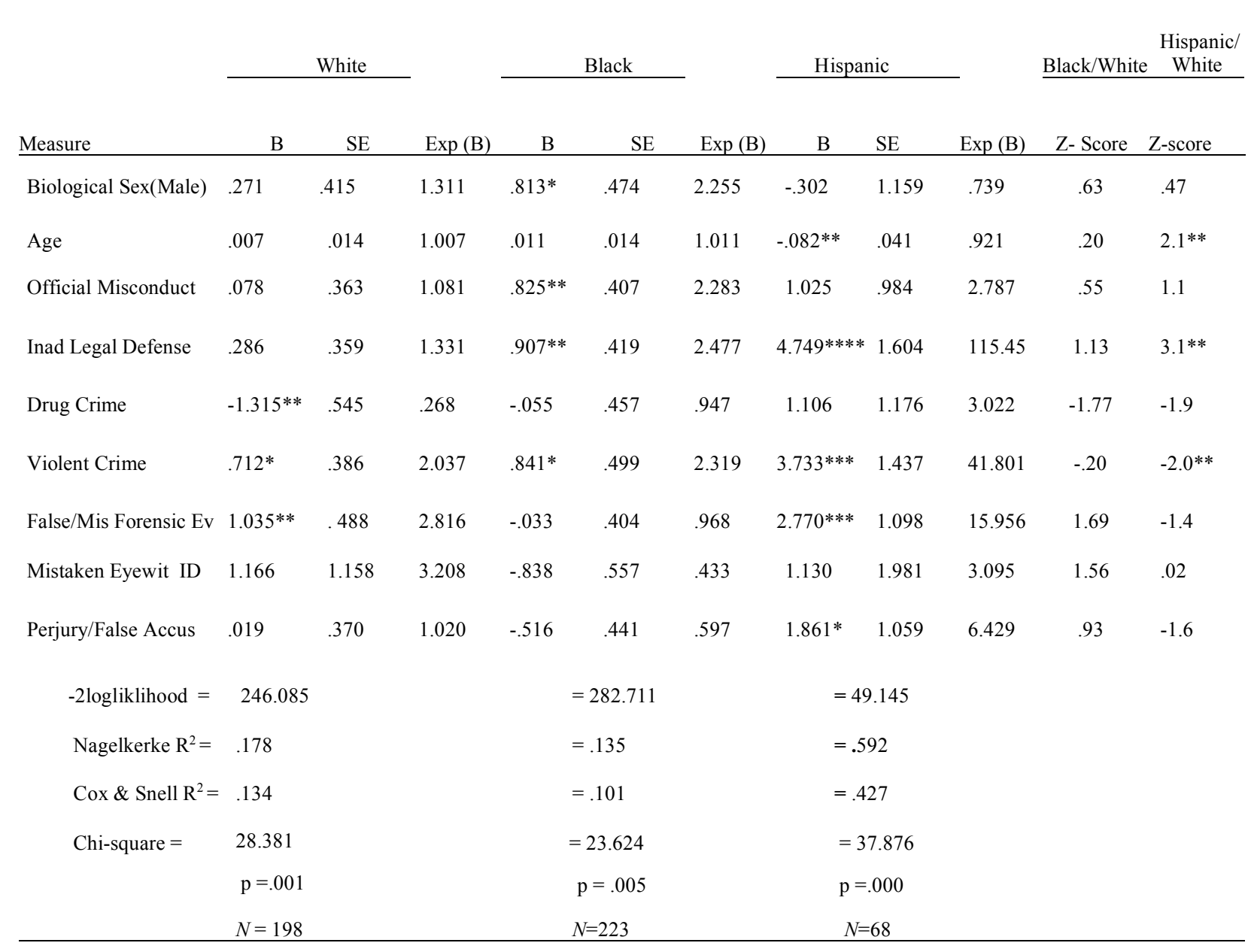

${ }^{*} \mathrm{p}<.10 * * \mathrm{p}<.05 \quad * * * \mathrm{p}<.01 * * * * \mathrm{p}<.000$ 
White exonerees: Predictors of exoneration length

The data shows that $49.5 \%$ of white exonerees experienced a time to exoneration that exceeded 1,000 days. An examination of the findings for the regression analysis of each race and ethnicity shows that for white exonerees, the legal variables of False and Misleading Forensic Evidence, Violent Crime, and Drug Crime did have an impact on time to exoneration. Specifically, white exonerees who had False or Misleading Forensic Evidence in their case were 2.81 times more likely $(b=1.035, \operatorname{Exp}(b)=2.816, p<.05)$ to be exonerated after the median time to exoneration than those who did not have False or Misleading Forensic Evidence present in their wrongful conviction. Those who had been wrongfully convicted of a Violent Crime were 2.037 times more likely $(b=.712$, $\operatorname{Exp}(b)=2.037, p<.05)$ to experience a time to exoneration which was longer than 1,000 days than those exonerees wrongfully convicted of any other type of crime, other than drug crimes. For those white exonerees convicted of a Drug Crime, the odds of having to wait longer than 1,000 days to be exonerated were $73 \%$ lower than for those white exonerees convicted of any other type of crime, other than a Violent Crime. These results are supportive of the focal concerns theory in that that the legal measures of a case were found to have an impact on time to exoneration.

\section{Black exonerees: Predictors of exoneration length}

The data reveals that $56 \%$ of black exonerees experienced a time to exoneration that was greater than approximately three years. In evaluating the results of the regression analysis for the black exonerees in this sample, it was found that the non-legal variable of biological sex did have an impact on time to exoneration which approached significance. 
Specifically, black males were 2.255 times more likely $(b=.813, \operatorname{Exp}(b)=2.255, p<$ .10) to be exonerated after the median time to exoneration than black females. Biological sex was not found to be a factor impacting time to exoneration for whites or Hispanics, pointing to support for the elements of focal concerns impacting time to exoneration for black male exonerees.

The legal variable of Official Misconduct was found to impact time to exoneration for black exonerees. Those black exonerees who had Official Misconduct in their case were found to be 2.283 times more likely $(b=.825, \operatorname{Exp}(b)=2.283, p<.05)$ to experience a time to exoneration longer than 1,000 days than black exonerees who did not have Official Misconduct as a factor in their wrongful conviction. Similarly, the legal variable of Inadequate Legal Defense was also predictive of longer time to exoneration. Specifically, the results showed that black exonerees who had Inadequate Legal Defense were 2.477 times more likely $(b=.907, \operatorname{Exp}(b)=2.477, p<.05)$ to be exonerated beyond the median time of 1,000 days than black exonerees whose cases did not include Inadequate Legal Defense. As with white exonerees, being convicted of a Violent Crime did impact time to exoneration. Specifically, the results indicated that black exonerees who had been convicted of a Violent Crime were 2.319 times more likely $(b=.841$, $\operatorname{Exp}(b)=2.319, p<.10)$ to be incarcerated longer than approximately three years while awaiting exoneration than black exonerees convicted of any other type of crime, other than a drug crime. These results demonstrate outcomes which provide support for the second hypothesis as well as for the focal concerns measures in that the both legal and non-legal measures were found to affect the time to exoneration experienced by black exonerees. 


\section{Hispanic exonerees: Predictors of exoneration length}

The data shows that $34 \%$ of Hispanic exonerees were incarcerated more than approximately three years while waiting to be exonerated. An examination of the regression analysis for Hispanic exonerees revealed that both legal and non-legal variables had an impact on time to exoneration. The greatest number of significant predictors was found in the group of Hispanic exonerees when compared to black or white exonerees. First, it was found that for every one unit increase in the age of the exoneree at the time of crime commission, there was a decrease of $7.9 \%(b=-.082$, $\operatorname{Exp}(b)=.921, p<.05)$ in the likelihood of being exonerated after 1,000 days. Next the results demonstrated that those Hispanic exonerees who had Inadequate Legal Defense as a factor in their wrongful conviction were significantly more likely $(b=4.749, \operatorname{Exp}(b)=$ $115.45, \mathrm{p}<.000)$ to spend longer times incarcerated before being exonerated than Hispanic exonerees who had access to adequate legal defense. Additionally, it was also found that a Violent Crime conviction resulted in a Hispanic exoneree being 41.801 times more likely $(b=3.733, \operatorname{Exp}(b)=41.801, p<.01)$ to spend more than 3 years incarcerated before being exonerated than Hispanic exonerees who had been convicted of any other type of crime.

The legal variable of False or Misleading Forensic Evidence was also predictive of longer time to exoneration. Hispanic exonerees with False or Misleading Forensic Evidence in their case were 15.956 times more likely $(b=2.770, \operatorname{Exp}(b)=15.956, p<$ $.01)$ to have to wait longer than 1,000 days to be exonerated than those Hispanic exonerees whose did not have False or Misleading Forensic Evidence as a factor. Lastly, the legal variable of Perjury and False Accusation was also shown to impact the length of 
time a Hispanic exoneree experienced before being exonerated. The results demonstrated that those Hispanic exonerees who had Perjury or False Accusation as a factor in their wrongful conviction were 6.429 times more likely $(b=1.861, \operatorname{Exp}(b)=6.429, \mathrm{p}<.10)$ to spend longer than 1000 days incarcerated before being exonerated than Hispanic exonerees for whom Perjury or False Accusation was not present. The findings for the Hispanic exonerees demonstrate support for the second hypotheses that the legal measures representing focal concerns are associated with racial and ethnic differences in time to exoneration.

The results of the logistic regression analysis within each racial and ethnic group provide support for the second hypothesis that the legal components of a case are associated with racial and ethnic differences in time to exoneration. Further, support for the influence of both the legal and non-legal measures which represent the focal concerns measures is demonstrated in the results. Specifically, the results indicated that the impact of these variables on time to exoneration was greater for blacks and Hispanics than for whites.

Next, in order to establish whether these disparities between racial and ethnic groups was statistically significant, the Paternoster et al. (1998) z-score was applied. The results of this analysis can be seen in Table 5. The results of the application of the zscores showed that there were no differences in the impact on time to exoneration rising to the level of significance when comparing the disparities in the focal concerns measures between white exonerees and black exonerees. However, there were several disparities between the Hispanic and white exonerees which were found to be significant. Namely, the differences in the slopes of the extra-legal measure of age, and the legal measures of 
Inadequate Legal Defense and Violent Crime were found to be statistically significant. The results indicate that the impact of being younger at the time of conviction was stronger $(\mathrm{p}<.05)$ for Hispanics than for white exonerees, resulting in greater time to exoneration for younger wrongfully convicted Hispanics than for younger wrongfully convicted white exonerees. Similarly, the detriment to Hispanic exonerees who had Inadequate Legal Defense in their case, was greater $(p<.05)$ than it was for white exonerees who also had Inadequate Legal Defense as a factor in their case. This increased the likelihood that innocent Hispanic defendants with this factor would spend longer than approximately three years incarcerated before being exonerated when compared to white innocent defendants with this same factor. Lastly, the impact of being convicted of a Violent Crime was greater for Hispanic exonerees $(p<.05)$ than it was for white exonerees who had been convicted of a violent crime, resulting in significantly greater likelihood for Hispanic exonerees of experiencing a time to exoneration which exceeded 1,000 days. 


\section{CHAPTER 5}

\section{DISCUSSION}

The research on time-to-exoneration is sparse. The results from this study make a modest contribution to the literature on the racial and ethnic differences in time-toexoneration. Moreover, there is little theoretical driven research in this area, and this study has shed some light on how Focal Concerns Theory can help explain the racial and ethnic differences in time-to-exoneration.

This study aimed to answer whether or not there are racial and ethnic differences present in time to exoneration. Additionally, this study purposed to answer whether or not the legal components of a case are associated with racial and ethnic differences in time to exoneration. In regards to the first hypothesis, the results of this study demonstrate that racial and ethnic differences do occur in days-to-exoneration. The results of this study indicated that Black individuals were more likely to have to wait longer for exonerations than white and Hispanic individuals. Specifically, $56 \%$ of black exonerees experienced a time to exoneration that exceeded 1,000 days, or approximately three years. In contrast, $49.5 \%$ of white exonerees and $38 \%$ of Hispanic exonerees spent longer than 1,000 days incarcerated before being exonerated. Additionally, black exonerees spent an average of 1,414.95 days incarcerated awaiting an exoneration while white exonerees and Hispanic exonerees experienced $1,146.14$ and 818 days respectively.

In regards to the second hypothesis, the results of this study do show that the legal components of a case are associated with racial and ethnic differences in time to 
exoneration. Illustrating this, while overall as a group Hispanics were not shown to spend more time before being exonerated than whites or Blacks, it was demonstrated that certain legal and non-legal variables did result in Hispanics being more likely to experience longer times to exoneration than white exonerees with the same factors present. Additionally, it was shown that these differences rose to the level of significance. For example, it was demonstrated that younger (at the time of conviction) Hispanics were less likely to be exonerated before spending approximately three years in prison. Additionally, though both Blacks and Hispanics who were convicted of a violent crime experienced a longer time to exoneration than did whites convicted of a violent crime, the $\mathrm{z}$ scores revealed the difference was significant for Hispanics when compared to white exonerees. This means that the negative impact of being convicted of a violent crime was greater for innocent Hispanic exonerees $(\mathrm{p}<.05)$ than for innocent white exonerees also convicted of a violent crime, resulting in longer times to exoneration. Similarly, wrongfully convicted blacks and Hispanics who had Inadequate Legal Defense as a factor, both experienced a longer time to exoneration than did whites with this factor. However, as with the legal variable of Violent Crime, the $\mathrm{z}$ scores revealed this difference was significant $(\mathrm{p}<.05)$ for innocent Hispanics who did not have access to adequate legal defense when compared to innocent white exonerees who also lacked adequate legal defense. This finding suggests inequity in the way this particular factor affected the different racial and ethnic groups. These findings do support the second hypothesis, demonstrating that the legal components of a case are associated with racial and ethnic differences in time to exoneration. 
These results provide additional evidence of another area of the criminal justice system where racial and ethnic disparities exist. For black and Hispanic innocent defendants the travesty of the wrongful conviction is compounded by the impact of longer time spent incarcerated before being exonerated. In short, the remedy to the injustice of wrongful conviction is itself applied in a manner that is unjust and that disadvantages wrongfully convicted black and Hispanic defendants.

In addition to these results, the focal concerns measures do provide a theoretical understanding of the expected racial and ethnic differences, but first it is important to gain an understanding of the efficacy of theory, in this context. The results do indicate greater time-to-exoneration was associated with several measures which are posited by Focal Concerns theory to have an impact on outcomes. For example, research has consistently shown that the severity of the crime impacts sentencing outcomes (Kramer \& Steffensmeier, 1993; Steffensmeier et al., 1998; Ulmer \& Johnson, 2004). This was found to be the case in this study. This study therefore provides support for the focal concerns premise that severity of the crime does indeed impact outcomes. In this study, those wrongfully convicted of a violent crime did experience longer time to exoneration. However, racial and ethnic differences were still found in the outcomes associated with being convicted of a violent crime and the length of time experienced until exoneration. In other words, it was illustrated that the level of the severity of the crime did not impact all races and ethnicities in the same manner.

The study also illustrated that the legal variable of Inadequate Legal Defense, resulted in longer time to exoneration for both black and Hispanic exonerees but did not increase time to exoneration for white exonerees. However, it most impacted Hispanics 
and the difference reached statistical significance. This again illustrates support for Focal Concerns theory in that it illustrates how stereotypes surrounding minorities and proclivity for criminal activity may impact access to adequate legal resources and result in detriment to certain racial and ethnic groups. Additionally, this particular finding may indicate bias towards minorities who are non-English speaking, impacting their ability to secure adequate legal defense.

Research indicates that forensic evidence carries a great deal of weight in court settings and has a known impact on wrongful convictions (Cooley \& Oberfield, 2007; Gould et al., 2012). The results of this study found that the presence of False or Misleading Forensic Evidence impacted time-to-exoneration differently for whites and Hispanics. Though the level of difference did not reach statistical significance, the findings indicated that Hispanic exonerees with this factor in their case were more likely to experience a longer time to exoneration than whites whose cases also included this factor.

Additionally, it was illustrated that across the three groups, black exonerees were the only group where biological sex of the wrongfully convicted defendant impacted the time to exoneration. Specifically, black males were more likely than black females to experience a longer time to exoneration. There were no significant differences resulting from biological sex in time to exoneration for either Whites or Hispanics, suggesting that black males are disadvantaged in a way that others are not when it comes to length of time to exoneration. This supports the Focal Concerns theoretical concepts in that it points to a reliance on the stereotypical ideology of a young black predatory male that society must be protected from (Fontaine \& Emily 1978; Johnson et al. 2008; 
Steffensmeier et al., 1998). Similarly, the non-legal measure of age was found to be significant for Hispanic exonerees but not for black or White exonerees. Specifically, the younger an innocent Hispanic defendant was at the time of crime commission, the more likely they were to spend more time incarcerated before being exonerated.

In other words, non-whites in this study were more likely to be considered more blameworthy, as posing a danger the community must be protected from, and as associated with more practical constraints and consequences than whites (Bishop, et al., 2020; Johnson et al. 2008; Liebman et al., 2002; Steffensmeier, 1980; Steffensmeier et al., 1998). This was found to be statistically significant in some instances, and in others, approached significance.

Research indicates that even when controlling for other relevant legal and extralegal variables, which are empirically associated with harsher outcomes, racial and ethnic disparities are still present (Freiburger, 2009; Freiburger \& Romain, 2018; Higgins et al., 2013; Kamalu et al., 2010; Steffensmeier et al., 1998; Steffensmeier \& Demuth, 2000; Ulmer \& Johnson, 2004). This is seen in the results of the analysis from this study in the finding that black exonerees experienced a greater time-to-exoneration than whites. The inter-group difference was evident when controls were not used but decreased after controls were implemented. When controls were utilized, the results showed that certain factors had a stronger impact time to exoneration for black innocent defendants than for white innocent defendants and were significant $(\mathrm{p}<.05)$ for Official Misconduct and Inadequate Legal Defense and approached significance $(\mathrm{p}<.10)$ for Violent Crime.

While innocent Hispanics did not spend longer times incarcerated than innocent whites, certain legal factors were found to have impact which resulted in Hispanic 
exonerees being more likely to spend longer than 1,000 days before being exonerated when compared to white exonerees with these same factors. These differences were approached significance $(\mathrm{p}<.10)$ for Perjury and False Accusation. The differences were significant $(\mathrm{p}<.01)$ for the legal factors of False and Misleading Forensic Evidence and Violent Crime as well as for Inadequate Legal Defense $(\mathrm{p}<.000)$.

In summary, despite small differences in the time to exoneration between white exonerees and black and Hispanic exonerees, the findings show that certain legal factors, such as Inadequate Legal Defense, Official Misconduct, False and Misleading Forensic Evidence, Perjury and False Accusation, and being convicted of a Violent Crime did have a stronger impact on the likelihood of experiencing a time to exoneration that exceeded 1,000 days for innocent minority defendants than it did for white innocent defendants with those same factors present. Further, when the z-scores were applied, the factors of Age (younger at time of crime commission), Inadequate Legal Defense, and Violent Crime were found to be significant at $\mathrm{p}<.05$, resulting in longer times to exoneration for innocent Hispanic defendants with these factors present than for innocent white defendants with these same factors.

Though there are few studies which examine this topic, the results of this study echo the findings of other studies which have examined race and time to exoneration. Take for instance Olney \& Bonn, (2015) who found that black innocent defendants endured the longest time to exoneration when compared to all other races. Additionally, they found that even when controlling for other factors, being convicted of a violent crime had a greater impact on black innocent defendants than on innocent defendants of other races. Gross, et al., (2017) also found that black innocent defendants spent more 
time wrongfully incarcerated before being exonerated than any other race. This held true across every category of crimes that was present in the data.

This study finds results that are in line with the results of Rafail and Mahoney (2019) in their examination of the exoneration pipeline. Specifically, their findings indicated that severity of the crime, inadequate legal defense, and official misconduct had the effect of lengthening time-to-exoneration. Further, the results of their analysis showed that blacks were at a significant disadvantage in length of time to exoneration when compared to all other races.

The results of this study point to racial and ethnic differences in time to exoneration which disadvantages minorities. Additionally, this study demonstrates that legal components of a case do impact the racial and ethnic groups differently in regards to time to exoneration. This suggests a disparity which harms blacks and Hispanics in the exoneration process within the criminal justice system. Further, these results support the Focal Concerns theoretical premise that this is as a result of a reliance on stereotypes that suppose criminality to be a persistent attribute of non-whites (Albonetti, 1991; Bridges \& Steen, 1998; Fontaine \& Emily 1978; Steffensmeier et al., 1998).

\section{Policy and Programming}

It is widely acknowledged that in order for justice policy and programming to be effective, empirical study must go beyond informing on the state of the issue at hand and provide the critical link between research and practice (Andrews \& Bonta, 2010; Bennett, 2004; Gregrich, 2003; Mears, 2007; Mears \& Bacon, 2009). Therefore, an exploration of patent solutions as well as lessons learned from previous experiences is presented here. Additionally, suggestions for solutions that are likely to be effective based on what is 
known about the scope of the problem and what has worked in other arenas are presented as well.

The most obvious remedy to rectifying disparities in time-to-exoneration is to prevent the wrongful convictions that necessitate them. A wrongful conviction negatively impacts three spheres of our society (Norris et al., 2020). First, the wrongfully convicted individual who is torn from his family and community. Second, the community is placed at risk of continued wrongdoing by the guilty individual who has been allowed to go free. Third, the victim faces additional hardship and emotional turmoil when the truth comes to light and the realization sets in that the guilty party has not been held accountable.

As the public has become increasingly aware of these tragedies, the call for widespread reforms and measures to address wrongful convictions has been given consistent and persistent attention. Indeed, though the scope of what remains to be accomplished is considerable, and though deep-rooted resistance to change exists, progress has been made. Recent years have seen reforms in critical areas based on empirical findings (Garrett, 2017).

Decades of wrongful conviction research have stimulated reforms in police, prosecutorial, and judicial practices and policies (Acker et al., 2015; Gould \& Leo, 2015). For example, legislation addressing the way in which police interrogations are conducted and that establishes standards for how police lineups are facilitated have been enacted in many states in recent years. Additionally, all fifty states now have statutes providing access to post-conviction DNA testing. However, the focus of this dissertation is explicitly the identification of racial and ethnic disparities in time-to-exoneration. Therefore, policy changes that would directly contribute to reducing racial and ethnic 
disparities in time-to-exoneration while fully acknowledging empirically based work to reduce the occurrences of wrongful convictions overall is essential.

First, it is recommended that widespread training to address racial and ethnic stereotypes be implemented among the agencies and actors responsible for addressing claims of innocence. It is critical that the strategies implemented in the training be empirically based. Illustrating this, an analysis of hundreds of empirical studies, representing a diverse array of strategies and techniques to reduce and prevent prejudice, found only a few studies could convincingly argue for their effectiveness. (Paluck \& Green, 2009). Namely, it was found that cooperative learning and certain forms of narrative and normative communications were the most effective in reducing and preventing prejudice. In particular, those strategies incorporating narrative persuasion, perspective taking, and empathy, as well as extended contact were found to be the most effective. These findings highlight that introducing strategies for reduction and prevention in racial and ethnic prejudice is a decision that must be based upon sound empirical evidence if the desired results are to be achieved.

Evidence based research from the field of social-cognitive psychology indicates it is possible to reduce unconscious bias and reliance on stereotypes through education and training. Specifically, it has been found that certain strategies and skills can be taught, which enable an individual to focus on a person's individual qualities and characteristics, rather than on the group they belong to (Blair, 2002; Burgess, et al., 2007; Divine, et al., 2002; Johnson \& Frederickson, 2005; Pope, et al., 2014). These strategies are aimed at reducing the dependency on stereotypes in decision making that arise when an individual 
lacks the time, cognitive ability, or relevant information needed to assess a situation (McIntosh, et al., 2014).

The framework for this training is multi-tiered and includes elements which address the motivation to respond without bias as well as educating individuals in the etiology of psychological bias and racism. This is partnered with skills training in empathy, perspective taking, regulating emotional responses, and increasing confidence in interactions with members of different races and ethnicities. Given the evidence-based success of this type of training, it is likely that when applied to decision makers within the criminal justice system it will result in a reduction of bias (Burgess, et al., 2007; Chapman, et al., 2014; McIntosh, et al., 2014; Stone \& Moskowitz, 2007). While education and training measures aimed at reducing implicit bias would not yield instant results, as a part of comprehensive reform and when applied to all facets of our justice system, it is likely this would have a positive impact on reducing racial and ethnic disparities.

Second, it is recommended that research surrounding the effectiveness of Conviction Integrity Units (CIU's) be a priority. In the wake of the growing number of exonerations, some states have established Conviction Integrity Units (CIUs) that are models for internal regulation of prosecutors and seek to identify and prevent wrongful convictions (Scheck, 2017). Though at the outset, many were skeptical of the loyalties of units set up within the prosecutorial office, with each year that passes, CIUs are playing a decidedly more prominent role in exonerations (Norris, 2020). The most recent data indicates that many CIUs are even working in conjunction with professional exonerators, such as the Innocence Project (NRE, 2020). 
Third, it is recommended that Congressional legislation be enacted that would require states to regularly assess racial and ethnic disparities in the post-conviction process and report the findings in order to qualify for available funding. This recommendation is based on a model of reforms within the juvenile justice system that were mandated by the Juvenile Justice Delinquency and Prevention Act (JJDPA). Drawing from this model, all states would be required to address racial and ethnic disparities in the post-conviction processes through identification of the points where racial and ethnic bias are present, the development of action plans, and by performing outcome-based evaluations. Additionally, states would be required to publish the results of the outcome based evaluations annually, promoting transparency. The states would also be required to establish or designate existing bodies comprised of diverse stakeholders to act in an advisory capacity towards the aims of reducing racial and ethnic bias.

In the context of the adult justice system, it is likely that such requirements would be effective for reducing racial and ethnic disparities in the time-to-exoneration of wrongfully convicted minorities. In particular, the following four practices have been shown to be effective in reducing disproportionate minority contact in the juvenile justice system and would also be relevant in the context of reducing racial and ethnic bias in the post-conviction process. 1. Data review and decision point-mapping, 2. Cultural competency training, 3. Removing decision making subjectivity, 4. Cultivating state leadership to legislate system wide change (Cabaniss et al., 2007). Additionally, state and community level subcommittees, in conjunction with other community stakeholders, would provide representatives and coordinators to assist in the evaluation and analysis of 
data, and generally with any activities necessary to achieve compliance with the core requirements (Leiber \& Rodriguez, 2011).

This model described above employs aspects of the SARA model of community policing, which utilizes Scanning, Analysis, Response, and Assessment (Eck \& Spelman, 1987). These steps as part of an overall strategy to reduce unwanted outcomes have proven beneficial (Weisburd et al., 2010). Additionally, these steps can provide information on areas where "hot spots" are occurring, allowing redress that is aimed at the specific location (Braga \& Bond, 2008). It is likely that these steps, when undertaken as part of the larger coordinated efforts detailed above, would be beneficial as well in reducing racial and ethnic disparities in the exoneration process by identifying "hot spots" or consistently problematic agencies or policies that contribute to the disparities.

Fourth, research has repeatedly exposed the striking invisibility of Hispanic and Latino individuals in the criminal justice data (Arya et al., 2009; Shuck et al., 2004; Valencia, 1994). Capturing data is critical to transparency, to reform and to understanding what is working and what is not. The justice system is woefully lacking on consistent data leaving criminal justice actors very much in the dark and forced to rely on their own "gut" instinct in arriving at their decisions (Bergeron \& Donnelly, 2020). Assessments of how race and ethnicity affect interactions with the justice system cannot be conducted without a consistent and accurate method of capturing ethnicity at all points in the justice system. Therefore, data collection guidelines and procedures that record ethnicity consistently throughout the justice system is of paramount importance in order to facilitate accurate analysis of criminal justice data and guide reforms that address 
ethnic disparities (Epler-Estein et al.,2016; Pullman et al., 2013; Steffensmeier \& Demuth, 2001).

Lastly, it is suggested that considerable attention be devoted to the problems inherent in communications with minorities who speak little to no English. Research shows language barriers pose significant hurdles for Hispanics and Latinos, which often impacts their ability to comprehend what is transpiring in the legal process at all stages Menjivar \& Bejarano, 2012). This study illustrated the impact of certain factors which resulted in a longer time to on the length of time a Hispanic exoneree experienced, including inadequate legal defense. Problems with communication due to language barriers prevent non-English speaking defendants from accessing adequate representation, from responding to authorities in ways that could be beneficial to them, and from accessing information needed to pursue and exoneration (Reynoso, 2017; Urbina, 2004; IP, 2017). Therefore, it is recommended that policies be put in place that guarantee translation services that have been vetted will be provided to all individuals who require them. Furthermore, it is recommended that the appropriate steps be taken to ensure easy access to legal forms, transcripts, and other media that are written in the language of the individual seeking an exoneration.

- Limitations

While the current dissertation contributes to the criminological and legal literatures on time-to-exoneration, it is not without limitations. First, the study uses secondary data that does not directly or completely measure the concepts of focal concerns theory. Second, the possibility exists the data in the study are not accurate. The nature of archival data requires some judgements to be made, and these judgments are not 
always accurate. To date, these data have been considered the most comprehensive and representative data on exonerations (Rafail \& Mahoney, 2019).

Third, consistent with the biases of exonerations, which are more likely to occur with more severe crimes, violent crimes are overrepresented in the data which presents a statistical limitation. Fourth, the data considered Hispanic as a separate category but did not specify what races were captured within this category. It is therefore possible that race and ethnicity could be crossed (e.g., a person could be White Hispanic or Black Hispanic and so forth). Fifth, the number of Hispanic exonerees in this study was relatively small, which could impact the estimates. Sixth, the data on exonerations represented actual exonerations as captured by the NRE and, as such, was not equally distributed across geographical locations. This presents the possibility that factors associated with place could have an impact on the findings. Lastly, the data does not provide any measures on access to legal services and other support that may have an impact on time-to-exoneration.

Future research should address a number of issues. First, researchers should replicate this study by collecting their own quantitative data. This will allow the researchers to better measure the concepts of focal concerns theory. In addition, this will allow researchers to verify the validity of the data. Second, researchers should investigate the impact of other extralegal factors on time-to-exoneration such as the exoneree's level of education and whether or not the defendant pursued a claim of innocence in front of the same judge and/or prosecutor present in the original wrongful conviction. Additionally, researchers should collect data on what type of legal representation the wrongfully convicted defendant had when pursuing an innocence 
claim, e.g. private attorney, Innocence Organization, or Conviction Integrity Unit. Third, researchers should supplement their quantitative data by interviewing individuals and criminal justice decision-makers about exonerations. This will provide much needed context for the exonerations and the use of focal concerns theory in this area.

- Conclusions

This dissertation focused on examining the racial and ethnic differences in timeto-exoneration using focal concerns theory. The results indicate racial and ethnic disparities do exist in the time-to-exoneration. Further, the results illustrated racial and ethnic differences in the focal concerns concepts in understanding time-to-exoneration. These results are limited by their secondary nature, validity, and cross-sectional nature. Despite these limitations, this dissertation is the first study to assess the time-toexoneration using a theoretical perspective via survival analysis among a national sample of individuals and shows racial and ethnic disparities in exonerations do exist. 


\section{REFERENCES}

Acker, J. R., Redlich, A. D., Bonventre, C. L., \& Norris, R. J. (2015). Elephants in the Courtroom: Examining Overlooked Issues in Wrongful Convictions. Alb. L. Rev., 79, 705.

Akers, R. (1999) Criminological Theories. Fitzroy Dearborn.

Albonetti, C. (1991). An integration of theories to explain judicial discretion. Social Problems, 38, 247-266.

Albonetti, C. A. (1997). Sentencing under the federal sentencing guidelines: Effects of defendant characteristics, guilty pleas, and departures on sentence outcomes for drug offenses, 1991-1992. Law and Society Review, 789-822.

Albonetti, C. A., \& Hepburn, J. R. (1996). Prosecutorial discretion to defer criminalization: The effects of defendant's ascribed and achieved status characteristics. Journal of Quantitative Criminology, 12(1), 63-81.

Andrews, D. A., \& Bonta, J. (2010). Rehabilitating criminal justice policy and practice. Psychology, Public Policy, and Law, 16(1), 39.

Arya, N., Augarten, I., Villaneuva, C., \& Villarruel, F. (2009). America's invisible children: Latino youth and the failure of justice. Available at SSRN 1892966.

Becker, H. S. (2008). Outsiders. Simon and Schuster.

Beckett, K., Nyrop, K., \& Pfingst, L. (2006). Race, drugs, and policing: Understanding disparities in drug delivery arrests. Criminology, 44(1), 105-137

Bedau, H. A., \& Radelet, M. L. (1987). Miscarriages of justice in potentially capital cases. Stanford law review, 21-179.

Beichner, D., \& Spohn, C. (2012). Modeling the effects of victim behavior and moral character on prosecutors' charging decisions in sexual assault cases. Violence and Victims, 27(1), 3-24.

Bennett, R. R. (2004). Comparative criminology and criminal justice research: The state of our knowledge. Justice Quarterly, 21(1), 1-21. 
Berdejó, C. (2018). Criminalizing race: Racial disparities in plea-bargaining. BCL Rev., $59,1187$.

Bergeron, P., Donnelly, M. (2020, December, 14). How a spreadsheet could change the criminal-justice system. The Atlantic Monthly. https://www.theatlantic.com/ideas/archive/2020/12/how-a-spreadsheet-couldchange-the-criminal-justice-system/617370/

Berry, S. M. (2003). Bad Lawyering-How Defense Attorneys Help Convict the Innocent. N. Ky. L. Rev., 30, 487.

Bewick, V., Cheek, L., \& Ball, J. (2004). Statistics review 12: survival analysis. Critical care, $8(5), 389$.

Bishop, E., Hopkins, B., Obiofuma, C., \& Owusu, F. (2020, November). Racial Disparities in the Massachusetts Criminal System (Rep.). Retrieved March 11, from The Criminal Justice Policy Program, Harvard Law School https://hls.harvard.edu/content/uploads/2020/11/Massachusetts-Racial-DisparityReport-FINAL.pdf

Blair, I. V. (2002). The malleability of automatic stereotypes and prejudice. Personality and social psychology review, 6(3), 242-261.

Blumstein, A. (2015). Racial disproportionality in prison. In Race and social problems (pp. 187-193). Springer, New York, NY.

Bobo, L. D., \& Thompson, V. (2006). Unfair by design: The war on drugs, race, and the legitimacy of the criminal justice system. Social Research: An International Quarterly, 73(2), 445-472.

Bonczar, T. P. (2003). Prevalence of Imprisonment in the US Population, 19742001.https://sentencingproject.org/wp-content/uploads/2016/01/Trends-in-USCorrections.pdf

Borchard, Е. М. (1961). Convicting the innocent. Рипол Классик.

Braga, A. A., \& Bond, B. J. (2008). Policing crime and disorder hot spots: A randomized controlled trial. Criminology, 46(3), 577-607.

Brennan, P. K., \& Spohn, C. (2008). Race/Ethnicity and Sentencing Outcomes Among Drug Offenders in North Carolina. Journal of Contemporary Criminal Justice, 24(4), 371-398. https://doi.org/10.1177/1043986208322712

Bridges, George S., \& Steen, Sara. (1998). "Racial Disparities in Official Assessments of Juvenile Offenders: Attributional Stereotypes as Mediating Mechanisms." American Sociological Review 63:554-70 
Bronson J. and Carson, E.A. (2019). Prisoners in 2017. Washington, DC: Bureau of Justice Statistics. https://www.bjs.gov/content/pub/pdf/p17.pdf

Burch, T. (2015). Skin color and the criminal justice system: Beyond Black-White disparities in sentencing. Journal of Empirical Legal Studies, 12(3), 395-420.this one shows lighter skinned Blacks less penalized than darker skinned.

Burgess, D., van Ryn, M., Dovidio, J., \& Saha, S. (2007). Reducing racial bias among health care providers: lessons from social-cognitive psychology. Journal of general internal medicine, 22(6), 882-887. https://doi.org/10.1007/s11606-0070160-1

Cabaniss, E. R., Frabutt, J. M., Kendrick, M. H., \& Arbuckle, M. B. (2007). Reducing disproportionate minority contact in the juvenile justice system: Promising practices. Aggression and Violent Behavior, 12(4), 393-401.

Cabrera, A. F. (1994). Logistic regression analysis in higher education: An applied perspective. Higher Education: Handbook of Theory and Research, Vol. $10,225-256$.

Campbell, K., \& Denov, M. (2004). The burden of innocence: Coping with a wrongful imprisonment. Canadian journal of criminology and criminal justice, 46(2), 139164.

Cardoza, B. (2016). Making up for lost time: What the wrongfully convicted endure and how to provide fair compensation. (Rep.). Retrieved February, 2019, from Innocence Project website: https:/www.innocenceproject.org/wpcontent/uploads/2016/06/innocence_project_compensation_report-6.pdf

Carnevale, A. P., \& Stone, S. C. (1995). The American mosaic: An in-depth report on the future of diversity at work. McGraw-Hill Companies.

Carson, E. A., \& Anderson, E. (2015). Prisoners in 2014. US Department of Justice, Office of Justice Programs, Bureau of Justice Statistics, NCJ, 247282, 2.

Chapman, E. N., Kaatz, A., \& Carnes, M. (2013). Physicians and implicit bias: How doctors may unwittingly perpetuate health care disparities. Journal of General Internal Medicine, 28(11), 1504- 1510.

Chinn, J., \& Ratliff, A. (2008). I Was Put out the Door with Nothing-Addressing the Needs of the Exonerated Under a Refugee Model. Cal. WL Rev., 45, 405.

Chunias, J. L., \& Aufgang, Y. D. (2008). Beyond monetary compensation: The need for comprehensive services for the wrongfully convicted. BC Third World LJ, 28, 105 
Clark, T., Bradburn, M., Love, S. et al. Survival Analysis Part I: Basic concepts and first analyses. Br J Cancer 89, 232-238 (2003). https://doi.org/10.1038/sj.bjc.6601118

Clow, K. A., \& Leach, A. (2013). After innocence: Perceptions of individuals who have been wrongfully convicted. Legal and Criminological Psychology, 20(1), 147164. doi:10.1111/lcrp. 12018

Coker, D. (2002). Foreword: Addressing the real world of racial injustice in the criminal justice system. J. Crim. L. \& Criminology, 93, 827.

Cooley, C. M., \& Oberfield, G. S. (2007). Increasing Forensic Evidence's Reliability and Minimizing Wrongful Convictions: Applying Daubert Isn't the Only Problem. Tulsa L. Rev., 43, 285.

Cox, D. (1972). Regression Models and Life-Tables. Journal of the Royal Statistical Society. Series B (Methodological), 34(2), 187-220.

Cox, D. R., \& Snell, E. J. (1989). The analysis of binary data (2nd ed.). London: Chapman and Hall

Cox, D. R., \& Oakes, D. (1984). Analysis of survival data (Vol. 21). CRC Press.

Crawford, C., Chiricos, T., \& Kleck, G. (1998). Race, racial threat, and sentencing of habitual offenders. Criminology, 36(3), 481-512.

Crow, M. S., \& Adrion, B. (2011). Focal concerns and police use of force: Examining the factors associated with Taser use. Police Quarterly, 14(4), 366-387.

Crow, M. S., \& Bales, W. (2006). Sentencing guidelines and focal concerns: The effect of sentencing policy as a practical constraint on sentencing decisions. American Journal of Criminal Justice, 30(2), 285-304.

Death Penalty Information Center (2020). Innocence Database. https://deathpenaltyinfo.org/news/dpic-adds-eleven-cases-to-innocence-listbringing-national-death-row-exoneration-total-to-185

Demuth, S., \& Steffensmeier, D. (2004). Ethnicity effects on sentence outcomes in large urban courts: Comparisons among White, Black, and Hispanic defendants. Social Science Quarterly, 85(4), 994-1011.

DeVeaux, M. I. (2013). The trauma of the incarceration experience. Harv. CR-CLL Rev., $48,257$.

Devine, P. G., \& Elliot, A. J. (1995). Are racial stereotypes really fading? The Princeton trilogy revisited. Personality and social psychology bulletin, 21(11), 1139-1150. 
Devine, P. G., Plant, E. A., Amodio, D. M., Harmon-Jones, E., \& Vance, S. L. (2002). The regulation of explicit and implicit race bias: the role of motivations to respond without prejudice. Journal of personality and social psychology, 82(5), 835.

Doerner, J. \& Demuth, S. (2010). "The Independent and Joint Effects of Race/Ethnicity, Gender, and Age on Sentencing Outcomes in U.S. Federal Courts." Justice Quarterly 27:1-27.

Drizin, S. A., \& Leo, R. A. (2003). The problem of false confessions in the post-DNA world. NCL Rev., 82, 891.

Eberhardt, J. L., Goff, P. A., Purdie, V. J., \& Davies, P. G. (2004). Seeing black: race, crime, and visual processing. Journal of personality and social psychology, 87(6), 876.

Eck, J.E., Spelman, W., Police Executive Research Forum (PERF), America. (1987). Problem-Solving: Problem Oriented Policing in Newport News.

Eppler-Epstein, S., Gurvis, A., \& King, R. (2016). The alarming lack of data on Latinos in the criminal justice system. Washington, DC: Urban Institute.

Ericson, R. D., \& Eckberg, D. A. (2016). Racial disparity in juvenile diversion: The impact of focal concerns and organizational coupling. Race and justice, 6(1), 3556.

Fader, J. J., Kurlychek, M. C., \& Morgan, K. A. (2014). The color of juvenile justice: Racial disparities in dispositional decisions. Social Science Research, 44, 126140.

Feldmeyer, B., Warren, P., Siennick, S., \& Neptune, M. (2015). "Racial, Ethnic, and Immigrant Threat: Is There a New Criminal Threat on State Sentencing?" Journal of Research in Crime \& Delinquency 52(1):62-92.

Fellner, J., Walsh, S., Roth, K., \& Smart, M. (2000). Punishment and prejudice: Racial disparities in the war on drugs. Human Rights Watch.

Fernandez, K. E., \& Bowman, T. (2004). Race, political institutions, and criminal justice: an examination of the sentencing of Latino offenders. Colum. Hum. Rts. L. Rev., 36,41 .

Fontaine, G., \& Emily, C. (1978). Causal attribution and judicial discretion. Law and Human Behavior, 2(4), 323-337. 
Ford, G. (2009). The New Jim Crow: Male and Female, South and North, from Cradle to Grave, Perception and Reality: Racial Disparity and Bias in America's Criminal Justice System. Rutgers Race \& L. Rev., 11, 324

Fox, J. (2002). Cox proportional-hazards regression for survival data. An R and S-PLUS companion to applied regression, 2002.

Fox, J. \& Weisberg, S. (2011). An R Companion to Applied Regression. Sage, Thousand Oaks, CA, second edition.

Franklin, T. W. (2010). The intersection of defendants' race, gender, and age in prosecutorial decision making. Journal of Criminal Justice, 38(2), 185-192.

Free, M. D., \& Ruesink, M. (2012). Race and justice: Wrongful convictions of Black men. Boulder, CO: Lynne Rienner Publishers.

Free Jr., M. D., \& Ruesink, M. (2018). Flawed justice: A study of wrongly convicted Black women. Journal of Ethnicity in Criminal Justice, 16(4), 333-347. https://doi-org.echo.louisville.edu/10.1080/15377938.2015.1015199

Freiburger, T. L. (2009). Race and the Sentencing of Drug Offenders: An Examination of the Focal Concerns Perspective. Southwest Journal of Criminal Justice

Freiburger, T. L., Marcum, C. D., \& Pierce, M. (2010). The impact of race on the pretrial decision. American Journal of Criminal Justice, 35(1-2), 76-86.

Freiburger, T. L., \& Romain, D. (2018). An examination of the impacts of gender, race, and ethnicity on the judicial processing of offenders in family violence cases. Crime \& Delinquency, 64(13), 1663-1697.

Fuller, J. R. (2009). Juvenile delinquency: Mainstream and crosscurrents. Pearson/Prentice Hall.

Garrett, B. L. (2005). Innocence, harmless error, and federal wrongful conviction law. Wis. L. Rev., 35.

Garrett, B. L. (2007). Claiming innocence., Minn. L. Rev., 92, 1629.

Garrett, B. L. (2008). Judging innocence. Colum. L. Rev., 108, 55.

Garrett, B. (2011). Convicting the innocent. Harvard University Press.

Garrett, B. L. (2015). Contaminated confessions revisited. Va. L. Rev., 101, 395. 
Garrett, B. L. (2017). Actual innocence and wrongful convictions. Academy for Justice, A Report on Scholarship and Criminal Justice Reform (Erik Luna ed., 2017 Forthcoming).

Garrett, B. L., \& Neufeld, P. J. (2009). Invalid forensic science testimony and wrongful convictions. Virginia Law Review, 1-97.

Goel, S., Rao, J. M., \& Shroff, R. (2016). Precinct or prejudice? Understanding racial disparities in New York City's stop-and-frisk policy. The Annals of Applied Statistics, 10(1), 365-394.

Goel, M. K., Khanna, P., \& Kishore, J. (2010). Understanding survival analysis: KaplanMeier estimate. International journal of Ayurveda research, 1(4), 274.

Gould, J., \& Leo, R. A. (2015). The path to exoneration. /Alb. L. Rev./, /79/, 325

Gould, J., \& Leo, R. (2010). One hundred years later: Wrongful convictions after a century of research. The Journal of Criminal Law and Criminology (1973-), 100(3), 825-868.

Gould, J., Carrano, J., Leo, R., \& Young, J. (2012). Predicting Erroneous Convictions: A Social Science Approach to Miscarriages of Justice (pp. 1-409, Rep. No. 241389). Washington,DC: National Institute of Justice. Retrieved 2012.

Gregrich, R. J. (2003). A note to researchers: communicating science to policy makers and practitioners. Journal of Substance Abuse Treatment, 25(3), 233-237.

Grimsly, E. (2012, September 26). What Wrongful Convictions Teach Us About Racial Inequality. Retrieved April 15, 2019, from https://www.innocenceproject.org/what-wrongful-convictions-teach-us-aboutracial-inequality/

Gross, S. R. (2013). How Many False Convictions are There? How Many Exonerations are There?. Wrongful Convictions and Miscarriages of Justice: Causes and Remedies in North American and European Criminal Justice Systems, CR Huff \& M. Killias eds., Routledge.

Gross, Samuel (2018). Mass Exonerations and Group Exonerations since 1989. National Registry of Exonerations.https://www.law.umich.edu/special/exoneration/Documents/NREM assExonConf4418.pdf

Gross R., O'brien, B., Hu, C., \& Kennedy, E. H. (2014). Rate of false conviction of criminal defendants who are sentenced to death. Proceedings of the National Academy of Sciences, 111(20), 7230-7235. doi:10.1073/pnas.1306417111 
Gross, S. R. (2016). What we think, what we know and what we think we know about false convictions. Ohio St. J. Crim. L., 14, 753.

Gross SR, O’Brien B. 2007. Frequency and predictors of false conviction: why we know so little, and new data on capital cases. J.Empirical Legal Stud. 5: 927-62.

Gross, S. R., Cousino, M., O’Brien, B., Stephens, K. (2018). Exonerations in the United States before 1989. Report by the National Registry of Exonerations. National Registry of Exonerations: University of Michigan Law School and the Center on Wrongful Convictions at Northwestern University School of Law.

Gross, S. R., \& Ellsworth, P. C. (2012). False Convictions. In E. Shafir (Ed.), The Behavioral Foundations of Public Policy (pp. 163-180). Princeton University Press. https://repository.law.umich.edu/book_chapters/96

Gross, S., \& Mauro, R. (1984). Patterns of Death: An Analysis of Racial Disparities in Capital Sentencing and Homicide Victimization. Stanford Law Review, 37(1), $27-$ 153. doi: $10.2307 / 1228652$

Gross, S.R., Jacoby, K., Matheson, D.J., Montgomery, N. (2005). Exonerations in the United States: 1989 through 2003. The Journal of Criminal Law and Criminology, 95(2), 523-560.

Gross, S. R., \& Shaffer, M. (2012). Exonerations in the United States, 1989 - 2012 Report by the National Registry of Exonerations (pp. 1-102, Rep.). MI: National Registry of Exonerations. Retrieved May 05, 2019, from http://www.law.umich.edu/special/exoneration/Documents/exonerations_us_1989 _2012_full_report.pdf

Gross, S. R., Possley, M., \& Stephens, K. (2017). Race and wrongful convictions in the United States (Rep.). Retrieved February 19, 2019, from National Registry of Exonerations website: http://www.law.umich.edu/special/exoneration/Documents/Race and Wrongful Convictions.pdf

Grounds, A. (2005). Psychological Consequences of Wrongful Conviction and Imprisonment. Canadian Journal of Criminology and Criminal Justice, 46(2), 165-182. doi:10.3138/cjccj.46.2.165

Gutman, J. S. (2017). An Empirical Reexamination of State Statutory Compensation for the Wrongly Convicted. Mo. L. Rev., 82, 369.

Hagan, J., \& Peterson, R. (1995). Criminal inequalities in America: Patterns and consequences. In J. Hagan \& R. Peterson (Eds.), Crime and inequality (pp. 14-36). Stanford, CA: Stanford University Press. 
Hampikian, G., West, E., \& Akselrod, O. (2011). The genetics of innocence: Analysis of 194 US DNA exonerations. Annual Review of Genomics and Human Genetics, 12, 97-120.

Haney, C. (2001). The Psychological Impact of Incarceration Implications for PostPrison Adjustment (pp. 77-92) (USA, Urban Institute, Office of Justice Programs). Washington DC: Urban Institute. Retrieved June 15, 2019, from http://webarchive.urban.org/UploadedPDF/410624_PyschologicalImpact.pdf

Haney, C. (2006). Reforming punishment: Psychological limits to the pains of imprisonment. American Psychological Association.

Harmon, T. R. (2004). Race for Your Life: An Analysis of the Role of Race in Erroneous Capital Convictions. Criminal Justice Review (Georgia State University), 29(1), 76-96. https://doi-org.echo.louisville.edu/10.1177/073401680402900106

Harmon, T. R., \& Lofquist, W. S. (2005). Too Late for Luck: A Comparison of PostFurman Exonerations and Executions of the Innocent. Crime \& Delinquency, 51(4), 498-520. https://doi-org.echo.louisville.edu/10.1177/0011128705275977

Harre Jr, F. E., Lee, K. L., \& Pollock, B. G. (1988). Regression models in clinical studies: determining relationships between predictors and response. JNCI: Journal of the National Cancer Institute, 80(15), 1198-1202.

Harris, A. (2009). Attributions and institutional processing: How focal concerns guide decision-making in the juvenile court. Race and Social Problems, 1(4), 243-256.

Hartley, R. D., Maddan, S., \& Spohn, C. C. (2007). Concerning Conceptualization and Operationalization: Sentencing Data and the Focal Concerns Perspective--A Research Note. Southwest Journal of Criminal Justice, 4(1).

Harvey, J. H., \& Weary, G. (1984). Current issues in attribution theory and research. Annual review of psychology, 35(1), 427-459.

Heitzeg, N. A. (2009). Education or Incarceration: Zero Tolerance Policies and the School to Prison Pipeline. In Forum on public policy online (Vol. 2009, No. 2). Oxford Round Table. 406 West Florida Avenue, Urbana, IL 61801.

Hessick, C. B. (2017). DNA Exonerations and the Elusive Promise of Criminal Justice Reform. Ohio St. J. Crim. L., 15, 271.

Higgins, G. E., Vito, G. F., \& Grossi, E. L. (2012). The impact of race on the police decision to search during a traffic stop: A focal concerns theory perspective. Journal of Contemporary Criminal Justice, 28(2), 166-183. 
Higgins, G. E., Ricketts, M. L., Griffith, J. D., \& Jirard, S. A. (2013). Race and juvenile incarceration: A propensity score matching examination. American Journal of Criminal Justice, 38(1), 1-12.

Holloway, John, (2016). Conviction Review Units: A National Perspective. Faculty Scholarship. Paper 1614.

http://scholarship.law.upenn.edu/faculty_scholarship/1614

Holmes, W. (2001). Who are the wrongly convicted on death row. Wrongly convicted: Perspectives on failed justice, 99-113.

Hosmer, D. W. \& Lemeshow, S. (1989) Applied Logistic Regression, 1st Edn. John Wiley, New York.

Hosmer Jr, D. W., \& Lemeshow, S. (1999). Applied survival analysis: regression modelling of time to event data (1999). Eur Orthodontic Soc, 561-2.

Huebner, B. M., \& Bynum, T. S. (2006). An analysis of parole decision making using a sample of sex offenders: A focal concerns perspective. Criminology, 44(4), 961991.. The Sociological Quarterly, 54(4), 647-669

Innocence Project. (2017) Wisconsin Latino exoneration program celebrates first anniversary of launch. https://www.innocenceproject.org/wlep-celebrates-firstanniversary-launch/

Innocence Project. (2018). DNA exonerations in the United States. https://www.innocenceproject.org/dna-exonerations-in-the-united-states/

Ishoy, G. A., \& Dabney, D. A. (2018). Policing and the focal concerns framework: Exploring how its core components apply to the discretionary enforcement decisions of police officers. Deviant Behavior, 39(7), 878-895.

Johnson, B. D. (2003). Racial and ethnic disparities in sentencing departures across modes of conviction. Criminology, 41(2), 449-490.

Johnson, K. J., \& Fredrickson, B. L. (2005). "We all look the same to me" Positive emotions eliminate the own-race bias in face recognition. Psychological science, 16(11), 875-881.

Johnson, B. D., Ulmer, J. T., \& Kramer, J. H. (2008). The social context of guidelines circumvention: The case of federal district courts. Criminology, 46(3), 737-783.

Johnson, M., Griffith, S., \& Barnaby, C. (2013). Blacks Wrongly Convicted of Sexual Assault Against Whites: Eyewitness Error and Other Case Features. Journal of Ethnicity in Criminal Justice, 11(4), 277-294. https://doiorg.echo.louisville.edu/10.1080/15377938.2013.813285 
Jones, C. S., \& Kaplan, M. F. (2003). The effects of racially stereotypical crimes on juror decision-making and information-processing strategies. Basic and Applied Social Psychology, 25(1), 1-13.

Jordan, K. L., \& Freiburger, T. L. (2015). The effect of race/ethnicity on sentencing: Examining sentence type, jail length, and prison length. Journal of Ethnicity in Criminal Justice, 13(3), 179-196

Joy, P. A. (2006). Brady and jailhouse informants: Responding to injustice. Case W. Res. L. Rev., 57, 619.

Kamalu, N. C., Coulson-Clark, M., \& Kamalu, N. M. (2010). Racial disparities in sentencing: Implications for the criminal justice system and the Black community. African Journal of Criminology and Justice Studies: AJCJS, 4(1), 1.

Kaplan, E. L., \& Meier, P. (1958). Nonparametric estimation from incomplete observations. Journal of the American statistical association, 53(282), 457-481.

Kartsonaki, C. (2016). Survival analysis. Diagnostic Histopathology, 22(7), 263-270

Keil, T.J., Vito, G.F. Race and the death penalty in Kentucky murder trials: 19761991. AJCJ 20, 17-36 (1995). https://doi.org/10.1007/BF02886116

King, N. J. (2019). Chapter 13 Judicial Review: Appeals and Postconviction Proceedings. In Y. Kamisar, W. R. LaFave, J. H. Israel, N. J. King, O. S. Kerr, \& E. B. Primus (Authors), Advanced criminal procedure: Cases, comments, and questions. St. Paul, MN: West Academic Publishing.

Klein, J. P., \& Moeschberger, M. L. (1997). Refinements of the semiparametric proportional hazards model. In Survival Analysis (pp. 269-303). Springer, New York, NY.

Kleinbaum, D. G., \& Klein, M. (2010). Survival analysis (Vol. 3). New York: Springer.

Konvisser, Z. D. (2011). Psychological consequences of wrongful conviction in women and the possibility of positive change. DePaul J. Soc. Just., 5, 221.

Kovera, M. B. (2019). Racial disparities in the criminal justice system: Prevalence, causes, and a search for solutions. Journal of Social Issues, 75(4), 1139-1164.

Kramer, J., \& Steffensmeier, D. (1993). Race and imprisonment decisions. The Sociological Quarterly, 34(2), 357-376.

Kramer, J. H., \& Ulmer, J. T. (2002). Downward departures for serious violent offenders: Local court "corrections" to Pennsylvania's sentencing guidelines. Criminology, 40(4), 897-932. 
Kregg, C. (2016). Right To Counsel: Mental Health Approaches to Support the Exonerated [Scholarly project]. In University of Chicago Social Service Administration. Retrieved June 06, 2019, from https://ssa.uchicago.edu/rightcounsel-mental-health-approaches-support-exonerated

KS Stat $§ 22-3501$ (2019) https://law.justia.com/codes/kansas/2019/chapter-22/article$35 /$ section-22-3501/

LaPorte, G. (2017, September 8). Wrongful Convictions and DNA Exonerations: Understanding the Role of Forensic Science (USA, Department of Justice, Office of Justice Programs, National Institute of Justice). Retrieved May 25, 2019, from https://www.nij.gov/journals/279/Pages/wrongful-convictions-and-dnaexonerations.aspx\#note3

Lee, R. J., \& Nicewander, W. A. (1988). Thirteen ways to look at the correlation coefficient. The American Statistician, 42(1), 59-66.

Leiber, M. J., \& Blowers, A. N. (2003). Race and misdemeanor sentencing. Criminal Justice Policy Review, 14(4), 464-485.

Leiber, M., \& Rodriguez, N. (2011). The implementation of the disproportionate minority confinement/contact (DMC) mandate: A failure or success?. Race and Justice, $1(1), 103-124$.

Leo, R. A. (2005). Rethinking the study of miscarriages of justice: Developing a criminology of wrongful conviction. Journal of Contemporary Criminal Justice, 21(3), 201-223.

Leo, R. A. (2009). False confessions: Causes, consequences and implications. The Journal of the American Academy of Psychiatry and the Law.

Leo, R. A. (2016). The criminology of wrongful conviction. Journal of Contemporary Criminal Justice, 33(1), 82-106. doi:10.1177/1043986216673013

Leo, R. A. (2016). Has the innocence movement become an exoneration movement? The risks and rewards of redefining innocence. The Risks and Rewards of Redefining Innocence (March 1, 2016). Daniel Medwed, ed., Innocent Reflections: A Quarter Century of DNA Exonerations (Cambridge University Press 2016).

Leo, R. A., \& Gould, J. (2009). Studying wrongful convictions: Learning from social science. /Ohio St. J. Crim. L./, /7/, 7. 
Leung, K. M., Elashoff, R. M., \& Afifi, A. A. (1997). Censoring issues in survival analysis. Annual review of public health, 18(1), 83-104.

Liebman, J. S., Fagan, J., Gelman, A., West, V., Davies, G., \& Kiss, A. (2002). A broken system, part II: Why there is so much error in capital cases, and what can be done about it. Report, Columbia University Law School.

Loftus, E. F. (1975). Reconstructing memory: The incredible eyewitness. Jurimetrics Journal, 15(3), 188-193.

Logan, M. W., Dulisse, B., Peterson, S., Morgan, M. A., Olma, T. M., \& Paré, P. P. (2017). Correctional shorthands: Focal concerns and the decision to administer solitary confinement. Journal of criminal justice, 52, 90-100

McGlynn, K. E. (2019). Remedying Wrongful Convictions though DNA Testing: Expanding Post-Conviction Litigants' Access to DNA Database Searches to Prove Innocence. BCL Rev., 60, 709.

McIntosh, K., Girvan, E. J., Horner, R., \& Smolkowski, K. (2014). Education not incarceration: A conceptual model for reducing racial and ethnic disproportionality in School Discipline, 5.

Males, M., \& Macallair, D. (2000). The Color of Justice: An Analysis of Juvenile Adult Court Transfers in California

Mann, C. R., \& Zatz, M. S. (Eds.). (2002). Images of color, images of crime: Readings. Los Angeles, CA: Roxbury

Mauer, M. (2011). Addressing racial disparities in incarceration. The Prison Journal, 91(3_suppl), 87S-101S.

Mauer, M., \& Jones, S. (2013). Race to incarcerate: A graphic retelling. The New Press

Mauer, M., \& King, R. S. (2007). Uneven justice: State rates of incarceration by race and ethnicity.

Mears, D. P. (2007). Towards rational and evidence-based crime policy. Journal of Criminal Justice, 35(6), 667-682.

Mears, D. P., \& Bacon, S. (2009). Improving criminal justice through better decision making: Lessons from the medical system. Journal of Criminal Justice, 37(2), 142-154. 
Meehan, A. J., \& Ponder, M. C. (2002). Race and place: The ecology of racial profiling African American motorists. Justice Quarterly, 19(3), 399-430.

Meissner, C. A., \& Brigham, J. C. (2001). Thirty years of investigating the own-race bias in memory for faces: a meta-analytic review. Psychology, Public Policy, and Law, 7(1), 3.

Menjívar, C., \& Bejarano, C. (2004). Latino immigrants' perceptions of crime and police authorities in the United States: A case study from the Phoenix metropolitan area. Ethnic and racial studies, 27(1), 120-148.

Mitchell, O., \& MacKenzie, D. L. (2004). The relationship between race, ethnicity, and sentencing outcomes: A meta-analysis of sentencing research. Final Report Submitted to the National Institute of Justice.

Mostaghel, D. M. (2011). Wrongfully incarcerated, randomly compensated - how to fund wrongful-conviction compensation statutes. Ind. L. Rev,, 2010(44), 503-544.

Munoz, E. A., \& Freng, A. B. (2008). Age, racial/ethnic minority status, gender and misdemeanor sentencing. Journal of Ethnicity in Criminal Justice, 5(4), 29-57.

Murray, B. M. (2014). Beyond the right to counsel: Increasing notice of collateral consequences. U. Rich. L. Rev., 49, 1139.

Natapoff, A. (2006). Beyond unreliable: How snitches contribute to wrongful convictions. Golden Gate UL Rev., 37, 107.

National Registry of Exonerations. (2018). Milestone: Exonerated defendants spent 20,000 years in prison.

https://www.law.umich.edu/special/exoneration/Documents/NRE.20000.Years.Re port.pdf

National Registry of Exonerations. (2020). Exoneration Detail List. http://www.law.umich.edu/special/exoneration/Pages/detaillist.aspx

National Registry of Exonerations. (2020). Annual Report (2019). http://www.law.umich.edu/special/exoneration/Documents/Exonerations_in_2019 .pdf

National Registry of Exonerations. (2019). Glossary. https://www.law.umich.edu/special/exoneration/Pages/glossary.aspx

National Registry of Exonerations. (2019). Public Spreadsheet. [Dataset and Code Manual]. National Registry of Exonerations. 
Nellis, A. (2016). The color of justice: Racial and ethnic disparity in state prisons. Sentencing Project. http://www.sentencingproject.org/publications/color-ofjustice-racial-and-ethnic-disparity-in-state-prisons

Norris, R., Acker, J., Bonventre, C., \& Redlich, A. (2020). Thirty Years of Innocence. The Wrongful Conviction Law Review, 1(1), 2-58.

O'Brien, B., Stephens, K., Possley, M., \& Grosso, C. M. (2019). Latinx Defendants, False Convictions, and the Difficult Road to Exoneration. UCLA L. Rev., 66, 1682.

Olney, M., \& Bonn, S. (2015). An Exploratory Study of the Legal and Non-Legal Factors Associated With Exoneration for Wrongful Conviction: The Power of DNA Evidence. Criminal Justice Policy Review, 26(4), 400-420. https://doiorg.echo.louisville.edu/10.1177/0887403414521461

Paluck, E. L., \& Green, D. P. (2009). Prejudice reduction: What works? A review and assessment of research and practice. Annual review of psychology, 60, 339-367.

Parker, K. F., DeWees, M. A., \& Radelet, M. L. (2003). Race, the death penalty, and wrongful convictions. Crim. Just., 18, 49.

Parzen, M., \& Lipsitz, S. R. (1999). A global goodness-of-fit statistic for Cox regression models. Biometrics, 55(2), 580-584.

Paternoster, R., Brame, R., Mazerolle, P., \& Piquero, A. (1998). Using the correct statistical test for the equality of regression coefficients. Criminology, 36(4), 859866.

Peng, C. Y. J., Lee, K. L., \& Ingersoll, G. M. (2002). An introduction to logistic regression analysis and reporting. The journal of educational research, 96(1), 314.

Petersilia, J. (1985). Racial disparities in the criminal justice system: A summary. Crime \& Delinquency, 31(1), 15-34.

Pierce, M. B. (2012). Continuing the conversation--The operationalization of focal concerns perspective: Assessing sentencing decisions for criminal child neglect. Southwest Journal of Criminal Justice, 8(2).

Piquero, A. R. (2008). Disproportionate minority contact. The future of children,18(2) 59- 79. https://doi.org/10.1353/foc. 0.0013 
Pope, D. G., Price, J., \& Wolfers, J. (2013). Awareness reduces racial bias (No. w19765). National Bureau of Economic Research.

Pratt, T. C. (1998). Race and sentencing: A meta-analysis of conflicting empirical research results. Journal of Criminal Justice, 26(6), 513-523

Prinja, S., Gupta, N., \& Verma, R. (2010). Censoring in clinical trials: review of survival analysis techniques. Indian journal of community medicine: official publication of Indian Association of Preventive \& Social Medicine, 35(2), 217.

Pullmann, M. D., Ague, S., Walker, S. C., Negrete, A., Quick, H. F., \& Trupin, E. (2013). Washington state disproportionate minority contact assessment. Seattle, WA: University of Washington.

Quigley, W. (2011). Racism: the crime in criminal justice. Loy. J. Pub. Int. L., 13, 417.

Raeder, M. S. (2007). See no evil: wrongful convictions and the prosecutorial ethics of offering testimony by jailhouse informants and dishonest experts. Fordham L. Rev., 76, 1413.

Rafail, P., \& Mahoney, M. (2019). A Long Road to Freedom: The Exoneration Pipeline in the United States, 1989-2015. The Sociological Quarterly, 60(4), 537-558.

Raphael, S., \& Rozo, S. V. (2019). Racial disparities in the acquisition of juvenile arrest records. Journal of Labor Economics, 37(S1), S125-S159

Ray, B., \& Dollar, C. B. (2013). Examining mental health court completion: A focal concerns perspective. The Sociological Quarterly, 54(4), 647-669Reynoso, C. (2017). Hispanics and the Criminal Justice System. Hispanics in the United States: An Agenda for the Twenty-first Century.

Rehavi, M. M., \& Starr, S. B. (2014). Racial disparity in federal criminal sentences. Journal of Political Economy, 122(6), 1320-1354.

Reynoso, C. (2017). Hispanics and the Criminal Justice System. Hispanics in the United States: An Agenda for the Twenty-first Century

Risinger, D. M. (2006). Innocents convicted: An empirical justified factual wrongful conviction rate. J. Crim. l. \& Criminology, 97, 761.

Rizer, A. (2003). The race effect on wrongful convictions. William Mitchell Law Review, 29(3), 845-868. 
Roberts, J., \& Stanton, E. (2007, November 25). A Long Road Back After Exoneration, and Justice Is Slow to Make Amends. The New York Times

Rosich, Katherine J. 2007. Race ethnicity, and the Criminal Justice System. Washington, DC: American Sociological Association. (Available at http://asanet.org.).

Scheck, B. (2007). Innocence, race, and the death penalty. Howard Law Journal, 50(2), 445-470

Scheck, B. (2017). Conviction integrity units re-visited. Ohio State Journal of Criminal Law, 14, 705-752. doi:10.2139/ssrn.2890341

Sheck, B., Neufeld, P., \& Dwyer, J. (2000). Actual innocence: five days to execution, and other dispatches from the wrongly convicted. Doubleday.

Schindler, M. A. (2001). Building Block for Youth-For a Fair and Effective Youth Justice System. Guild Prac., 58, 92.

Schlesinger, T. (2005). Racial and ethnic disparity in pretrial criminal processing. Justice Quarterly, 22(2), 170-192.

Schuck, A. M., Lersch, K. M., \& Verrill, S. W. (2004). The "invisible" Hispanic? The representation of Hispanics in criminal justice research: What do we know and where should we go?. Journal of Ethnicity in Criminal Justice, 2(3), 5-22.

Scott, L. (2009). It Never, Ever Ends: The Psychological Impact of Wrongful Conviction. Crim. L. Brief, 5, 10.

Sharp, S. F., Braley, A., \& Marcus-Mendoza, S. (2000). Focal concerns, race \& sentencing of female drug offenders. Free Inquiry in Creative Sociology, 28(2), 316.

Simms, T. (2016). Statutory compensation for the wrongly imprisoned. Social work, 61(2), 155-162.

Singh, R., \& Mukhopadhyay, K. (2011). Survival analysis in clinical trials: Basics and must know areas. Perspectives in clinical research, 2(4), 145.

Smith, E., \& Hattery, A. J. (2011). Race, wrongful conviction \& exoneration. Journal of African American Studies, 15(1), 74-94.

Smith, M. R., \& Petrocelli, M. (2001). Racial profiling? A multivariate analysis of police traffic stop data. Police Quarterly, 4, 4-27. 
Sperandei S. (2014). Understanding logistic regression analysis. Biochemia medica, 24(1), 12-18. https://doi.org/10.11613/BM.2014.003

Spohn, C., \& Holleran, D. (2000). The imprisonment penalty paid by young, unemployed Black and Hispanic male offenders. Criminology, 38(1), 281-306.

Spohn, C. (2000). Thirty years of sentencing reform: The quest for a racially neutral sentencing. Crime and.

Spohn, C., \& Sample, L. L. (2013). The dangerous drug offender in federal court: Intersections of race, ethnicity, and culpability. Crime \& Delinquency, 59(1), 331.

Spruance, S. L., Reid, J. E., Grace, M., \& Samore, M. (2004). Hazard ratio in clinical trials. Antimicrobial agents and chemotherapy, 48(8), 2787-2792.

Steen, S., Engen, R. L., \& Gainey, R. R. (2005). Images of danger and culpability: Racial stereotyping, case processing, and criminal sentencing. Criminology, 43(2), 435-468.

Steffensmeier, D. J. (1980). Assessing the impact of the women's movement on sexbased differences in the handling of adult criminal defendants. Crime \& Delinquency, 26(3), 344-357.

Steffensmeier, D. J., Ulmer, J. T., \& Kramer, J. H. (1998). The interaction of race, gender, and age in criminal sentencing: The punishment cost of being young, Black, and male. Criminology, 36, 763-797.

Steffensmeier, D., \& Demuth, S. (2000). Ethnicity and sentencing outcomes in US federal courts: Who is punished more harshly?. American sociological review, 705-729.

Steffensmeier, D., \& Demuth, S. (2001). Ethnicity and judge's sentencing decisions: Hispanic-Black-White Comparisons. Criminology, 39(1), 145-178.

Steffensmeier, D., Painter-Davis, N., \& Ulmer, J. (2017). Intersectionality of race ethnicity, gender, and age on criminal punishment. Sociological Perspectives, 60(4), 810-833.

Stolzenberg, L., D’Alessio, S. J., \& Eitle, D. (2013). Race and cumulative discrimination in the prosecution of criminal defendants. Race and Justice, 3(4), 275-299.

Stone, J., \& Moskowitz, G. B. (2011). Non-conscious bias in medical decision making: what can be done to reduce it?. Medical education, 45(8), 768-776. 
Substance Abuse and Mental Health Services Administration. (2019). Key substance use and mental health indicators in the United States: Results from the 2018 National Survey on Drug Use and Health (HHS Publication No. PEP19-5068, NSDUH Series H-54). Rockville, MD: Center for Behavioral Health Statistics and Quality, Substance Abuse and Mental Health Services Administration. Retrieved from https://www.samhsa.gov/data/

Taylor, R. (1990). Interpretation of the correlation coefficient: a basic review. Journal of diagnostic medical sonography, 6(1), 35-39

Tillyer, R., \& Hartley, R. D. (2010). Driving racial profiling research forward: Learning lessons from sentencing research. Journal of Criminal Justice, 38(4), 657-665.

Ulmer, J. T., \& Johnson, B. (2004). Sentencing in context: A multilevel analysis. Criminology, 42(1), 137-178.

Ulmer, J. T., Kurlychek, M. C., \& Kramer, J. H. (2007). Prosecutorial discretion and the imposition of mandatory minimum sentences. Journal of Research in Crime and Delinquency, 44(4), 427-458.

Urbina, M. G. (2004). Language barriers in the Wisconsin court system: the latino/a experience. Journal of Ethnicity in Criminal Justice, 2(1-2), 91-118. https://doi.org/10.1300/J222v02n01_06

U.S. Census Bureau. (2018). U.S. Census Bureau QuickFacts: United States. https://www.census.gov/quickfacts/fact/table/US/PST045218

Valencia, R. A. (1994). Latinos and the Criminal Justice System: An Overview of the Invisible/Visible Minority. Harv. Latino L. Rev., 1, 27.

Vito, A. G. (2015). Racial profiling : using propensity score matching to examine focal concerns theory(dissertation). University of Louisville.

Vito, A. G., Grossi, E. L., \& Higgins, G. E. (2018). Analyzing racial profiling from traffic searches: Using focal concerns theory and propensity score matching. Policing: An International Journal, 41(6), 721-733.

Vito, G.F., Higgins, G.E. \& Vito, A.G. Capital Sentencing In Kentucky, 2000-2010. Am J Crim Just 39, 753-770 (2014). https://doi.org/10.1007/s12103-014-9258-2

Warden, R. (2001). How mistaken and perjured eyewitness identification testimony put 46 innocent Americans on death row. Center on Wrongful Convictions. Northwestern University School of Law. 
Warren, P., Chiricos, T., \& Bales, W. (2012). The imprisonment penalty for young Black and Hispanic males: A crime-specific analysis. Journal of Research in Crime and Delinquency, 49(1), 56-80.

Weigand, H. \& Anderson, T. (2007). Abstract to life after exoneration stages. [Presented at the Innocence Network Conference at Harvard University]. Retrieved from http://www.r-a-e.org/sites/default/files/Psychological\%20 Stages $\% 20$ of $\% 20$ Exoneration.pdf

Weigand, H. (2008). Rebuilding a life: The wrongfully convicted and exonerated. $B U$ Pub. Int. Lj, 18, 427.

Weisburd, D., Telep, C. W., Hinkle, J. C., \& Eck, J. E. (2010). Is problem-oriented policing effective in reducing crime and disorder? Findings from a Campbell systematic review. Criminology \& Public Policy, 9(1), 139-172.

West, E. M. (2010). Court Findings of Ineffective Assistance of Counsel Claims in PostConviction Appeals Among the First 255 DNA Exoneration Cases. Innocence Project.

West, E., \& Meterko, V. (2015). Innocence project: DNA exonerations, 1989-2014: review of data and findings from the first 25 years. Alb. L. Rev., 79, 717.

Westervelt, S. D., \& Cook, K. J. (2012). Life after death row: Exonerees' search for community and identity. New Brunswick, NJ: Rutgers Univ. Press.

White, P. J. (2000). Newly Available, Not Newly Discovered. J. App. Prac. \& Process, $2,7$.

Wildeman, J., Costelloe, M., \& Schehr, R. (2011). Experiencing Wrongful and Unlawful Conviction. Journal of Offender Rehabilitation, 50(7), 411-432. doi:10.1080/10509674.2011.603033

Wildeman, C., \& Wang, E. A. (2017). Mass incarceration, public health, and widening inequality in the USA. The Lancet, 389(10077), 1464-1474.

Wilson, J. (2002). A perpetual battle of the mind. [Memo to FRONTLINE on the emotional impact of exoneration]. www.pbs.org/wgbh/pages/frontline/shows /burden/cameras/memo.html

Wiseman, S. R. (2012). Waiving innocence. Minnesota Law Review, 96, 952-1017.

Yaroshefsky, E., \& Schaefer, L. (2014). Defense lawyering and wrongful convictions. Available at: h ps://scholarlycommons.law.hofstra.edu/faculty_scholarship/906 
Zalman, M. (2010). An integrated justice model of wrongful convictions. Alb. L. Rev., 74, 1465 . 


\section{Appendix}

Table A1. Contributing Factors of Exonerations.

\begin{tabular}{|c|c|c|c|}
\hline $\begin{array}{c}\text { Contributing } \\
\text { Factor }\end{array}$ & $\begin{array}{l}\text { Percent Found in } \\
\text { all Exonerations }\end{array}$ & $\begin{array}{l}\text { Most Frequent } \\
\text { Type of Crime }\end{array}$ & Empirical Literature \\
\hline $\begin{array}{l}\text { Perjury/False } \\
\text { Accusation }\end{array}$ & $58.4 \%$ & Child Sex Abuse & $\begin{array}{l}\text { Norris et al., 2020; } \\
\text { West \& Meterko, } \\
2015\end{array}$ \\
\hline Official Misconduct & $53.9 \%$. & Homicide & $\begin{array}{l}\text { Gross \& Shaffer, } \\
\text { 2012; Gross et al., } \\
\text { 2017; Norris et al., } \\
2020\end{array}$ \\
\hline $\begin{array}{l}\text { Mistaken Eye } \\
\text { Witness ID }\end{array}$ & $28.4 \%$ & Sexual Assault & $\begin{array}{l}\text { Gould \& Leo, 2010; } \\
\text { Gross \& O’Brien, } \\
\text { 2007; Gross \& } \\
\text { Shaffer, 2012; Norris } \\
\text { et al., } 2020\end{array}$ \\
\hline $\begin{array}{c}\text { Inadequate Legal } \\
\text { Defense }\end{array}$ & $26.2 \%$ & Homicide & $\begin{array}{l}\text { Berry, 2003; Gould } \\
\text { et al., 2012; Leo \& } \\
\text { Gould, 2009 }\end{array}$ \\
\hline $\begin{array}{l}\text { False or Misleading } \\
\text { Forensic Evidence }\end{array}$ & $22.8 \%$ & Sexual Assault & $\begin{array}{l}\text { Gross \& Shaffer, } \\
\text { 2012; Garrett \& } \\
\text { Neufeld, 2009; } \\
\text { Hampikian et al., } \\
\text { 2011; West \& } \\
\text { Meterko, } 2015\end{array}$ \\
\hline False Confessions & $12.1 \%$ & Homicide & $\begin{array}{l}\text { Drizin \& Leo, 2003; } \\
\text { Garrett, 2015; Gross } \\
\text { \& Shaffer, 2012; } \\
\text { Hampikian et al., } \\
2011\end{array}$ \\
\hline $\begin{array}{l}\text { Use of Police } \\
\text { Informant }\end{array}$ & $7.1 \%$ & Homicide & $\begin{array}{l}\text { Garrett, 2008; } \\
\text { Garrett, 2011; Joy, } \\
\text { 2006; Natapoff, } \\
\text { 2006; Raeder, } 2007\end{array}$ \\
\hline
\end{tabular}

Note. Due to the presence of multiple factors in exonerations the sum of the percentages is greater than 100 . 
Table A2. Split sample descriptive statistics with bivariate results.

\begin{tabular}{|c|c|c|c|c|c|c|}
\hline Measure & $\begin{array}{l}\text { White } \\
\text { Mean }\end{array}$ & $\begin{array}{l}\text { Black } \\
\text { Mean }\end{array}$ & $\begin{array}{l}\text { Hispanic } \\
\text { Mean }\end{array}$ & $\begin{array}{l}\text { B/W } \\
\text { Cross- } \\
\text { Tab }\end{array}$ & $\begin{array}{l}\mathrm{H} / \mathrm{W} \\
\text { Cross- } \\
\text { Tab }\end{array}$ & t-Test \\
\hline Median Days & .495 & .56 & .34 & .210 & .025 & \\
\hline Days to Exon & 1146.14 & 1414.95 & 818.18 & & & .007 \\
\hline Male & .808 & .888 & .853 & .022 & .407 & \\
\hline Age & 34.7 & 31.5 & 29.9 & & & .005 \\
\hline Off Misconduct & .343 & .341 & .368 & .955 & .718 & \\
\hline Inad Legal Def & .288 & .211 & .162 & .067 & .040 & \\
\hline Drug Crime & .263 & .466 & .485 & .000 & .001 & \\
\hline Violent Crime & .298 & .314 & .206 & .724 & .142 & \\
\hline $\begin{array}{l}\text { False/Mislead } \\
\text { Forensic Evid }\end{array}$ & .232 & .336 & 191 & .019 & 481 & \\
\hline $\begin{array}{l}\text { Mistaken } \\
\text { Eyewitness ID }\end{array}$ & .025 & .179 & .088 & .000 & .024 & \\
\hline \multirow[t]{2}{*}{ Perj/False Acc } & .455 & .363 & .382 & .057 & .300 & \\
\hline & $\mathrm{n}=198$ & $n=223$ & $\mathrm{n}=68$ & & & \\
\hline
\end{tabular}

Note: $\mathrm{B} / \mathrm{W}=$ Black vs. White, $\mathrm{H} / \mathrm{W}=$ Hispanic vs. White 


\section{CURRICULUM VITAE}

Virginia Braden

P: (859) 462-4760

E: Virginia.Braden@Louisville.edu

\section{Education}

Ph.D., Criminal Justice

Graduation 5/6/21

University of Louisville

GPA 3.9

Master of Science, Administration of Justice

May 2014

University of Louisville

GPA: 3.9

Bachelor of Science, Administration of Justice

May 2010

University of Louisville

GPA: 3.3

Industry Designations, Certificates/Training, and Awards

- Certified Hostage Negotiator

- Kentucky Women in Law Enforcement Benefactor Award

- Liaison Officer with Kentucky Dept of Homeland Security

- Ida B. Wells Award

- Facial Action Coding System

- American College of Forensic Examiners

- National Association of Fire Investigators

- Linguistic Statement Analysis

- Sudden Unexplained Infant Death Syndrome

- Offender Profiling: Statistical Basis for Arson Investigation

- National Institute of Justice Scholarship Recipient
2017, 2019

2017

2016

2014

2012

$2009-2014$

$2009-2012$

2011

2010

2009

2009 
- University of Louisville Women Alumni

Scholarship Recipient

- Death Investigations

- Crime Scene Basics for Forensic Analysts

- Evidence at the Crime Scene

- Forensic Anthropology for Investigators

- History and Types of DNA Testing

- DNA Evidence and First Responders

- Collecting DNA Evidence at Property Crimes

- Profiling Serial Offenders

- Violent Crimes Behavioral Analysis

- Serial Killers

- Victimology

- Crime Scene Investigations and Blood Spatter 2007 Interpretation

- Dean's Scholar

$2005-2010$

\section{Publications}

- $\quad$ LMPD Traffic Stops Report 2019

- $\quad$ Citizen and Police Attitudes Survey 2018

- LMPD Traffic Stops Report 2018

- Program Evaluation: Louisville Metro Police Department Real Time Crime Center 2017

- Program Evaluation: The Living Room Project 2017

\section{Summary of Qualifications}

- Proven experience in adult education as an Investigative Training Instructor

- Experienced lecturer with state level political advocacy experience

- Skilled investigator and behavioral profiler with high level expertise in cold case, death, and missing person investigations, and wrongful convictions cases

- Expert in non-verbal communication including body language and facial queues

- Proven dedication to the community shown through community care outreach at 7 Hills

Church and pro bono work as victim's advocate and investigator

- Exemplary project-management and leadership skills developed through years of service with

7 Hills Church

- Skilled behavioral analyst working closely with individuals and families in crisis

- Experienced bereavement coach assisting individuals who have experienced a traumatic loss

- Experienced public speaker for various organizations, conferences, and events

- Author "Life is Hard...Here's Some Help"

- Author "Sanctuary: Musings, Prayers, and Affirmations to Soothe the Broken Heart 


\section{Work Experience}

- Behavioral Profiler Analyst and Consultant- 2000 - 2021

- Consultant for local and state law enforcement agencies including:

- Florence Police, Butler County Sheriff, Las Vegas Metro Police, Clinton County Sheriff, Kentucky State Police, Michigan State Police, Warren County Sherriff, Indiana State Police, Boone County Sheriff

- Functioned as international liaison for overseas death investigations

- Coordinates strategies and techniques for person of interest interrogations

- Interprets non-verbal communication including body language and facial queues in context of video interviews \& interrogations

- Analyzes past or previous witness and suspect interviews both written and verbal

- Develops new persons of interest

- Provides offender profiles and victimology assessments

- Identifies new approaches for dealing with old suspects

- Analyzes and interprets crime scenes

- Facilitated a monthly Grief Support group for members of community dealing the death of a loved one

- Worked with America's Most Wanted as liaison on a Kentucky cold case in 2007

- Licensed Private Investigator

$$
2006-2021
$$

- Professional License Issued by the State of Kentucky 2006

- Investigates and analyzes cold cases, death, and missing person investigations for private sector clients and attorneys at law.

- Provides investigative and behavioral analysis services for the Ohio Innocence Project

- Provides investigative and behavioral analysis services for attorneys at law and private clients

- Constructs strategies and techniques for person of interest interviews and interrogations for Ohio Innocence Project, and attorneys at law

- Interprets and analyzes non-verbal communication including body language and facial queues

- Coordinates services to victims \& their families

- Founded StillTheySpeak.com: A website dedicated to giving a voice to the voiceless

\section{Probono Services}

2006- Present

- Provides investigative and behavioral analysis and consulting services pro-bono to law enforcement and National Innocence Project organizations as well as other non-profit organizations

- Provides victims advocacy services to victims of violent crimes and their families

- Provides investigative services to families of violent crime victims

- $\quad$ Provides grief support and bereavement services for individuals and agencies

\section{Investigative Training Instructor} $2006-2019$

- Conference Presenter- Victory Over Violence Conference

- Conference Presenter- $7^{\text {th }}$ Annual Child Abuse Prevention Conference 
- Conducted Statewide Training for Ky Cabinet for Health and Family Services

- Conducted Regional Training for Kentucky Family Resource Coordinators and Head Start coordinators

- Teaches courses on Non-Verbal Communication (Body Language Interpretation), Compassion Fatigue, Leadership for Crisis Service Providers, Domestic Violence, Workplace Violence, Interview and Interrogation Techniques, Serial Violent Offenders, General Investigative Technique, and Basic Forensic Investigation, Responding to Suicide Survivors (children $\&$ adult).

- Clients include Kentucky Cabinet for Health and Family Services, Kentucky Department of Community Based Services, Community Action Commission/Collaboration for Children, Kentucky Family Resource Coordinators, School Counselors, Attorneys, Politicians, Private Sector, Non-Profit Sector, Middle School \& High School Students

- Taught Interview/Interrogation strategies, Loss Prevention and Body Language interpretation for private security firms and loss prevention coordinators and non-profit security management teams

- Taught with the Greater Joy Educational Co-Op program for home school students in 2011 and 2012

\section{Community Care \& Outreach Director, 7 Hills Church} $2012-2017$

- Ordained Minister responsible for coordination of all services to individuals and families in crisis

- Director of Services for Addiction \& Recovery Ministry

- Director of Pastoral Care \& Grief Services

- Provided Chaplain Services for local Fire and EMS personnel

- Coordinated and directed 6,000+ volunteers and 300+ community service projects annually

- Organized and managed 89,000+ volunteer hours in 2017

- Responsible for building and maintaining relationships with $200+$ community non-profit \& service agencies

- Responsible for media communications regarding community service including but not limited to television interviews

- Director of Safety Operations responsible for developing and implementing security practices, protocols, and trainings as well as managing security team personnel

- Served as liaison officer with the Kentucky Department of Homeland Security

- Director, Guardians of Our Children $2000-2006$

- Directed and coordinated a community based service agency

- Promoted awareness and prevention of sexual abuse and domestic violence

- Interacted and advised community service providers, Kentucky State Legislators, and the general public

- Lectured on domestic violence and child predators

- Contributed and led a domestic violence prevention initiative with the Kentucky Lt.

Governor's office 
- Independent Victims Advocate

$$
2000-2012
$$

- Provided advocacy services free of charge to victims of violent crimes and their families

- Worked with both state agencies and community organizations

- Represented victims in meetings with law enforcement

- Accompanied sexual assault and domestic violence victims to medical exams and court

\section{References}

Joy Kramer, Esq.

JoyKramer@kycourts.net

mobile: (859) 760-3001

Dr. Marc Rogers, Ph.D

Professor/Department Chair

Purdue University

rogersmk@purdue.edu

office: (765) 494-4545

mobile: (765) 418-6916

Frank J. Cardis, Esq.

Cardis Law

126 N. Main Street

Benton, AR 72015

cardislaw@gmail.com

office: $\underline{501.575 .0100}$

mobile:859-802-7341

Jennifer Bergeron, JD

Professor of Clinical Practice

University of Cincinnati

bergerjm@ucmail.uc.edu

office: (513) 556-4274

mobile: (513) 746-7190

Dr. Thomas Hughes, JD, Ph.D

Professor, Research Associate

University of Louisville

thomas.hughes@louisville.edu

office: (502) 852-0332

mobile: (502) 212-2900

Dr. Dacia McCoy, Ph.D

Ass't. Professor-Educator 
University of Cincinnati

dacia.mccoy@uc.edu

office: (513) 556-6763

mobile: (859) 486-0523 